\title{
Adaptação de vídeo ao vivo apoiada em informações de contexto
}

\author{
Marcelo Garcia Manzato
}





\title{
Adaptação de vídeo ao vivo apoiada em informações de contexto
}

\author{
Marcelo Garcia Manzato
}

Orientador: Prof. Dr. Rudinei Goularte

Dissertação apresentada ao Instituto de Ciências Matemáticas e de Computação - ICMC-USP, como parte dos requisitos para obtenção do título de Mestre em Ciências - Ciências de Computação e Matemática Computacional.

"VERSÃO REVISADA APÓS A DEFESA"

Data da defesa:

$22 / 09 / 2006$

Visto do Orientador:

USP - São Carlos

Outubro/2006 

Dedico este trabalho a meus pais, Lucia e Valdomiro, pelo amor incondicional.

"Não há escola que se iguale a um lar decente, nem professores que se igualem a pais honestos e virtuosos" (M. Gandhi) 


\section{Agradecimentos}

Agradeço, primeiramente, a Deus, pelos inúmeros benefícios concedidos em minha vida e pelas valiosas oportunidades que sempre contribuem para o meu aperfeiçoamento moral e intelectual.

Agradeço, com muito amor, aos meus queridos pais, Lucia e Valdomiro, pelo inestimável apoio recebido nesta importante conquista de minha vida. Sou grato a eles pela educação ímpar que me deram, pelos confortáveis consolos e orientações, e pela preocupação e dedicação que alavancaram a formação de minha índole.

Agradeço aos meus queridos irmãos, Daniel e Gustavo, pelas incessantes trocas de confidências e conselhos, os quais estimulam e fortalecem nossa amizade recíproca. Agradeço ainda à minha querida tia Josefa, pela paciência e dedicação, consideradas como um exemplo de vida por mim; aos meus queridos avós, Maria e Henrique, pelo carinho e amor sempre presentes; aos meus queridos avós em memória, Gema e José, pelas boas lembranças de minha infância; e aos meus queridos padrinhos, Elvira e Hipólito, pelas agradáveis conversas, conselhos e simpatia que sempre tivemos.

Agradeço à minha querida companheira Carol, pelo seu amor, apoio e carinho que sempre teve comigo. Tudo teria sido mais difícil sem nossos momentos de descontração, amizade e aprendizado mútuo.

Agradeço, em especial, ao meu orientador, Prof. Rudinei Goularte, pela ajuda, amizade, confiança e atenção concedidas em todas as fases deste trabalho. Agradeço também pelos incentivos dados, atendimentos fora de hora, críticas construtivas, cobranças e orientações com as quais aprendi muito.

Agradeço aos professores do ICMC-USP, em particular à Profa. Maria da Graça Campos Pimentel, pelo apoio e recomendação no processo de seleção do doutorado de 2005; ao Prof. Dilvan de Abreu Moreira e Prof. Luis Gustavo Nonato, com quem fiz disciplinas de mestrado e que também me recomendaram no processo de seleção do doutorado; e ao Prof. Rodrigo Fernandes de Mello, pela amizade e valiosa ajuda nos momentos críticos de desenvolvimento deste trabalho.

Agradeço aos amigos do laboratório de Intermídia, em especial a Robson Eisinger e Renan Cattelan, pelas sugestões e esclarecimentos de diversas dificuldades do projeto. E também aos amigos de mestrado, pelas inesquecíveis noites de Jam Session, pelas conversas no bandejão e pela diversão e amizade.

Agradeço aos funcionários do ICMC-USP, pela prestimosidade nos serviços. Aos técnicos, que sempre estiveram dispostos a resolver quaisquer problemas de equipamentos, rede e infra-estrutura; aos seguranças, pela confiança e amizade conquistadas ao 
longo desses dois anos; e às moças da limpeza, que sempre se preocuparam em deixar os laboratórios e os banheiros em ordem.

Agradeço aos amigos de mesmo ideal cristão, em especial a Michell Macedo, pela confiança, amizade e oportunidades de trabalho solidário; Eduardo Marmo, por ter guiado meus passos no início do mestrado em relação ao movimento espírita de São Carlos; e também aos amigos do centro Francisco Thiesen, pela calorosa amizade sempre presente.

Agradeço a todos os companheiros de escalada, por sempre proporcionarem descontração e divertimento, tão importantes nesta fase difícil.

Agradeço, por fim, a todas as pessoas que, direta ou indiretamente, contribuiram para que este trabalho se realizasse. Obrigado! 


\section{Sumário}

Lista de Figuras $\quad$ vii

Lista de Tabelas $\quad$ ix

Lista de Siglas $\quad$ xi

Resumo xiii

Abstract $\quad$ Xv

1 Introdução 1

2 Técnicas de Adaptação de Vídeo 5

2.1 Considerações Iniciais . . . . . . . . . . . . . . . . . . . . 5

2.2 Modelo de Distribuição por Difusão Simultânea . . . . . . . . . . . . . . 6

2.3 Modelo de Mídia Escalável . . . . . . . . . . . . . . . . . . . . . . . 8

2.4 Modelo de Recodificação . . . . . . . . . . . . . . . . . . . . . . . . . . . 10

2.4.1 Redução da Taxa de Bits . . . . . . . . . . . . . . . . . . . . 12

2.4.2 Redução da Resolução Espacial . . . . . . . . . . . . . . . . . . . 12

2.4.3 Redução da Resolução Temporal . . . . . . . . . . . . . . . . . . . 13

2.4.4 Alteração de Padrões . . . . . . . . . . . . . . . . . . . . . . . . . . 14

2.4 .5 Inserção de Informações . . . . . . . . . . . . . . . . . . . . . . . 14

2.5 Considerações Finais . . . . . . . . . . . . . . . . . . . . . 15

3 Computação Ciente de Contexto $\quad 17$

3.1 Considerações Iniciais . . . . . . . . . . . . . . . . . . . 17

3.2 Definição de Contexto . . . . . . . . . . . . . . . . . . . . . . 19

3.3 Definição de Computação Ciente de Contexto . . . . . . . . . . . . . . . . 20

3.4 Classificação de Contexto . . . . . . . . . . . . . . . . . . . 21

3.5 Representação de Contexto . . . . . . . . . . . . . . . . . . . . 21

3.6 Considerações Finais . . . . . . . . . . . . . . . . . . . . 25

4 Sistema de Adaptação de Vídeo $\quad 27$

4.1 Considerações Iniciais . . . . . . . . . . . . . . . . . . . . . . . 27

4.2 Arquitetura do Sistema . . . . . . . . . . . . . . . . . . . 28

4.3 Captura de Informações de Contexto . . . . . . . . . . . . . . . . . . 30 
4.3.1 Resolução do Dispositivo . . . . . . . . . . . . . . . . . . . . . . 30

4.3.2 Largura de Banda . . . . . . . . . . . . . . . . . . . . . 32

4.4 Representação de Dispositivos . . . . . . . . . . . . . . . . . . . 33

4.4.1 Modelo para Descrição de Dispositivos . . . . . . . . . . . . . 34

4.4 .2 Biblioteca de Dispositivos . . . . . . . . . . . . . . . . . 36

4.4 .3 Extensão da Biblioteca . . . . . . . . . . . . . . . . . . 36

4.5 Processamento de Informações de Contexto . . . . . . . . . . . . . . . . . . 39

4.6 Recodificação de Vídeo . . . . . . . . . . . . . . . . . . . . . . . 42

4.7 Interface de Acesso . . . . . . . . . . . . . . . . . . . . . . . . . . 43

4.7 .1 Criação de uma Aula . . . . . . . . . . . . . . . . . . . . . 44

4.7 .2 Acesso pela Interface . . . . . . . . . . . . . . . . . . . 45

4.8 Considerações Finais . . . . . . . . . . . . . . . . . . . . . . 46

$\begin{array}{lll}5 & \text { Análise do Sistema } & 47\end{array}$

5.1 Considerações Iniciais . . . . . . . . . . . . . . . . . . . . . . . . . . . . . . . . . . . . . .

5.2 Infra-estrutura Utilizada . . . . . . . . . . . . . . . . . . . . . . . 48

5.2.1 Componentes em Hardware . . . . . . . . . . . . . . . . . . . . 48

5.2 .2 Componentes em Software . . . . . . . . . . . . . . . . 50

5.3 Cenários Propostos . . . . . . . . . . . . . . . . . 50

5.3.1 Cenário 1: Acesso por RTSP . . . . . . . . . . . . 51

5.3 .2 Cenário 2: Acesso por HTTP . . . . . . . . . . . . . . 51

5.4 Metodologia de Análise . . . . . . . . . . . . . . . . . . 52

5.4 .1 Cálculo do Atraso Total . . . . . . . . . . . . . . . . . . 54

5.4 .2 Instrumentalização do Recodificador . . . . . . . . . . . . . . . 56

5.4 .3 Cálculo do Número de Quadros . . . . . . . . . . . . . . . . . . 56

5.4 .4 Cálculo do Atraso de Recodificação . . . . . . . . . . . . . . . . . . . 57

5.5 Resultados Obtidos . . . . . . . . . . . . . . . . . 58

5.6 Considerações Finais . . . . . . . . . . . . . . . . . . . . . . . . . . . . 59

6 Conclusões $\quad 61$

6.1 Considerações Iniciais . . . . . . . . . . . . . . . . . . . . . . 61

6.2 Contribuições . . . . . . . . . . . . . . . . . . . . . . 62

6.3 Limitações . . . . . . . . . . . . . . . . . . . . . . . . . . 63

6.4 Trabalhos Futuros . . . . . . . . . . . . . . . . . . 64

$\begin{array}{ll}\text { Anexo A } & 67\end{array}$

$\begin{array}{lr}\text { Anexo B } & 69\end{array}$

$\begin{array}{ll}\text { Referências Bibliográficas } & 71\end{array}$

$\begin{array}{ll}\text { Apêndice A } & 79\end{array}$

$\begin{array}{lr}\text { Apêndice B } & 89\end{array}$

$\begin{array}{ll}\text { Glossário } & 95\end{array}$ 


\section{Lista de Figuras}

3.1 Componentes do contexto do sistema (GOULARTE, 2003). . . . . . . . . . 23

3.2 Definição do tipo UserType como uma extensão de PrimaryContextType (GOULARTE, 2003). . . . . . . . . . . . . . . . 24

3.3 Exemplo de criação do tipo NickNameType (GOULARTE, 2003). . . . . . . 24

3.4 Exemplo de utilização do novo tipo NickNameType (GOULARTE, 2003). . . 24

4.1 Arquitetura do sistema de adaptação. . . . . . . . . . . . . . . . . . . 28

4.2 Captura da informação de contexto resolução do dispositivo. . . . . . . . 31

4.3 Estimativa da largura de banda utilizando a aplicação cliente no Windows

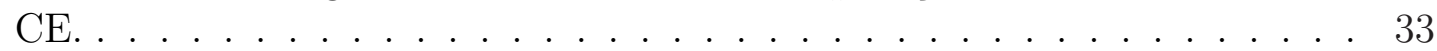

4.4 Estimativa da largura de banda utilizando a aplicação cliente no Windows

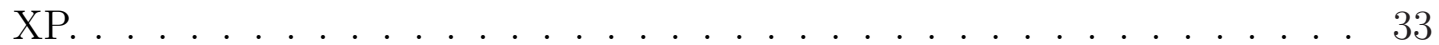

4.5 Representação de dispositivos. . . . . . . . . . . . . . . . . . 35

4.6 Definição do tipo DeviceldentityType. . . . . . . . . . . . . . . . 37

4.7 Extensão da biblioteca de dispositivos por meio da criação do tipo MemoryType. . . . . . . . . . . . . . . . . . . . 37

4.8 Definição de um novo tipo SpecType. . . . . . . . . . . . . . . . . . . . . 39

4.9 Definição do tipo SpeedType. . . . . . . . . . . . . . . . . . . . . . . . 39

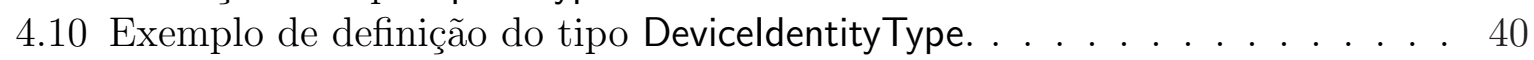

4.11 Exemplo de uso do tipo SpecType criado. . . . . . . . . . . . . . . . . . . 40

4.12 Algoritmo de processamento de informações de contexto. . . . . . . . . . . 42

4.13 Criação de uma aula pelo professor. . . . . . . . . . . . . . . . . . . 44

4.14 Acesso ao conteúdo utilizando a interface. . . . . . . . . . . . . . . . 45

5.1 Arquitetura da análise do sistema de adaptação. . . . . . . . . . . . . . . . 49

5.2 Esquema para análise do atraso de recodificação. . . . . . . . . . . . . . . . 52

5.3 Captura do tempo total utilizando um laptop e um pocket pc. . . . . . . . 55 


\section{Lista de Tabelas}

3.1 Exemplos de tipos presentes na biblioteca de contexto (GOULARTE; PI-

MENTEL; MOREIRA, 2006). . . . . . . . . . . . . 25

4.1 Lista dos SpecTypes e seus componentes. . . . . . . . . . . . . . . . . . 38

4.2 Taxas de bits permitidas para cada resolução espacial. . . . . . . . . . . . . 42

5.1 Computadores utilizados na análise do atraso de recodificação. . . . . . . . 49

5.2 Aplicativos utilizados na análise do atraso de recodificação. . . . . . . . . . 50

5.3 Configuração do vídeo no cenário $1 \ldots \ldots \ldots \ldots$. . . . . . . . 51

5.4 Configuração do vídeo no cenário $2 \ldots \ldots \ldots \ldots$. . . . . . . . . 52

5.5 Definição das varáveis utilizadas. . . . . . . . . . . . . . . . 53

5.6 Resultados do cenário $1 . \ldots \ldots \ldots \ldots$. . . . . . . . . . . . . 58

5.7 Resultados do cenário 2. . . . . . . . . . . . . . . . . . . . . . . . 59 


\section{Lista de Siglas}

CC/PP - Composite Capacities/Preferences Profiles

CPU - Central Processing Unit

DELI - Delivery Context Library for CC/PP and UAProf

DCT - Discrete Cossin Transform

DSS - Darwin Streaming Server

FGS - Fine Granular Scalability

HTML - HyperText Markup Language

HTTP - Hypertext Transfer Protocol

ICMC - Instituto de Ciências Matemáticas e de Computação

IDCT - Inverse Discrete Cossin Transform

INCA - Infrastructure for Capture and Access Applications

IP - Internet Protocol

ISDN - Integrated Services Digital Network

ITU - International Telecommunication Union

JSP - JavaServer Pages

MAC - Media Access Control

MTU - Maximum Transmission Unit

PDA - Personal Digital Assistant

RTP - Real Time Protocol

RTSP - Real Time Streaming Protocol

SDP - Session Description Protocol

SNR - Signal-Noise Ratio

TCP - Transmission Control Protocol

TTL - Time To Live

UMA - Universal Multimedia Access

UPS - Universal Profile Schema

URL - Uniform Resource Locators

USP - Universidade de São Paulo

VLC - VideoLan Client

XML - Extensible Markup Language

WURFL - Wireless Universal Resource File 


\section{Resumo}

O trabalho apresentado nesta dissertação trata do desenvolvimento de um mecanismo para adaptação automática de vídeo MPEG-4 ao vivo, de modo a atender as necessidades ou capacidades atuais de usuários e do sistema. Um dos desafios dessa área é capturar e representar as informações necessárias para realizar a adaptação. Assim, utilizando técnicas da área de computação ciente de contexto, foi desenvolvido um modelo extensível para representação de dispositivos. Também foram desenvolvidos métodos automáticos e semi-automáticos para capturar as informações necessárias. Neste trabalho foi adotado o modelo de recodificação de vídeo, o qual pode gerar atrasos que inviabilizam a adaptação de vídeo ao vivo em aplicações interativas. Assim, este trabalho realizou uma avaliação do impacto causado pela recodificação no atraso total, fim-a-fim, percebido pelo usuário.

Palavras-chave: adaptação de vídeo, recodificação, ciência de contexto, MPEG-4. 


\section{Abstract}

This work presents the development of a mechanism to automatically adapt MPEG-4 live video, in a way to response the actual necessities or capacities of users or systems. One of the challanges in this area is to capture and represent the information needed to adapting content. Thus, using context aware computing techniques, an extensible model has been developed, which can be used to represent devices. It has also been developed automatic and semi-automatic methods to capture the needed information. In this work, the transcoding model has been adopted, which may generate latency, making difficult to use transcoding with interactive applications. In this way, this work has evaluated the impact caused by the transcoding when compared to the end-to-end total delay perceived by the user.

Keywords: video adaptation, transcoding, context awareness, MPEG-4. 


\section{Capítulo \\ 1 \\ Introdução}

Com o desenvolvimento da Internet a globalização sofreu um significativo aumento, visto que a comunicação e a troca de informações ao redor do mundo têm estado cada vez mais fáceis de serem realizadas. O uso da banda larga e o crescimento acelerado na utilização de dispositivos portáteis têm contribuído para que a comunicação entre usuários e sistemas se torne mais comum e eficiente, podendo-se transmitir e receber maiores quantidades de dados em um mesmo intervalo de tempo. Além disso, o acesso é realizado não mais apenas por meio de computadores pessoais, mas também utilizando-se aparelhos que podem ser carregados a qualquer lugar. Assim, aproveitando essas facilidades tecnológicas, novas aplicações têm surgido para cobrir uma demanda de serviços que trabalhem com grandes quantidades de dados, como em aplicações multimídia, e também aqueles que podem utilizar dispositivos portáteis, como em aplicações ubíquas.

Multimídia, basicamente, consiste em combinar em uma única aplicação diversos tipos de mídia, onde essas informações podem ser acessadas em conjunto ou isoladas. Aplicações multimídia, portanto, podem trabalhar com vários tipos de dados ao mesmo tempo, e desse modo, requerem um gerenciamento dinâmico de dados, o que consiste em uma mistura e sincronização de texto, voz, componentes de áudio e vídeo, e animações (MAYER, 2001).

A computação ubíqua, por sua vez, refere-se à incorporação de facilidades computacionais ao ambiente, a fim de auxiliar as atividades diárias das pessoas, mudando minimamente a forma como tais atividades são realizadas (WEISER, 1991). A utilização de dispositivos portáteis pode ser bem aceita no contexto da computação ubíqua, tendo em vista a sua portabilidade, ou seja, a possibilidade de serem utilizados em qualquer lugar e a qualquer hora. Além disso, o desenvolvimento de redes sem fio facilitou a conectividade desses dispositivos com outros computadores, permitindo que vários tipos de dados sejam 
enviados ou recebidos da rede.

Em paralelo ao desenvolvimento de dispositivos portáteis e à implantação da banda larga em redes sem fio ou cabeadas, a alta acessibilidade por conteúdo multimídia contribuiu com a familiarização da busca por informações provindas da rede. Em conseqüência, mais usuários, equipados com diferentes tipos de dispositivos, estão solicitando serviços que oferecem acesso a conteúdo multimídia de qualidade, com suporte à interatividade. Tendo isso em vista, diversos provedores de serviço, empresas de telecomunicação e produtores/difusores de conteúdo estão centrando esforços no fornecimento de serviços interativos para o acesso multimídia independentemente do dispositivo utilizado.

A utilização de conteúdo multimídia, devido ao grande volume de dados, requer uma demanda considerável de processamento dos dados durante o acesso pelos dispositivos. Além disso, a transmissão dos dados necessita de um canal de comunicação capaz de transmitir as informações sem causar problemas, tais como perda de pacotes, latência, congestionamento, etc. Considerando que conteúdo multimídia, em especial, vídeo e áudio, normalmente é configurado para ser acessado por computadores pessoais, a utilização de diferentes tipos de dispositivos e topologias de rede gera problemas durante o acesso aos dados. Esses problemas podem ser causados por consideráveis oscilações na largura de banda, ou por aparelhos que fazem uso de componentes com características restritas, como por exemplo, tela com pequena área de visualização, baixo poder de processamento, capacidade de memória e autonomia de bateria limitadas, etc.

Com o propósito de solucionar os problemas citados, uma alternativa pesquisada atualmente é a adaptação de conteúdo, que visa beneficiar uma escala diversa de aplicações, tais como TV interativa, e-learning, videoconferência, telemedicina, etc. Um sistema de adaptação decide a versão de conteúdo ótima para ser apresentada ao usuário, e a melhor estratégia para se criar essa versão (LUM; LAU, 2002).

No caso de vídeo, diversas técnicas de adaptação são reportadas pela literatura. O modelo de distribuição por difusão simultânea (do Inglês, simulcast distribution model) (LIPPMAN, 1999; CONKLIN et al., 2001) consiste em produzir várias cópias de vídeo codificadas com diferentes parâmetros, tais como taxas de bits, taxas de quadros e resoluções espaciais. O modelo de mídia escalável (do Inglês, scalable media model) (HORN; GIROD, 1997; LI, 2001; OHM, 2005), consiste na codificação de vídeo por camadas, onde uma camada base contém as informações mínimas necessárias para apresentação, e camadas adicionais melhoram a qualidade do vídeo por meio do aumento das taxas de bits ou quadros, ou do aumento da resolução espacial. O modelo de recodificação (do Inglês, transcoding model) (VETRO; CHRISTOPOULOS; SUN, 2003; XIN; LIN; SUN, 2005; AHMAD et al., 2005), por fim, consiste em converter um vídeo de um formato para outro, mudando algumas características, tais como taxa de bits, resolução espacial, resolução temporal, padrão de codificação, entre outras.

Apesar de estarem em constante desenvolvimento, cada estratégia enfrenta problemas 
específicos que acabam dificultando a sua utilização, que serão discutidos no Capítulo 2. No contexto deste trabalho, foi selecionada a técnica da recodificação.

Um dos problemas da área de adaptação, como um todo, e da recodificação de vídeo, em especial, é obter de modo automático as informações necessárias para se produzir uma versão personalizada do conteúdo, atendendo as necessidades de usuários e sistemas. Essas informações incluem o estado atual da rede, as características do dispositivo utilizado para realizar o acesso ao conteúdo e o formato de apresentação desejado pelo usuário.

Nesse sentido, a área de computação ciente de contexto, subárea de computação ubíqua, pode auxiliar. Seu objetivo é utilizar informações sobre o sistema computacional e sobre a interação entre o usuário e o sistema de modo a ajustar, automaticamente, o comportamento desse sistema frente a uma situação específica (DEY, 2001). No entanto, a captura e a representação de informações de contexto ainda são temas atuais de pesquisas na área.

Assim, o objetivo deste trabalho é desenvolver um mecanismo que utilize informações de contexto para promover recodificação automática de vídeo ao vivo, atendendo usuários de dispositivos, redes e preferências diversos. Para isso, neste trabalho foi desenvolvida uma extensão (EISINGER; MANZATO; GOULARTE, 2005) do modelo proposto por Goularte (2003). Tal extensão permite a descrição dos dispositivos utilizados pelos usuários durante o acesso a um vídeo, dando subsídios para a recodificação automática. A captura das informações de contexto necessárias para descrição é realizada por métodos automáticos e semi-automáticos (MANZATO; GOULARTE, 2005), descritos no Capítulo 4. Outra contribuição deste trabalho é a avaliação do atraso fim-a-fim devido à recodificação. Embora seja sabido que a recodificação de vídeo é um processo computacionalmente caro, calcular o custo exato desse processo, em especial com o padrão MPEG-4 (STANDARDISATION, 2002), não é uma tarefa amplamente explorada na literatura.

De posse desses dados, pesquisadores e desenvolvedores de sistemas interativos podem avaliar, em cada caso, se são necessárias estratégias alternativas de modo a diminuir a latência gerada pela recodificação. Aplicações interativas, tal como o iClass (CATTELAN et al., 2003), desenvolvido no ICMC-USP (Instituto de Ciências Matemáticas e de Computação - Universidade de São Paulo), poderão se beneficiar do mecanismo proposto, compartilhando informações de contexto por meio do modelo desenvolvido, e permitindo o acesso ao vivo de vídeo adaptado.

Esta dissertação está organizada da seguinte maneira. No Capítulo 2, discute-se as principais técnicas de adaptação de vídeo, de modo a justificar a escolha da recodificação no presente projeto. Apresenta-se, inicialmente, o modelo de distribuição por difusão simultânea, incluindo suas vantagens e desvantagens. Em seguida, descreve-se o modelo de mídia escalável, contendo os diferentes tipos de escalabilidade, e os problemas presentes nesse tipo de adaptação. Por fim, explica-se o modelo de recodificação, com enfoque para as principais técnicas utilizadas para recodificar os dados sem degradar a qualidade da 
imagem e com o mínimo de processamento possível.

No Capítulo 3, realiza-se um estudo dos principais conceitos pertinentes à subárea computação ciente de contexto, de modo a auxiliar as tarefas de captura e de processamento das informações de contexto adotadas neste trabalho, bem como facilitar o entendimento do modelo proposto. Define-se, inicialmente, o termo contexto, com base nos trabalhos de Dey (2001) e Goularte (2003). Em seguida, define-se computação ciente de contexto, comparando-se as definições de diversos autores em trabalhos anteriores com a definição de Dey (2001) e Dey \& Abowd (1999). Na seqüência, descreve-se uma classificação de contexto; e por fim, apresenta-se alguns trabalhos que exploram a representação de contexto, e o framework proposto por Goularte (2003) que visa eliminar alguns problemas existentes nos modelos anteriores.

No Capítulo 4, introduz-se um sistema de adaptação de vídeo ao vivo, o qual realiza recodificação automática com base em informações de contexto. Descreve-se, inicialmente, a arquitetura do sistema, com enfoque para a explicação de funcionamento de cada módulo. Em seguida, explica-se os métodos para captura automática e semi-automática das informações de contexto. Na seqüência, apresenta-se o modelo de representação de dispositivos proposto no presente trabalho. Posteriormente, propõe-se um algoritmo para processamento das informações de contexto capturadas, a fim de especificar a configuração de vídeo ótima para o acesso. Em seguida, descreve-se a recodificação de vídeo no sistema, identificando-se as técnicas utilizadas e o modo de transmissão dos dados entre servidor, recodificador e usuários. Por fim, apresenta-se a interface de acesso, a qual foi implementada com enfoque para aplicações de captura e acesso em salas de aula.

No Capítulo 5, descreve-se uma avaliação realizada no sistema, de modo a medir o atraso imposto pela recodificação. Explica-se, inicialmente, a infra-estrutura utilizada durante a avaliação, incluindo os componentes em hardware e software. Em seguida, propõe-se dois cenários de aplicação, o primeiro realiza o acesso ao vídeo por RTSP e, no segundo, o acesso é realizado por HTTP. Na seqüência, descreve-se a metodologia de análise adotada na avaliação, ou seja, como os dados foram coletados e como os cálculos foram realizados a fim de se encontrar os resultados desejados. Por fim, discute-se os resultados obtidos em ambos os cenários propostos.

No Capítulo 6, finalmente, encerra-se o presente trabalho com as conclusões finais. Discute-se, inicialmente, as contribuições alcançadas. Em seguida, identifica-se as limitações do presente trabalho. Por fim, menciona-se possíveis trabalhos futuros a serem considerados. 


\section{Capítulo \\ 2 \\ Técnicas de Adaptação de Vídeo}

\subsection{Considerações Iniciais}

Conteúdo audiovisual normalmente requer uma grande quantidade de dados para ser representado. Apesar de os padrões de codificação disponíveis atualmente, como o MPEG2 (STANDARDISATION, 2000) e o MPEG-4, serem eficientes em relação à compressão, vídeo com alta qualidade de som e imagem ainda enfrenta problemas durante a transmissão e visualização de seus dados.

O sucesso da transmissão de informações audiovisuais está, em parte, relacionado com a largura de banda disponível na rede. Quando a taxa de bits de um vídeo, por exemplo, é maior que a largura de banda entre cliente e servidor, a transmissão poderá ser prejudicada por problemas tais como perda de pacotes, latência e congestionamento, dificultando, conseqüentemente, o acesso aos dados.

Além dos problemas gerados pela transmissão, usuários que utilizam dispositivos com capacidades limitadas terão dificuldades em acessar vídeo e áudio com alta qualidade. Tais dispositivos, normalmente portáteis, contêm baixo poder de processamento e memória limitada, e, por isso, podem não conseguir realizar o processo de decodificação. Adicionalmente, dispositivos portáteis geralmente contêm tela com pequena área de visualização, o que dificulta acessar vídeo com resolução maior que a área da tela.

Outros fatores, tais como preferências de usuário, meio ambiente e representação de conteúdo também podem interferir durante o acesso aos dados (DOGAN et al., 2004). Em relação às preferências, um usuário, por exemplo, poderá escolher o nível de interação com o conteúdo, assim como personalizar o seu acesso ao vídeo. Em relação ao meio ambiente, por sua vez, dada uma situação, é possível que um usuário não deseje receber um determinado tipo de informação naquele momento. Em relação, por fim, à repre- 
sentação de conteúdo, dependendo do tipo de dispositivo utilizado, diferentes taxas de bits e quadros, resoluções espaciais e formatos de sintaxe poderão ser preferíveis durante o acesso ao vídeo.

Desse modo, um meio de resolver os problemas citados é a adaptação de conteúdo. Um sistema de adaptação procura decidir a versão de conteúdo ótima para apresentação, e a melhor estratégia para gerar essa versão (LUM; LAU, 2002). Assim, suponha-se um cenário onde um vídeo com taxa de bits de $15 \mathrm{Mbits} / \mathrm{s}$ e resolução de 640x480 deva ser transmitido a um dispositivo pocket pc, cuja resolução é de 240x320. Suponha-se ainda que a largura de banda entre o dispositivo e o servidor de vídeo é de $5 \mathrm{Mbits} / \mathrm{s}$. O dispositivo terá condições de acessar o conteúdo de maneira satisfatória somente se o vídeo sofrer uma adaptação em sua resolução (de 640x480 para 320x240 ou menos) e em sua taxa de bits (de $15 \mathrm{Mbits} / \mathrm{s}$ para $5 \mathrm{Mbits} / \mathrm{s}$ ou menos).

Diferentes estratégias de adaptação de vídeo foram propostas pela literatura, sendo que as três principais delas são: modelo de distribuição por difusão simultânea, modelo de mídia escalável e modelo de recodificação (LIU; LI; ZHANG, 2003; LI, 2001). Nas Seções seguintes os modelos serão apresentados, descrevendo-se também alguns trabalhos que utilizam as técnicas propostas a fim de se adaptar dados de vídeo de acordo com as necessidades dos usuários ou do sistema.

\subsection{Modelo de Distribuição por Difusão Simultânea}

O modelo de distribuição por difusão simultânea é o meio mais simples e direto de se disponibilizar conteúdo audiovisual para usuários com diferentes restrições de rede e de dispositivos. Consiste em produzir várias cópias de vídeo codificadas com diferentes parâmetros, tais como taxas de bits, taxas de quadros e resoluções espaciais. Essas cópias são disponibilizadas para acesso por clientes com velocidades de rede variadas ou dispositivos com características limitadas (DOGAN et al., 2004). Como exemplo, o produtor de um fluxo contendo uma apresentação multimídia, utilizando esse modelo, necessita criar versões independentes do conteúdo para usuários que utilizam conexões de $56 \mathrm{Kbits} / \mathrm{s}$, $128 \mathrm{Kbits} / \mathrm{s}$, linhas ISDN (Rede Digital de Integração de Serviços - do Inglês, Integrated Services Digital Network), etc. O usuário, por sua vez, se encarrega de decidir e escolher a melhor versão de vídeo a ser acessada (CONKLIN et al., 2001; DOGAN et al., 2004).

Diversos provedores e sites nacionais e estrangeiros utilizam esse modelo de modo a possibilitar que mais usuários acessem conteúdo multimídia por meio de diferentes velocidades de conexão de rede. Os portais Terra ${ }^{1}$ e $\mathrm{UOL}^{2}$ (Universo Online), por exemplo, disponibilizam atualmente duas versões de cada conteúdo, sendo uma para conexões entre 56 e $100 \mathrm{Kbits} / \mathrm{s}$, e outra para conexões em banda larga, entre 100 e $500 \mathrm{Kbits} / \mathrm{s}$.

\footnotetext{
${ }^{1}$ http://www.terra.com.br

${ }^{2}$ http://www.uol.com.br
} 
Embora o modelo de distribuição por difusão simultânea seja utilizado em vários sistemas de transmissão de vídeo, ele apresenta alguns problemas que prejudicam a entrega dos dados. O principal deles é que o referido modelo é baseado na suposição de que a largura de banda entre cliente e servidor é igual ao valor nominal da conexão. Tal suposição nem sempre é verdadeira, pois o canal de comunicação pode ser utilizado simultaneamente por outros usuários, diminuindo a banda realmente disponível, e prejudicando a transmissão do vídeo. Outro problema presente nesse modelo refere-se a ele não implementar a possibilidade de mudanças dinâmicas na taxa de bits, de acordo com variações na largura de banda e estatísticas de perda de dados (CONKLIN et al., 2001).

Uma solução para tais problemas foi proposta pela RealNetworks ${ }^{3}$, por meio do sistema RealSystem G2 (LIPPMAN, 1999). Introduzido em 1998, e utilizando a tecnologia SureStream $^{T M}$, o RealSystem G2 faz com que o codificador produza múltiplas representações (ou fluxos) do conteúdo original, otimizado de acordo com as características de vários canais de comunicação. Esses fluxos codificados são então armazenados em arquivos SureStream de modo a facilitar sua recuperação eficiente pelo servidor. Durante a sessão de streaming, um cliente (RealPlayer G2) monitora a largura de banda atual e as estatísticas de perda de dados da conexão, e instrui o servidor para enviar um determinado fluxo de dados, específico para as atuais condições, de modo a minimizar possíveis problemas de transmissão e distorções na reconstrução do sinal (CONKLIN et al., 2001).

O sistema RealSystem G2 forneceu funcionalidades para os usuários, tal como a possibilidade de se adaptar vídeo dinamicamente de acordo com o estado atual da rede. A tarefa de monitorar a largura de banda e as estatísticas referentes à perda de pacotes, sendo realizada no cliente, trouxe algumas vantagens para o sistema: a) reduziu consideravelmente a complexidade de processamento do servidor necessária para a seleção de fluxos específicos, aumentando, conseqüentemente, a possibilidade de atender um número maior de conexões simultâneas; e b) permitiu uma extensão do mecanismo SureStream para entrega multicast - se vários fluxos codificados de um mesmo conteúdo foram inscritos em diferentes endereços multicast, então o cliente somente precisa se inscrever dinamicamente em novos endereços multicast utilizando a mesma política de minimização de distorções, para que os dados sendo recebidos por ele sofram uma adaptação de acordo com a situação atual do sistema (CONKLIN et al., 2001).

Por outro lado, alguns problemas relacionados ao RealSystem G2 são encontrados. Uma vez que ele utiliza várias versões de um mesmo conteúdo, os links de comunicação podem ser obstruídos com a utilização excessiva da largura de banda (DOGAN et al., 2004). Além disso, para atender diferentes configurações de rede, personalizações e preferências de usuários, o fornecedor de conteúdo é obrigado a disponibilizar um grande número de versões de um mesmo fluxo de vídeo, podendo gerar problemas de armazenamento dos arquivos SureStream no servidor.

\footnotetext{
${ }^{3}$ http://www.realnetworks.com
} 


\subsection{Modelo de Mídia Escalável}

Novas técnicas de codificação de vídeo foram desenvolvidas com o surgimento do padrão MPEG-2 com suporte à escalabilidade. Tais técnicas estão centradas na tentativa de solucionar os problemas causados pela transmissão de vídeo em canais de comunicação heterogêneos, além de minimizar os efeitos das desvantagens presentes no modelo de distribuição por difusão simultânea (HORN; GIROD, 1997; DOGAN et al., 2004).

O modelo de mídia escalável consiste na codificação de vídeo por camadas, onde uma camada base contém as mínimas informações necessárias para apresentação, e camadas adicionais oferecem meios de se melhorar a qualidade do vídeo por meio do aumento das taxas de bits ou quadros, ou do aumento da resolução (DOGAN et al., 2004). O usuário, portanto, dependendo da situação do seu canal de comunicação com o servidor de conteúdo, recebe a camada base e possíveis camadas adicionais, de acordo com a largura de banda, a fim de assistir ao vídeo com a melhor qualidade possível.

A fim de fornecer vídeo com suporte à escalabilidade, o padrão MPEG-2 especificou quatro diferentes técnicas que podem ser aplicadas durante a codificação (HORN; GIROD, 1997; CONKLIN et al., 2001; LI, 2001): escalabilidade espacial, particionamento de dados, escalabilidade SNR (Razão Sinal-Ruído - do Inglês, Signal-Noise Ratio) e escalabilidade temporal. A escalabilidade espacial consiste em oferecer diferentes resoluções para o usuário, onde a camada base contém a menor resolução, e uma camada adicional contém resolução maior. São utilizados quadros decodificados de uma camada inferior para a estimativa de blocos pertencentes à camada superior. Quando um quadro está a uma resolução menor, é utilizada interpolação para que os dados possam ser usados na decodificação de quadros na camada superior (HORN; GIROD, 1997; LI, 2001).

O particionamento de dados consiste em dividir os dados codificados em dois fluxos de bits, de acordo com a importância de cada informação. Coeficientes DCT (Transformada Discreta do Cosseno - do Ingês, Discrete Cossin Transform) de baixa freqüência e vetores de movimento são considerados dados importantes, uma vez que são essenciais para a aplicação. Na ocorrência de congestionamento, ou quando a largura de banda torna-se indisponível para a transmissão de todo o conteúdo, somente esses dados são transmitidos para o cliente, permitindo com que uma imagem visível de baixa qualidade seja decodificada (HORN; GIROD, 1997).

A escalabilidade SNR consiste em oferecer diferentes qualidades de imagem para a aplicação. Isso é realizado por meio de um refinamento de coeficientes DCT, onde a camada base contém coeficientes primários, e uma camada adicional contém informações que podem ser utilizadas para se obter uma escala de quantização refinada da imagem (HORN; GIROD, 1997; LI, 2001).

A escalabilidade temporal consiste em excluir quadros do tipo B do fluxo de bits, de modo a se obter uma resolução temporal menor. Porém, considerando que quadros 
do tipo B são, em termos de compressão, os mais eficientemente codificados, a taxa de bits sofre poucas modificações durante o uso desse tipo de escalabilidade (HORN; GIROD, 1997; LI, 2001).

Apesar dos esforços em se desenvolver diferentes técnicas de codificação escalável, a utilização desse modelo gera alguns problemas. A entrega de vídeo personalizado pode ser limitada uma vez que funcionalidades de interação do usuário com o conteúdo são restritas às condições da rede e dos dispositivos. Além disso, a interdependência entre as camadas requer que o usuário receba toda a camada adicional para que ocorram melhorias na qualidade e serviços (DOGAN et al., 2004). Outro problema existente é o efeito de tração (do Inglês, drift effect) gerado pelo particionamento de dados e pela escalabilidade SNR, que ocorre quando somente a camada base é transmitida para a aplicação. Nessas condições, diferentes quadros de referência para a compensação de movimento são utilizados durante a codificação e decodificação. Com esse efeito, a imagem decodificada é apresentada com borrões em certas regiões, persistindo até que um quadro do tipo I seja decodificado (HORN; GIROD, 1997; LI, 2001; OHM, 2005).

Tendo em vista os problemas relacionados, o padrão MPEG-4 propôs a especificação FGS (Escalabilidade Granular Refinada - do Inglês, Fine Granular Scalability) (LI, 2001), que tem como finalidade prover escalabilidade progressiva na taxa de bits dependendo da largura de banda disponível. A principal diferença entre a FGS e a codificação escalável é que, embora a FGS também codifique a seqüência de vídeo em várias camadas, o fluxo de bits adicional, independentemente de ter sido totalmente recebido pela aplicação, pode ser aplicado nos quadros da camada base a fim de fornecer melhorias na qualidade da imagem proporcionais à quantidade de dados recebidos (LI, 2001).

Desse modo, diversos trabalhos presentes na literatura (WU et al., 2001; WANG et al., 2002; KIM; AMMAR, 2003; LIU; LI; ZHANG, 2004) exploram a especificação FGS. Outros trabalhos (VIÉRON; GUILLEMOT, 2003; ANDREOPOULOS et al., 2003; SU, 2003) combinam codificação Wavelet com FGS, substituindo a escalabilidade temporal por transformadas espaço-temporais e eliminando, conseqüentemente, o efeito de tração anteriormente citado (OHM, 2005).

Por outro lado, a especificação FGS ainda enfrenta alguns problemas que dificultam a sua utilização. A qualidade do vídeo pode ser prejudicada quando é utilizado um nível alto de escalabilidade, particularmente se a camada base é codificada a uma baixa taxa de bits. Pode-se evitar esse problema codificando a camada base a altas taxas de bits, porém essa estratégia gera problemas ainda maiores quando a largura de banda é limitada, não sendo possível transmitir nem mesmo a camada base. Além disso, outro problema que ocorre tanto com a FGS quanto com a codificação escalável é que o decodificador necessita estar habilitado para entender múltiplas camadas, o que nem sempre acontece, principalmente quando estão sendo utilizados dispositivos móveis (DOGAN et al., 2004). 


\subsection{Modelo de Recodificação}

Visando proporcionar uma solução mais flexível ao problema do acesso a conteúdo audiovisual em ambientes heterogêneos, diversos pesquisadores têm centrado esforços no modelo de recodificação. Recodificação de vídeo é a operação de converter um vídeo de um formato para outro, mudando algumas características, tais como taxa de bits, resolução espacial, resolução temporal, padrão de codificação, entre outras (VETRO; CHRISTOPOULOS; SUN, 2003; XIN; LIN; SUN, 2005; AHMAD et al., 2005). Por ser uma operação que é realizada no servidor, ou em algum proxy ou gateway entre servidor e cliente, funcionalidades de adaptação ou personalização de conteúdo podem ser eficientemente implementadas, com possibilidade de trabalharem de modo estático ou dinâmico (DOGAN et al., 2004).

Diferentemente do modelo de mídia escalável, a recodificação não requer nenhuma funcionalidade adicional do decodificador presente no dispositivo, uma vez que a operação de adaptação de conteúdo é realizada antes dos dados serem recebidos pelo usuário. Além disso, a utilização prática do modelo de mídia escalável é inibida devido ao fato de muitas aplicações que utilizam vídeo em alta qualidade, atualmente, já terem adotado um padrão de codificação em única camada (VETRO; CHRISTOPOULOS; SUN, 2003). Por outro lado, em certas situações, como por exemplo, quando vários usuários fazem requisições de diferentes níveis de qualidade de um mesmo conteúdo, a utilização do modelo da mídia escalável é melhor, pois exige menos processamento de dados (XIN; LIN; SUN, 2005).

A principal utilização da recodificação é possibilitar o acesso multimídia universal (UMA - do Inglês, Universal Multimedia Access) (MOHAN; SMITH; LI, 1999), onde diferentes aplicações, sendo executadas por dispositivos com capacidades limitadas, acessam dados audiovisuais em formatos de codificação específicos, utilizando canais de comunicação com largura de banda variável. No entanto, outras funcionalidades podem ser obtidas com esse modelo, tais como inserção de marcas de água, logomarcas e funcionalidades de recuperação de erros.

Segundo Assunção \& Ghanbari (1998), para que a recodificação seja realizada satisfatoriamente, são necessárias três condições: a) as informações do fluxo de bits original devem ser exploradas o máximo possível; b) a qualidade do vídeo após a recodificação deve ser parecida com a qualidade do vídeo original; e c) em aplicações que fazem uso de interatividade, como por exemplo, videoconferência, o atraso de recodificação deve ser consideravelmente minimizado, a fim de satisfazer as necessidades da situação. Assim, pesquisas estão em constante desenvolvimento de modo a cumprirem esses requerimentos, cujo principal desafio está em prover recodificação ao vivo com o mínimo de interrupções do fluxo de vídeo (KEESMAN et al., 1996).

A maneira mais simples de se aplicar a recodificação em um sinal de vídeo é por meio da decodificação dos dados seguida da codificação no formato desejado. Nessa técnica, não é aproveitado nenhum parâmetro de codificação dos dados originais, como por e- 
xemplo, vetores de movimento, coeficientes DCT, etc. Essas informações são calculadas novamente durante a recodificação, o que, obviamente, exige uma demanda muito grande de processamento (XIN; LIN; SUN, 2005). Conseqüentemente, outras técnicas de recodificação são necessárias, entre as mais conhecidas (VETRO; CHRISTOPOULOS; SUN, 2003; XIN; LIN; SUN, 2005; AHMAD et al., 2005):

- Recodificador em Loop Aberto (do Inglês, Open-Loop Transcoder): trabalha com um mínimo de complexidade, modificando apenas os coeficientes DCT a fim de reduzir a taxa de bits. Inclui as funcionalidades de requantização e transmissão seletiva, descritas nas Subseções seguintes. Esse tipo de recodificação está sujeito a sofrer efeitos de tração, uma vez que as informações responsáveis pela estimativa e compensação de movimento podem estar inconsistentes em relação aos dados originais e recodificados.

- Recodificador em Loop Fechado (do Inglês, Closed-Loop Transcoder): parecido com o recodificador em loop aberto, porém, além de adicionar novas funcionalidades a fim de modificar os dados originais, contém um canal de retorno cuja finalidade é corrigir possíveis distorções de recodificação por meio da compensação dos erros que geram efeitos de tração. Pode atuar nos seguintes domínios:

Domínio Espacial (do Inglês, Spatial-Domain): reutiliza vetores de movimento do fluxo original, diminuindo consideravelmente a complexidade de processamento. São aplicadas as técnicas DCT e IDCT (do Inglês, Transformada Discreta do Cosseno Inversa - Inverse Discrete Cossin Transform) para que o processamento seja realizado no domínio espacial. Pode influenciar negativamente na qualidade final da imagem. Esse tipo de recodificação também é conhecido como recodificador de domínio em pixel (do Inglês, pixel-domain transcoder).

Domínio da Freqüência (do Inglês, Frequency-Domain): os algoritmos de compensação de movimento são aplicados no domínio da freqüência, de modo a eliminar a aplicação das técnicas DCT e IDCT. Esse tipo de recodificação contém baixa flexibilidade e está sujeito a sofrer erros que geram efeitos de tração.

Domínio Híbrido (do Inglês, Hybrid-Domain Transcoding): utilizando ambos os domínios Espacial e da Freqüência, são aplicadas técnicas de decodificação e codificação de acordo com o tipo de quadro (I, P ou B), a fim de minimizar as desvantagens oferecidas por cada domínio.

Uma vez definido o modo em que o recodificador irá atuar, é possível realizar uma série de conversões nas características de apresentação do vídeo. Ahmad et al. (2005) classificam essas conversões em dois grupos: recodificação homogênea de vídeo, caracterizada pela mudança de atributos, porém sem alterar o padrão de codificação (de MPEG-4 
para MPEG-4, por exemplo); e recodificação heterogênea de vídeo, definida também pela mudança de atributos, porém alterando-se o padrão de codificação (de MPEG-2 para MPEG-4, por exemplo).

Nas próximas Subseções algumas conversões realizadas pela recodificação são descritas, as quais foram selecionadas por serem amplamente utilizadas.

\subsubsection{Redução da Taxa de Bits}

O principal objetivo desse tipo de conversão é reduzir a taxa de bits do vídeo sem aumentar a complexidade do recodificador. É utilizada em ambientes onde a largura de banda da rede é insuficiente para transmitir um determinado fluxo de dados. Idealmente, a qualidade de um vídeo recodificado com uma taxa de bits reduzida deve ser igual à qualidade de um fluxo de vídeo codificado diretamente com essa mesma taxa de bits reduzida (VETRO; CHRISTOPOULOS; SUN, 2003). A uma mesma resolução espacial e temporal, a taxa de bits pode ser reduzida utilizando-se duas técnicas (AHMAD et al., 2005):

- Requantização: consiste em aumentar o fator de quantização no codificador durante a recodificação, gerando menos coeficientes diferentes de zero e conseqüentemente, diminuindo o fluxo de bits (WERNER, 1999).

- Transmissão Seletiva: consiste em descartar coeficientes DCT de alta freqüência em um bloco, preservando a qualidade da imagem. Pode gerar efeitos de blocagem (do Inglês, blocking effect) no vídeo reconstruído (SHANABLEH; GHANBARI, 2000).

\subsubsection{Redução da Resolução Espacial}

A redução na resolução espacial, diminuindo o tamanho do quadro, e conseqüentemente, a taxa de bits, permite que usuários utilizem dispositivos móveis ou portáteis para acessar vídeo originalmente configurado em alta resolução. Além da alta demanda de processamento e largura de banda, esse tipo de conteúdo requer tela com grande área de visualização, o que nem sempre é possível quando estão sendo utilizados dispositivos móveis ou portáteis (VETRO; CHRISTOPOULOS; SUN, 2003). A redução na resolução espacial pode ser realizada pelas seguintes técnicas (AHMAD et al., 2005):

- Filtragem e Subamostragem: consiste em realizar uma subamostragem da imagem por meio da aplicação de filtros que indicam quais pixels devem ser eliminados (SHANABLEH; GHANBARI, 2000; MOHAN; SMITH; LI, 1999).

- Média de Pixels: consiste em calcular a média de m x m pixels, cujo valor resultante corresponderá ao pixel da região reduzida. Dependendo da região, essa técnica pode borrar a imagem reconstruída (SHANABLEH; GHANBARI, 2000). 
- Descarte de Coeficientes DCT: consiste em reduzir um conjunto de m x m macroblocos em um único macrobloco por meio da eliminação de coeficientes DCT de alta freqüência (SHANABLEH; GHANBARI, 2000).

- Composição de Vetor de Movimento e Refinamento: com a redução de macroblocos por meio das técnicas de filtragem e subamostragem, média de pixels e descarte de coeficientes DCT, os vetores de movimento de cada região precisam ser mapeados. Para isso, podem ser aplicadas diferentes técnicas, tais como sorteio, média, média por peso, etc. (BJORK; CHRISTOPOULOS, 1998; SHANABLEH; GHANBARI, 2000; SHEN; SETHI; VASUDEV, 1999; CHEN; CHU; PAN, 2002).

- Modo de Codificação de Macroblocos: também com a redução de macroblocos, é necessário especificar que tipo de codificação terá o macrobloco resultante. São atribuídos, assim, pesos aos tipos INTRA, INTER e SKIP, e o macrobloco resultante terá o tipo de maior peso dentro do conjunto de macroblocos que será reduzido (MOHAN; SMITH; LI, 1999).

\subsubsection{Redução da Resolução Temporal}

A redução na resolução temporal consiste na eliminação de quadros do fluxo de vídeo de modo a diminuir a quantidade de quadros transmitidos por segundo. É utilizada para reduzir a taxa de bits nos casos em que a largura de banda da rede é insuficiente para a transmissão. Pode ser usada também para manter a alta qualidade de quadros codificados ou satisfazer as limitações de processamento, memória ou bateria impostas pelos dispositivos dos usuários (VETRO; CHRISTOPOULOS; SUN, 2003). Uma vez que quadros são descartados do fluxo de vídeo, é necessário recalcular os vetores de movimento. Desse modo, as seguintes técnicas são utilizadas (AHMAD et al., 2005):

- Interpolação Bilinear: consiste em estimar os vetores de movimento do quadro atual em relação ao quadro anterior não descartado, utilizando os vetores de movimento de quadros adjacentes (HWANG; WU, 1998).

- Seleção de Vetor Dominante: após especificar o vetor dominante de um determinado macrobloco, ou seja, aquele que mais se deslocou no conjunto de blocos, os macroblocos são seguidos quadro a quadro utilizando-se os vetores de movimento, até encontrar um quadro que não foi descartado (YOUN; SUN; LIN, 1999).

- Composição de Vetor Telescópico: consiste em somar os vetores de movimento de todos os macroblocos dos quadros descartados e calcular vetores de movimento resultantes referentes aos macroblocos correspondentes (SHANABLEH; GHANBARI, 2000). 
- Seleção de Vetor por Atividade Dominante: consiste em calcular os vetores de movimento com base na atividade dos macroblocos. Essa atividade é calculada pela soma dos coeficientes DCT diferentes de zero. Quanto maior a atividade de um macrobloco, mais significante é o movimento realizado (CHEN; CHU; PAN, 2002).

\subsubsection{Alteração de Padrões}

A recodificação, além de alterar características de apresentação do vídeo, pode também converter um padrão de codificação para outro, a fim de satisfazer determinadas exigências de algumas aplicações. A fim de realizar essa tarefa, é necessário um módulo de conversão de sintaxe, uma vez que são definidos diferentes formatos para cada padrão.

Ahmad et al. (2005) descrevem uma arquitetura de recodificação heterogênea de vídeo. Um módulo é responsável pela conversão de sintaxe entre os padrões, e um decodificador decodifica o fluxo de vídeo em alta resolução. Os vetores de movimento extraídos são processados de acordo com a estrutura de codificação do padrão de saída, e se necessário, são modificados para atender uma resolução espaço-temporal menor na codificação. É possível também aplicar refinamentos nos vetores de movimento para melhorar a eficiência da codificação. Em seguida, os quadros decodificados são convertidos em uma resolução espacial e temporal menor (de acordo com a requisição da aplicação), e codificados novamente com os novos vetores de movimento.

A principal vantagem de se realizar alteração de padrões é a possibilidade de o vídeo ser acessado por dispositivos cujo decodificador seja capaz de entender apenas padrões específicos. Como exemplo, se um dispositivo contém um decodificador para o padrão MPEG-2, e o vídeo está codificado no formato MPEG-4, pode-se realizar uma conversão de padrões (de MPEG-4 para MPEG-2) durante a recodificação, de modo que o dispositivo seja capaz de receber e processar os dados.

No entanto, essa funcionalidade traz algumas desvantagens para o sistema de recodificação. Uma vez que o vídeo é convertido de um padrão para outro, mais codificadores são necessários para se realizar determinadas tarefas. Além disso, a complexidade do sistema de recodificação torna-se muito maior, tendo em vista que formatos de apresentação e sintaxe dos dados são específicos para cada especificação.

\subsubsection{Inserção de Informações}

A recodificação pode também ser utilizada para inserir informações adicionais no vídeo. Dois exemplos de informações podem ser (XIN; LIN; SUN, 2005):

- Logomarcas ou Marcas de Água: uma vez que a inserção de logomarcas ou marcas de água em um vídeo afeta somente parte da imagem, é possível reutilizar os vetores de movimento nas regiões que não foram afetadas pela informação. No 
caso das regiões que foram afetadas, pode-se aplicar vários algoritmos (PENUSOPONE; CHEN; LING, 2001) para adaptar os vetores de movimento e as escalas de quantização.

- Recuperação de Erros: é a habilidade de um fluxo de bits se acomodar às condições de um canal de comunicação, e ainda produzir qualidade de vídeo aceitável. Um recodificador dessa natureza pode manter a qualidade do vídeo mesmo com a ocorrência de erros, uma vez que aplica métodos de prevenção de propagação de erros (REYES et al., 2000; DOGAN et al., 2002).

\subsection{Considerações Finais}

Conteúdo audiovisual, atualmente, pode ser acessado por diferentes aplicações, que são executadas em vários tipos de dispositivos. O acesso é realizado através de canais de comunicação, cuja topologia pode variar constantemente. Adicionalmente, usuários possuem preferências individuais, o que pode necessitar de personalização de conteúdo. Toda essa heterogeneidade de entidades acaba prejudicando o acesso ao vídeo, necessitando, assim, de estratégias que permitem o acesso nessas condições, sendo que uma alternativa é a adaptação de conteúdo.

Este Capítulo apresentou três modelos de adaptação de vídeo amplamente utilizados na literatura. Foram descritos conceitos, técnicas, vantagens e desvantagens dos modelos de distribuição por difusão simultânea, mídia escalável e recodificação. O propósito deste Capítulo, de acordo com o trabalho desenvolvido, foi fornecer informações que justificam a escolha do modelo de recodificação no sistema de adaptação. Dentre essas informações, destaca-se a possibilidade de ajustar a taxa de bits do fluxo de vídeo de acordo com a largura de banda, e a não necessidade do decodificador presente no dispositivo do usuário estar habilitado com funcionalidades adicionais, tais como decodificação em múltiplas camadas.

Apesar de todos os modelos apresentados realizarem a adaptação de vídeo, eles não especificam, automaticamente, a configuração ideal do vídeo para que o mesmo possa ser acessado pelos usuários com sucesso. Assim, o próximo Capítulo apresenta alguns conceitos sobre a área computação ciente de contexto, a qual, justamente, busca utilizar informações sobre o ambiente computacional para adaptar o sistema de acordo com a situação atual. 


\section{Capítulo \\ 3 \\ Computação Ciente de Contexto}

\subsection{Considerações Iniciais}

Computação ciente de contexto é um tema de pesquisa proveniente da área de computação ubíqua. Segundo Weiser (1991), a computação ubíqua refere-se a recursos computacionais que podem ser incorporados ao ambiente a fim de auxiliar as atividades humanas. Essa incorporação deve ser feita de modo não intrusivo, isto é, fazer com que os referidos recursos se adaptem ao comportamento humano em vez de o usuário se adaptar aos dispositivos de interação. Para isso, é necessário que a computação esteja presente no ambiente de modo transparente para o usuário, oferecendo-lhe serviços e informações quando solicitada.

Contribuindo para que a computação ubíqua cada vez mais faça parte da vida das pessoas, diferentes tipos de dispositivos de tamanhos variados foram e estão sendo desenvolvidos, envolvendo desde dispositivos portáteis até grandes dispositivos compartilhados (WEISER, 1991). Como exemplo, pode-se citar os PDAs (Assistente Pessoal Digital - do Inglês, Personal Digital Assistant), laptops, tablets, lousas eletrônicas, entre outros.

Visando fornecer auxílio às práticas cotidianas das pessoas por meio de dispositivos heterogêneos, além de gerenciá-los em rede de forma a oferecer ao usuário uma experiência holística, pesquisadores têm centrado esforços em três grandes temas de pesquisa na área de computação ubíqua (ABOWD; MYNATT, 2000), que são: interfaces naturais, captura e acesso de atividades humanas e computação ciente de contexto.

A área de interfaces naturais estuda a interação do usuário com os objetos computacionais que estão dispostos ao seu redor, de forma que essa interação seja parecida com a realizada pelos seres humanos com o mundo físico. Por meio da comunicação habitual, que é feita por meio da fala, gestos, escrita manual, entre outras, novos tipos de dados 
podem ser capturados pelos sistemas de computação ubíqua sem que o usuário necessite mudar seu modo de interagir com o mundo. Exemplos de pesquisa nessa área incluem: o sistema Ubiquitous Presenter (WILKERSON; GRISWOLD; SIMON, ), que oferece meios de se combinar apresentações de slides com anotações eletrônicas produzidas pelo professor e alunos utilizando tablets; o sistema Touch-Space (CHEOK et al., 2002), um jogo de entretenimento baseado em interfaces tangíveis que captura toques humanos e interações físicas com o meio ambiente real; e o sistema desenvolvido por Tapia et al. (2004), que realiza o reconhecimento de atividades do usuário dentro de sua casa utilizando sensores.

A área de captura e acesso de atividades humanas explora o uso de recursos computacionais para o registro, processamento e acesso de informações relacionadas às atividades dos usuários. A captura acontece quando uma entidade (dispositivo, programa, etc.) gera dados que descrevem o histórico dos eventos ocorridos, armazenando-os em seguida em fluxos de informação indexados ao longo do tempo. O acesso, por sua vez, acontece quando os dados capturados são revisitados após um período de tempo, o que pode variar de milissegundos a anos (TRUONG; ABOWD; BROTHERTON, 2001). Como exemplos de trabalhos relacionados nessa área podem-se citar o sistema iClass (CATTELAN et al., 2003), desenvolvido no ICMC-USP, que é uma aplicação de captura e acesso de vídeo, áudio, URLs (Localizadores de Recursos Uniformes - do Inglês, Uniform Resource Locators) visitados e anotações produzidas pelo professor em salas de aula; o trabalho de Ellis \& Lee (ELLIS; LEE, 2004), que fornece meios de se capturar, analisar, indexar, visualizar e relacionar dados auditivos com outras fontes de informações a fim de se criar arquivos pessoais; e o INCA (Infra-estrutura para Aplicações de Captura e Acesso - do Inglês, Infrastructure for Capture and Access Applications) (TRUONG; ABOWD, 2004), um toolkit que fornece uma infra-estrutura para criação de aplicações de captura e acesso.

A área de computação ciente de contexto estuda a comunicação entre usuário e sistema durante interações, de modo a capturar informações contextuais provenientes dessa comunicação. Essas informações são utilizadas para fornecer subsídios que auxiliem o gerenciamento e adaptação de serviços de acordo com as necessidades do usuário ou características dos dispositivos. Exemplos na área de computação ciente de contexto incluem: o Context Kernel (ARRUDA JÚNIOR, 2003), desenvolvido no ICMC-USP, que é um serviço web para armazenamento e recuperação de informações de contexto; o trabalho de Goularte (2003), desenvolvido também no ICMC-USP, que explora o desenvolvimento de técnicas com suporte à ciência de contexto, baseadas nos padrões MPEG-4 e MPEG7 (STANDARDISATION, 2004), para personalizar e adaptar conteúdo em TV interativa; e o Gator Tech Smart House (HELAL et al., 2005), um conjunto de tecnologias escaláveis, de baixo custo e programáveis, que são instaladas em uma casa para oferecerem serviços para os usuários de acordo com informações de contexto capturadas do ambiente por meio de sensores.

Não obstante os outros temas de pesquisa serem importantes para a computação 
ubíqua, a computação ciente de contexto tem papel fundamental no presente trabalho. Uma vez que ela define informações contextuais que descrevem a situação de entidades presentes no sistema computacional, ela pode ser utilizada para fornecer ao sistema subsídios que irão auxiliar na decisão do melhor formato de apresentação do vídeo em determinada situação.

Desse modo, este Capítulo revisa alguns conceitos pertinentes ao tema computação ciente de contexto. As Seções 3.2 e 3.3 apresentam definições sobre o termo contexto, a fim de esclarecer algumas questões, como por exemplo, quais informações podem ser consideradas contexto, se uma informação é relevante para ser considerada contexto, se algumas informações de contexto são mais importantes que outras, etc. A Seção 3.4 descreve as classificações de contexto presentes na literatura, de modo a organizar e estruturar informações de contexto capturadas de diferentes domínios. A Seção 3.5 apresenta alguns trabalhos para representação de informações contextuais, com enfoque para o modelo proposto por Goularte (2003), o qual foi estendido no presente trabalho. A Seção 3.6, por fim, apresenta as considerações finais deste Capítulo.

\subsection{Definição de Contexto}

O termo contexto é definido por vários autores na literatura (SCHILIT; ADAMS; WANT, 1994; BROWN; BOVEY; CHEN, 1997; SALBER; DEY; ABOWD, 1998; PASCOE, 1998), mas por serem todas definições restritivas demais, ou por serem baseadas em exemplos, são difíceis de serem aplicadas. No entanto, a definição de Dey (2001), por ser mais genérica, tem sido bem aceita pela comunidade acadêmica (DEY; ABOWD, 1999; DEY, 2001). Segundo Dey, "contexto é qualquer informação que pode ser utilizada para caracterizar a situação de uma entidade. Uma entidade é uma pessoa, lugar, ou objeto que é considerado relevante para a interação entre um usuário e uma aplicação, incluindo o usuário e a aplicação em si". De acordo com a definição, caso uma informação possa ser usada para caracterizar a situação de um participante da interação entre um usuário e uma aplicação, então essa informação é contexto (DEY; ABOWD, 1999; DEY, 2001).

Por outro lado, algumas situações necessitam soluções para questões tais como a caracterização do ambiente utilizado, os serviços prestados em determinado ambiente e o modo de se oferecer serviços de acordo com as preferências do usuário ou necessidades dos dispositivos. Para tratar essas questões, pode-se utilizar informações de contexto relacionadas não apenas ao contexto usuário e aplicação, mas também em relação à rede e à situação das possíveis interações entre as aplicações e o sistema (SANTOS JÚNIOR et al., 2001; SANTOS JÚNIOR, 2002). Desse modo, em seu trabalho, Goularte (2003) estendeu a definição de Dey, que é restritiva a interações entre o usuário e a aplicação, para que a mesma possa ser aplicada em ambientes interativos de forma mais ampla, explorando também as interações entre as aplicações e o sistema. Assim, segundo Goularte, "contexto 
é qualquer informação que pode ser utilizada para caracterizar a situação de uma entidade. Uma entidade é uma pessoa, lugar, ou objeto físico ou software que é considerado relevante para a interação entre um usuário e uma aplicação, e/ou entre a aplicação e o sistema, incluindo o usuário, aplicação e sistema em si".

Tanto pela definição de Dey quanto pela definição de Goularte, fica claro que é tarefa do desenvolvedor decidir qual ou quais informações podem ser consideradas contexto. Para saber se uma informação é importante ou relevante para ser considerada contexto pode-se utilizar as diretrizes "quem", "onde ", "o quê" e "quando" relacionadas a alguma entidade para se determinar o "porquê" de uma determinada situação estar ocorrendo (DEY; ABOWD, 1999; ABOWD; MYNATT, 2000).

Existem algumas informações de contexto que, na prática, são mais importantes que outras (SCHILIT; ADAMS; WANT, 1994; BROWN; BOVEY; CHEN, 1997; PASCOE, 1998; DEY; ABOWD, 1999; DEY, 2001). Esses tipos de informação são chamados de contexto primário, e são classificados em: localização, identidade, atividade e tempo. São importantes pois além de responderem as questões quem, onde, o quê e quando, também podem ser usados como índices para outras fontes de informação contextual. Pode-se obter, por exemplo, a partir da localização, quais serviços estão disponíveis atualmente em determinada situação.

\subsection{Definição de Computação Ciente de Contexto}

Vários autores têm tentado definir o termo computação ciente de contexto (WARD; JONES; HOPPER, 1997; BROWN, 1998; KORTEUM; SEGSLL; BAUER, 1998; HULL; NEAVES; BEDFORD-ROBERTS, 1997; PASCOE, 1998; SALBER; DEY; ABOWD, 1998), sendo que esse termo foi primeiramente introduzido por Schilit \& Theimer (1994). Eles o definiram como "o estudo de aplicações que se adaptam de acordo com sua localização de uso, com a coleção de objetos e pessoas nas proximidades e também de acordo com as mudanças ocorridas com esses objetos ao longo do tempo". No entanto, Dey \& Abowd (1999) e Dey (2001) argumentam que essa e outras definições, por estarem centralizadas na aplicação, requerem que o comportamento de uma aplicação seja modificado para que a mesma possa ser considerada ciente de contexto, e que o sistema seja capaz de detectar, interpretar e responder ao contexto. Conseqüentemente, esses autores propõem uma definição mais genérica, centralizada no usuário, a qual diz que "quando uma aplicação utiliza informaçôes de contexto para prover informações ou serviços relevantes para o usuário, ela é chamada de ciente de contexto" (DEY; ABOWD, 1999; DEY, 2001).

Desse modo, essa definição traz algumas vantagens, que são: a) não exclui as aplicações cientes de contexto existentes, que estão de acordo com as definições previamente propostas; b) por estar relacionada ao usuário, não limita a ciência a apenas interfaces de aplicações; e c) também por estar relacionada ao usuário, não requer aquisição de contexto 
em tempo real nem que as aplicações realizem serviços automaticamente (DEY, 2001).

\subsection{Classificação de Contexto}

Além do contexto relacionado ao usuário, outros tipos de contexto são reportados pela literatura (SCHILIT, 1995; DIX et al., 2000; CHALMERS, 2002; CROWLEY et al., 2002; ABOWD; MYNATT; RODDEN, 2002), e podem ser classificados da seguinte maneira: Infra-Estrutura, Sistema, Domínio e Ambiente.

O contexto Infra-Estrutura refere-se a informações pertinentes ao estado atual da infra-estrutura de comunicação entre a aplicação e os dispositivos. Essas informações indicam, por exemplo, possíveis mudanças de estado devido a falhas, entrada ou saída de um dispositivo no ambiente (SCHILIT, 1995; DIX et al., 2000).

O contexto Sistema trata de possíveis interações entre dispositivos e/ou aplicações. Uma vez que dispositivos influenciam outros dispositivos por meio da competição por recursos, é necessário saber até que ponto um determinado dispositivo está ciente de outros dispositivos nas suas proximidades, e, relacionado a isso, até que ponto uma aplicação está ciente de outras aplicações oferecendo serviços (DIX et al., 2000; CROWLEY et al., 2002; CHALMERS, 2002).

O contexto Domínio contém informações a respeito do domínio da aplicação, envolvendo desde os relacionamentos entre dispositivos e usuários a fim de se determinar a natureza do serviço sendo apresentado, até o nível de segurança e privacidade em que informações de usuários estarão disponíveis para outros usuários (DIX et al., 2000; ABOWD; MYNATT; RODDEN, 2002).

O contexto Ambiente agrega informações a respeito do ambiente onde determinada entidade se encontra, tais como: luminosidade, temperatura, localização, endereço, entre outras (DIX et al., 2000).

Em computação ciente de contexto, os tipos de contexto descritos aqui são os mais usuais. Dix et al. (2000) descrevem os tipos de contexto citados nesta Seção a fim de situar seu trabalho, o qual está relacionado ao contexto Ambiente. Do mesmo modo, Goularte (2003) estendeu essa classificação adicionando os tipos Usuário e Aplicação, uma vez que seu trabalho envolve adaptação e personalização de conteúdo interativo em relação ao usuário. Uma organização estruturada dos tipos de contexto é proposta pelo mesmo autor, a qual será apresentada na próxima Seção.

\subsection{Representação de Contexto}

Uma vez que informações de contexto foram capturadas pelo sistema, torna-se necessário representar essas informações de maneira conveniente para o acesso por parte das aplicações. Um dos desafios da computação ciente de contexto é a questão de como 
representar contexto. Sem boas representações, desenvolvedores são forçados a implementar esquemas proprietários e limitados para armazenamento e manipulação, dificultando o intercâmbio desse tipo de informação (ABOWD; MYNATT; RODDEN, 2002).

Diversos autores têm tentado implementar representações que forneçam suporte à abstração de informações de contexto que possam ser pesquisadas por aplicações. O Context Toolkit (SALBER; DEY; ABOWD, 1999) é uma arquitetura que descreve informações contextuais provindas de sensores para aplicações cientes de contexto. Essas informações são representadas usando pares do tipo atributo-valor, os quais simplificam o processo de definição. No entanto, uma vez que não é definido nenhum vocabulário para garantir uma representação sofisticada, essa simplicidade fornecida pela ferramenta dificulta a compreensão de contexto ao compartilhar as informações.

Outro trabalho que explora a aquisição e processamento de dados vindos de sensores é a arquitetura de Schmidt et al. (1999). Nesse trabalho, é fornecido um modelo em camadas de processamento de contexto no qual a saída dos sensores é transformada em dados, os quais são processados para criar uma descrição abstrata de contexto compreendendo um conjunto de valores.

Outros trabalhos disponíveis na literatura se concentram em modelar informações contextuais e entregar essas informações para a aplicação. O primeiro trabalho nessa área foi desenvolvido por Schilit et al. (1994), que propôs o uso de servidores dinâmicos de ambiente para gerenciar e disseminar informações de contexto. O projeto Cooltown (KINDBERG et al., 2000) representa contexto por meio de páginas HTML (Linguagem para Marcação de Hipertexto - do Inglês, HyperText Markup Language) representando as entidades contextuais. O projeto Sentient Computing (HARTER et al., 1999) representa contexto por meio de um modelo entidade-relacionamento, de modo que as informações de contexto são armazenadas em uma base de dados relacional. Crowley et al. (2002) representam contexto como um conjunto de variáveis representando o estado do sistema.

As abordagens citadas apresentam algumas limitações que dificultam a utilização. A maioria não se preocupa em classificar os tipos de contexto de modo a obter uma representação estruturada e abrangente das informações de contexto. Outro problema é que tais abordagens apresentam falta de flexibilidade para compartilhar as informações de contexto com outras aplicações (GOULARTE, 2003).

Tendo em vista os problemas relacionados aos trabalhos referenciados, Goularte (2003) desenvolveu um framework baseado na definição de contexto de Dey (2001) e sua extensão (ver Seção 3.2) que oferece: a) uma representação de contexto; b) meios de se definir entidades contextuais classificando-as de acordo com o modelo contextual; e c) um conjunto extensível de elementos contextuais pré-definidos - a biblioteca de contexto.

A representação de contexto proposta por Goularte segue uma organização parecida com a classificação de contexto discutida na Seção 3.4, a qual classifica contexto em Infra-Estrutura, Sistema, Usuário, Aplicação, Domínio e Ambiente. Os tipos 
de contexto - com exceção dos contextos Domínio e Ambiente - foram organizados de modo a auxiliar o desenvolvimento de uma representação contextual, conforme pode ser visualizado na Figura 3.1 (GOULARTE, 2003).

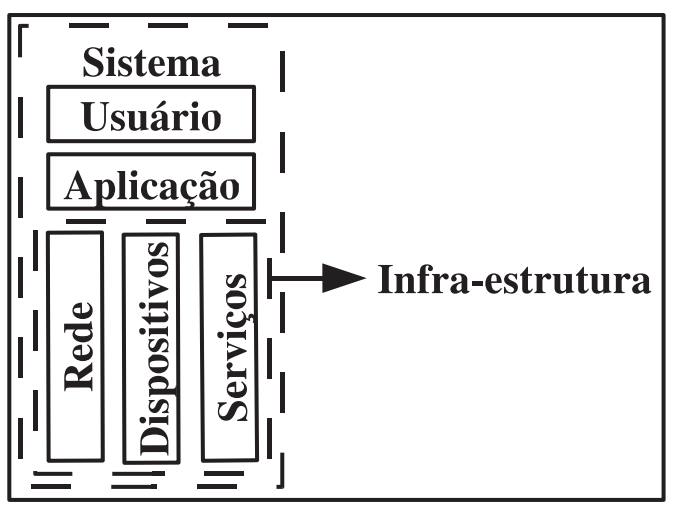

Figura 3.1: Componentes do contexto do sistema (GOULARTE, 2003).

A Figura 3.1 apresenta uma organização dos tipos de contexto. Os retângulos simbolizam entidades com representação própria e os retângulos pontilhados simbolizam entidades compostas por outras entidades. Usuários, aplicação e infra-estrutura compõem o sistema computacional. Usuários podem utilizar dispositivos (computadores pessoais, PDAs, controles-remotos, entre outros) para acessar aplicações e requisitar algum serviço específico. Aplicações utilizam dispositivos (impressoras, projetores, entre outros) e serviços (servidores de impressão, serviços de transferência de arquivos, máquinas de busca, entre outros) da infra-estrutura para realizar a tarefa requisitada. A comunicação entre usuários, dispositivos e aplicações é fornecida pela rede.

No framework desenvolvido por Goularte, cada tipo de contexto é definido estendendose contextos primários. Contextos primários são representados pelo tipo abstrato PrimaryContextType, o qual é composto pelos tipos abstratos IdentityType, LocationType, TimeType e ActivityType. Esses tipos abstratos são representações, respectivamente, dos contextos primários identidade, localização, tempo e atividade (ver Seção 3.2).

Utilizando essa definição, é possível construir entidades contextuais específicas de acordo com o contexto primário. Desse modo, definiu-se previamente uma biblioteca de contexto composta por um conjunto de entidades específicas - cada item da biblioteca é um tipo XML Schema (W3C, 2004) representando informações de contexto úteis para caracterizar uma determinada entidade. Assim, ao descrever uma entidade contextual, procura-se na biblioteca pré-definida qual informação melhor caracteriza a entidade a ser descrita. Se a biblioteca não contém a representação contextual adequada, pode-se criar novas representações por meio de extensões de PrimaryContextType.

Como exemplo, a descrição da entidade Usuário requer que o tipo UserType seja definido como extensão de PrimaryContextType, a fim de que esse tipo possa herdar todos os elementos definidos, ou seja, toda biblioteca de contexto. A Figura 3.2 (GOULARTE, 
2003) ilustra a definição do tipo UserType.

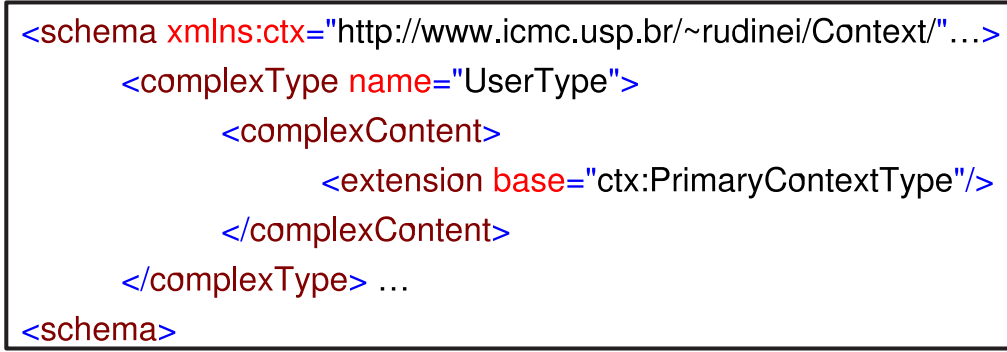

Figura 3.2: Definição do tipo UserType como uma extensão de PrimaryContextType (GOULARTE, 2003).

Ao descrever um usuário, o desenvolvedor escolhe alguns tipos da biblioteca que melhor caracterizam seus interesses. Isso é feito usando a ferramenta XML Schema xsi:type, um recurso usado para indicar qual implementação do tipo abstrato está sendo usada (Figura 3.4 (GOULARTE, 2003)). Se a biblioteca não contém a informação desejada, como por exemplo, na representação de um apelido, é possível estender os componentes PrimaryContextType, nesse caso IdentityType (Figura 3.3 (GOULARTE, 2003)), para que NickNameType possa ser usado (Figura 3.4).

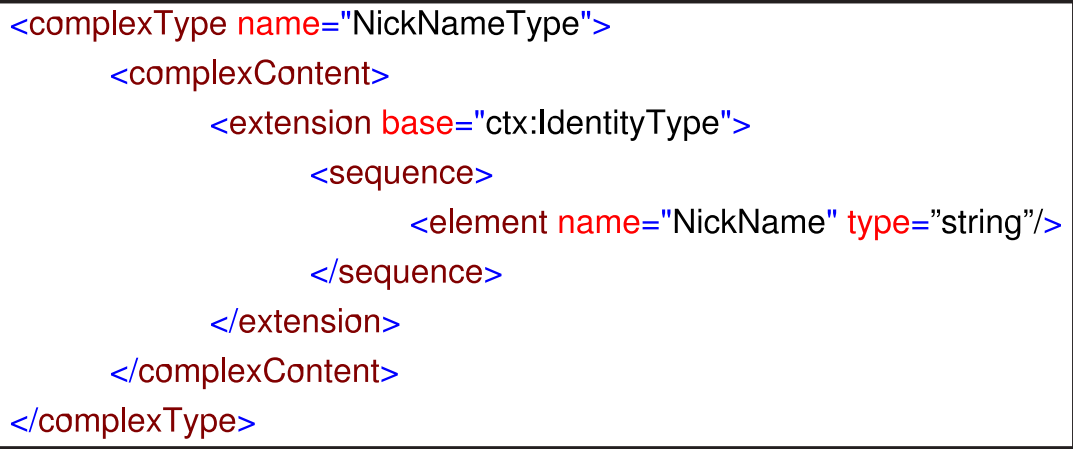

Figura 3.3: Exemplo de criação do tipo NickNameType (GOULARTE, 2003).

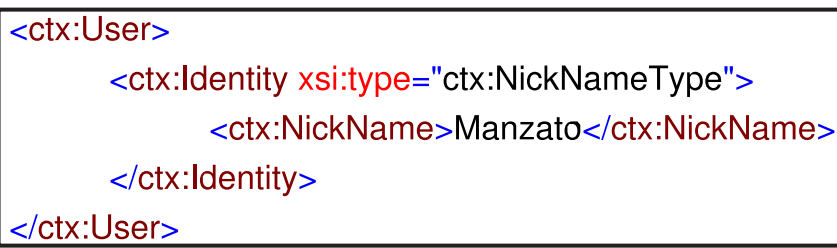

Figura 3.4: Exemplo de utilização do novo tipo NickNameType (GOULARTE, 2003).

Em seu trabalho, Goularte definiu um modelo de usuário formado por um conjunto de elementos contextuais, classificados de acordo com os tipos de contexto primário identidade, localização, tempo e atividade. Esses elementos contextuais compõem a biblioteca 
de contexto, podendo ser utilizados na representação de informações de contexto relacionadas a usuários. A Tabela 3.1 (GOULARTE; PIMENTEL; MOREIRA, 2006) lista alguns elementos presentes na biblioteca.

Tabela 3.1: Exemplos de tipos presentes na biblioteca de contexto (GOULARTE; PIMENTEL; MOREIRA, 2006).

\begin{tabular}{|c|c|c|}
\hline Contexto Primário & Tipos Complexos & Tipos Simples \\
\hline Identidade & $\begin{array}{l}\text { fullNameType } \\
\text { personallnformationType }\end{array}$ & $\begin{array}{l}\text { userIDType, roleType, } \\
\text { simpleNameType, ... } \\
\text { givenNameType, } \\
\text { middleNameType, } \\
\text { familyNameType, ... } \\
\text { ageType, heightType, } \\
\text { weightType, eyesType, } \\
\text { birthDateType, ... }\end{array}$ \\
\hline Localização & $\begin{array}{l}\text { indoorLocationType } \\
\text { postalAddressType }\end{array}$ & $\begin{array}{l}\text { floorType, room Type, } \\
\text { corridorType, gateType, } \\
\text { exitType, ... } \\
\text { streetType, numberType, } \\
\text { complementType, cityType, } \\
\text { stateType, countryType, ... }\end{array}$ \\
\hline Tempo & & $\begin{array}{l}\text { occasion Type, dateType, } \\
\text { simpleTimeType, } \\
\text { duration Type, ... }\end{array}$ \\
\hline Atividade & & $\begin{array}{l}\text { userActionType, } \\
\text { userActivityType, ... }\end{array}$ \\
\hline
\end{tabular}

De acordo com a Tabela 3.1, cada tipo corresponde a um elemento. Do mesmo modo que tipos complexos foram construídos a partir de tipos simples, desenvolvedores podem usar tipos simples ou complexos para construir novos elementos, conforme a necessidade da aplicação.

\subsection{Considerações Finais}

A adaptação de conteúdo necessita que o sistema tenha subsídios que indiquem o melhor formato de apresentação dos dados para que eles possam ser acessados satisfatoriamente pelos usuários. Esses subsídios são definidos por meio de informações de contexto que são capturadas do ambiente computacional, indicando, entre outras informações, o tipo de dispositivo que o usuário utiliza e a largura de banda disponível na rede.

Este Capítulo apresentou alguns conceitos importantes a respeito da área de computação ciente de contexto. Foi apresentado também um modelo de representação de contexto definido por Goularte (2003), o qual oferece meios de se organizar e estruturar informações de contexto. O propósito deste Capítulo, de acordo com o trabalho 
desenvolvido, foi apresentar conceitos que irão auxiliar durante as tarefas de captura e processamento das informações de contexto adotadas neste trabalho, bem como facilitar o entendimento do modelo de representação de dispositivos proposto.

Desse modo, o próximo Capítulo apresenta uma das contribuições deste trabalho, que é uma extensão do modelo de Goularte para representar informações de contexto relacionadas a dispositivos. Outra contribuição, também presente no próximo Capítulo, é a descrição de um sistema desenvolvido para adaptar vídeo ao vivo automaticamente com base em informações de contexto, utilizando a técnica da recodificação. 


\section{Capítulo \\ 4 \\ Sistema de Adaptação de Vídeo}

\subsection{Considerações Iniciais}

O objetivo deste trabalho é desenvolver um mecanismo que utilize informações de contexto para promover recodificação automática de vídeo ao vivo, atendendo usuários de dispositivos, redes e preferências diversos. Para isso, definiu-se uma arquitetura que utiliza ferramentas de código-aberto para atender requisições, assim como capturar, codificar e recodificar o vídeo que é transmitido para os usuários.

Além da arquitetura, definiu-se as informações de contexto utilizadas neste trabalho para a adaptação, e desenvolveu-se métodos automáticos e semi-automáticos para capturá-las do sistema computacional. A partir dessas informações, um algoritmo para processamento foi proposto, de modo a especificar automaticamente o melhor formato de apresentação do vídeo para ser acessado pelos usuários de acordo com a situação atual do sistema.

A representação das informações de contexto é realizada utilizando-se um modelo de representação de dispositivos estendido do modelo contextual proposto por Goularte (2003), o qual permite a descrição organizada, hierárquica e extensível de informações de contexto, além do compartilhamento dessas informações com outras aplicações.

Nas próximas Seções a infra-estrutura do sistema de adaptação de vídeo e o modelo de descrição de dispositivos são apresentados. Na Seção 4.2 a arquitetura do sistema é proposta, descrevendo-se seus componentes de maneira geral; na Seção 4.3 são descritos os mecanismos para extração de informações de contexto do ambiente computacional; na Seção 4.4 o modelo de descrição de dispositivos é apresentado; na Seção 4.5 o algoritmo para processamento das informações de contexto capturadas é proposto; na Seção 4.6 é 
descrito a maneira como o modelo de recodificação é utilizado para adaptar o vídeo; e por fim, na Seção 4.7 é apresentada uma interface de acesso com a finalidade de facilitar o acesso aos dados pelos usuários.

\subsection{Arquitetura do Sistema}

O sistema desenvolvido tem como objetivo fornecer vídeo ao vivo ou sob demanda para usuários em diferentes configurações de rede e de dispositivos. Por meio de um mecanismo de recodificação, o conteúdo é adaptado para que usuários sejam capazes de acessá-lo utilizando canais de comunicação com largura de banda limitada e dispositivos com baixa resolução de tela. A Figura 4.1 ilustra a arquitetura do sistema, que é dividida em quatro fases principais: captura multimídia e codificação, adaptação, captura de contexto e controle de acesso e acesso. Detalhes da especificação são descritas na Seção 5.2.

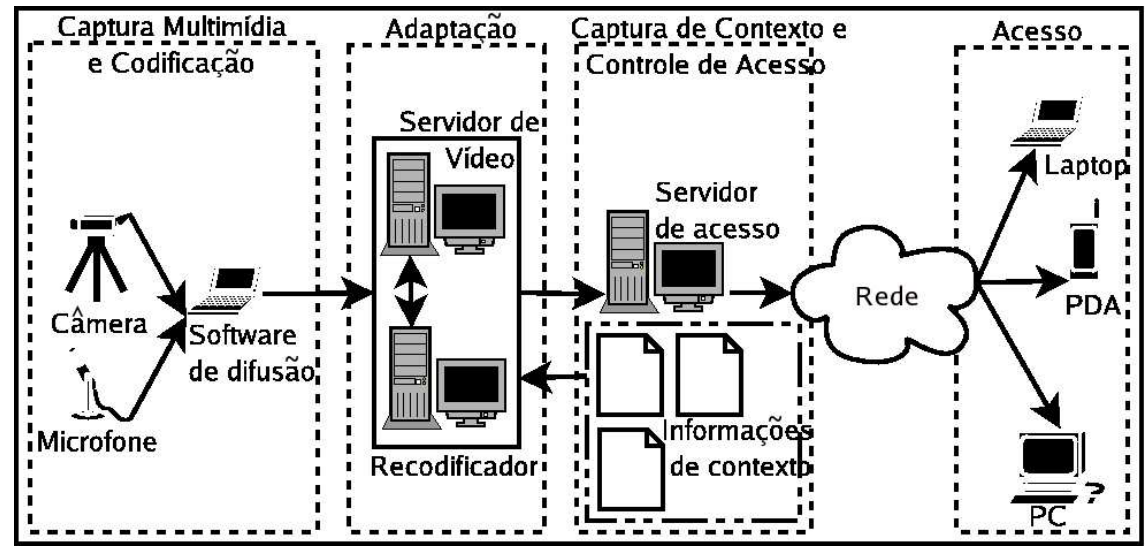

Figura 4.1: Arquitetura do sistema de adaptação.

A fase de captura multimídia e codificação é responsável pela captura de vídeo e áudio do ambiente, codificação e transmissão dos dados para o servidor de vídeo. A captura é realizada por uma câmera de vídeo e um microfone, os quais estão acoplados a um computador contendo a aplicação VideoLan Client $(\mathrm{VLC})^{1}$, que atua como software de difusão (ou difusor). Optou-se por esse programa devido ao fato de ser em códigoaberto, e à sua possibilidade de utilizar a biblioteca $f f m p e g^{2}$, responsável pela codificação de vídeo no formato MPEG-4. A escolha desse formato de codificação foi baseada em sua característica de realizar altos níveis de compressão com boa qualidade de imagem. Além disso, o padrão MPEG-4 permite a adição de novas funcionalidades ao vídeo (interação com o conteúdo, em especial), as quais poderão ser inseridas futuramente no sistema.

\footnotetext{
${ }^{1}$ http://www.videolan.org/vlc/

${ }^{2}$ http://www.ffmpeg.org/
} 
O servidor utilizado é o Darwin Streaming Server (DSS) ${ }^{3}$, que além de ser em códigoaberto, oferece funcionalidades de espelhamento (do Inglês, relaying), e fornecimento de conteúdo MPEG-4.

A transmissão dos dados entre difusor e servidor é realizada por meio do protocolo RTP (Protocolo em Tempo Real - do Ingês, Real Time Protocol) (SCHULZRINNE et al., 1996), o qual contém diferentes funções para aplicações em tempo real, tais como marcação de tempo, numeração de seqüência, identificação de fonte, etc. (WU et al., 2001).

À medida que os dados provenientes do software de difusão são recebidos pelo servidor de vídeo, é possível acessá-los por meio de um arquivo SDP (Protocolo de Descrição de Sessão - do Inglês, Session Description Protocol) (HANDLEY; JACOBSON, 1998), que descreve algumas características básicas do vídeo, como por exemplo, taxa de bits, resolução espacial, endereço IP (Protocolo de Internet - do Inglês, Internet Protocol), porta de acesso, entre outras. Esse arquivo normalmente é gerado pelo software de difusão, e deve estar disponível para acesso no servidor de vídeo. Assim, utiliza-se um compartilhamento de arquivos de modo a permitir que o difusor salve o arquivo SDP diretamente no servidor.

A adaptação é realizada pelo recodificador, que após ter sido inicializado com os parâmetros de recodificação, faz uma requisição RTSP (Protocolo de Streaming em Tempo Real - do Inglês, Real Time Streaming Protocol) (SCHULZRINnE; RAO; LANPHIER, 1998) do conteúdo original ao servidor de vídeo, acessando o arquivo SDP. Na arquitetura proposta, utiliza-se também a aplicação VLC como recodificador, devido principalmente à sua possibilidade de realizar recodificação ao vivo, além de conter outras funcionalidades, como por exemplo, poder ser controlado remotamente por meio de diferentes interfaces de acesso.

Após a requisição RTSP, o vídeo é transmitido ao recodificador, que adapta os dados, transmitindo-os de volta ao servidor, onde outro arquivo SDP será utilizado para acessar o conteúdo modificado. Quando requisitado, o recodificador pode também armazenar os dados (com ou sem adaptação) em um banco de dados, que estará disponível para futuros acessos.

A captura de contexto e controle de acesso são realizados por um servidor web de acesso, que processa as informações de contexto capturadas no momento em que o usuário faz a requisição de um determinado conteúdo, e gerencia as tarefas realizadas pelo recodificador por meio de uma conexão TCP (Protocolo de Controle de Transmissão - do Inglês, Transmission Control Protocol) entre servidor de acesso e recodificador.

$\mathrm{O}$ acesso consiste na requisição de um determinado conteúdo pelos usuários. As requisições podem ser do tipo RTSP ou HTTP (Protocolo de Transferência de Hipertexto - do Inglês, Hypertext Transfer Protocol) (FIELDING et al., 1999), dependendo da preferência do usuário ou restrição da aplicação. Independentemente do tipo de requisição (RTSP ou

\footnotetext{
${ }^{3}$ http://developer.apple.com/opensource/server/streaming/
} 
HTTP), o servidor de acesso verifica se o dispositivo utilizado necessita de adaptação de conteúdo, ou se o vídeo original pode ser acessado diretamente. No caso de requisições RTSP, o vídeo original ou adaptado é transmitido do servidor de vídeo para o usuário, e no caso de requisições HTTP, o vídeo original ou adaptado é transmitido do recodificador para o usuário ${ }^{4}$ Essa distinção existe, a princípio, porque o servidor de vídeo utilizado (Darwin Streaming Server) aceita apenas conexões RTSP (LORENZEN, 2001).

\subsection{Captura de Informações de Contexto}

Uma vez que o sistema de adaptação de vídeo utiliza informações de contexto para adaptar o conteúdo, e que essas informações descrevem as características do ambiente computacional, é necessário fazer uso de mecanismos para extrair esses dados, seja de maneira automática ou semi-automática.

A captura de informações de contexto é realizada no momento em que o usuário faz a requisição de um vídeo ao servidor de acesso. Neste trabalho, duas informações de contexto são consideradas:

- Resolução do dispositivo: relacionada diretamente à resolução espacial do vídeo. Devido ao fato de a cada dia surgir mais conteúdo multimídia em alta resolução disponível para o acesso, ao mesmo tempo em que dispositivos portáteis proliferam, é importante estar ciente de que alguns usuários podem não ser capazes de acessar vídeo em alta resolução espacial por meio de dispositivos específicos.

- Largura de banda: relacionada diretamente à taxa de bits do vídeo. Tendo em vista que a largura de banda varia conforme o canal de comunicação utilizado, a quantidade de dados que trafegam simultaneamente, os roteadores envolvidos, etc., é importante considerar qual taxa de bits o vídeo deverá ter para que não ocorram problemas de transmissão.

Assim, por meio da resolução do dispositivo e da largura de banda é possível obter várias configurações de vídeo de modo a permitir que diversos dispositivos, utilizando canais de comunicação diferentes, sejam capazes de acessar o conteúdo. Nas próximas Subseções são apresentados os mecanismos desenvolvidos para extração das informações de contexto.

\subsubsection{Resolução do Dispositivo}

A captura da informação de contexto resolução do dispositivo é realizada de maneira automática no momento em que o usuário requisita um determinado conteúdo.

\footnotetext{
${ }^{4} \mathrm{O}$ acesso do vídeo original faz com que os dados passem pelo recodificador apenas para permitir o acesso por HTTP, não havendo a recodificação propriamente dita.
} 
Essa requisição é feita utilizando-se páginas JSP (JavaServer Pages) contidas no servidor web de acesso, que por meio de códigos em JavaScript, recebe essa informação do navegador do usuário.

Uma importante distinção a ser feita é entre o tamanho de tela e a resolução do dispositivo. Enquanto o tamanho de tela corresponde às dimensões do dispositivo, como por exemplo, um monitor de 17 polegadas ou um pocket pc equipado com uma tela de 3.5 polegadas, a resolução do dispositivo indica quantos pixels existem em uma região, como por exemplo, uma resolução de 320x240 contém 76800 pixels, e uma resolução de 640x480 contém 307200 pixels. Assim, um dispositivo equipado com um monitor de 17 polegadas a uma resolução de 800x600, por exemplo, terá problemas em visualizar um vídeo configurado a 1280x960 de resolução espacial.

A Figura 4.2 ilustra o processo de captura da informação de contexto resolução do dispositivo. Utiliza-se o objeto screen da linguagem JavaScript, o qual contém as propriedades width e height, que informam, respectivamente, os componentes largura e altura da resolução do dispositivo. Desse modo, o navegador do usuário, ao acessar a página contendo o código apresentado na Figura 4.2, preenche os campos screen_width e screen_height do formulário, o qual será submetido ao servidor.

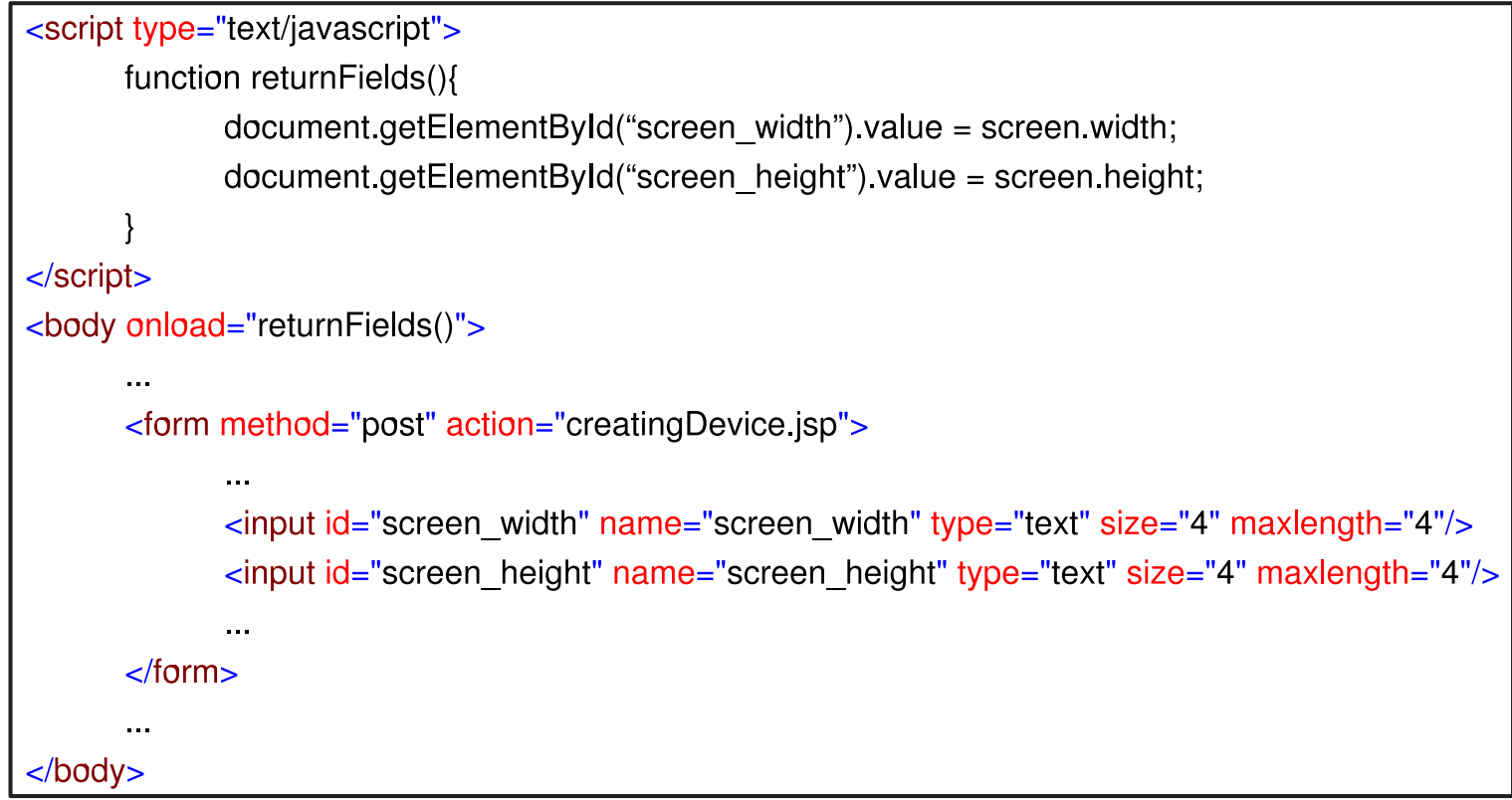

Figura 4.2: Captura da informação de contexto resolução do dispositivo.

Devido ao fato de alguns dispositivos não suportarem JavaScript, ou simplesmente pelo navegador do usuário estar desabilitado a processar códigos nessa linguagem, utilizase também algumas informações do cabeçalho HTTP (FIELDING et al., 1999), que são fornecidas no momento da requisição pelo usuário. O campo User-Agent pode informar o sistema operacional utilizado pelo dispositivo, possibilitando distingüir, por exemplo, a resolução de um pocket $p c$ da resolução de um desktop. 


\subsubsection{Largura de Banda}

A informação de contexto largura de banda também é obtida no momento em que o usuário requisita o conteúdo; no entanto, é calculada de maneira semi-automática, por meio da intervenção do usuário. Utiliza-se uma implementação, desenvolvida por Ferreira \& Mello (2004), do modelo $\log P$ (CULLER et al., 1993) e sua extensão com overheads diferenciados (CULLER et al., 1996). Essa implementação, que foi inicialmente proposta para avaliar interfaces de comunicação, permite obter a largura de banda por meio da troca de mensagens entre servidor e cliente. Desse modo, o usuário necessita ter instalado a aplicação cliente, que deverá se conectar ao servidor utilizando uma porta específica. O servidor, por sua vez, habilita as portas a serem acessadas, e gerencia a troca de mensagens obtendo-se alguns parâmetros, os quais são definidos pelo modelo LogP (FERREIRA; MELLO, 2004):

- L: Latência de transmissão de uma mensagem de um ponto a outro na rede. Depende da tecnologia e da topologia de rede utilizada.

- o: Overhead que consiste no tempo consumido pelo processador no empacotamento da mensagem. Seu valor depende da capacidade do processador, sistema operacional e do protocolo utilizado, sendo também limitado pela velocidade de comunicação entre a interface de rede e a memória do computador.

- g: Gap que consiste no intervalo de tempo entre duas transmissões ou recepções consecutivas de mensagens quando a rede encontra-se sobrecarregada.

- P: Número de elementos de processamento do sistema.

A largura de banda disponível é obtida dividindo-se o tamanho da mensagem (m) pelo gap (g). O tamanho da mensagem m é calculado pela subtração do MTU (Unidade de Transmissão Máxima - do Inglês, Maximum Transmission Unit) da rede utilizada pelo tamanho dos cabeçalhos IP (20 bytes) e TCP (20 bytes). Assim, o tamanho da mensagem em uma rede ethernet é 1500 (MTU) - 40 (IP + TCP $)=1460$ bytes. Esse cálculo é realizado devido ao fato de um datagrama ser dividido em datagramas menores caso o tamanho total exceda o valor máximo de transmissão (MTU) (SCHULZRINNE et al., 1996).

A implementação de Ferreira \& Mello (2004) criou uma aplicação servidora, responsável por gerenciar as conexões e calcular os parâmetros do modelo $\log P$, e uma aplicação cliente, responsável por conectar-se ao servidor e enviar as mensagens. Ambas as aplicações foram implementadas para o sistema operacional Linux.

A fim de fornecer suporte ao cálculo da largura de banda para usuários utilizando diferentes dispositivos, foram desenvolvidas duas versões da aplicação cliente: uma para dispositivos pocket $p c$, equipado com o sistema operacional Windows CE; e outra para 
computador pessoal, equipado com o sistema operacional Windows XP. A Figura 4.3 (a) ilustra a tela de abertura da aplicação para pocket pc; (b) ilustra o processo de inserção do endereço IP e porta do servidor; e (c) ilustra o fim do processo de estimativa de largura de banda.

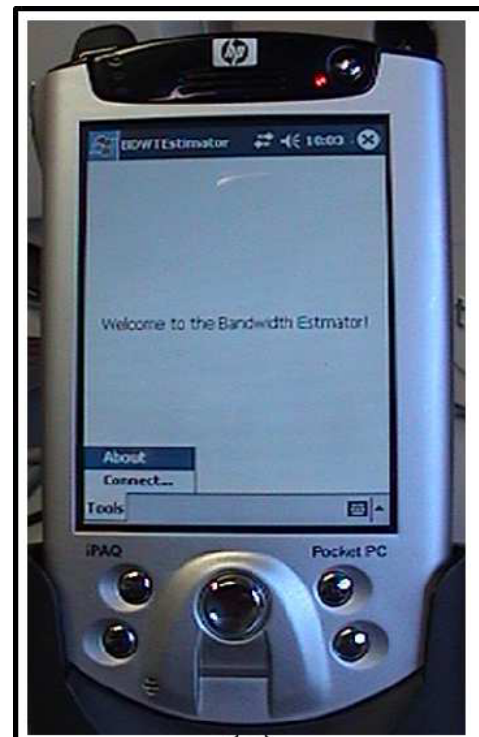

(a)

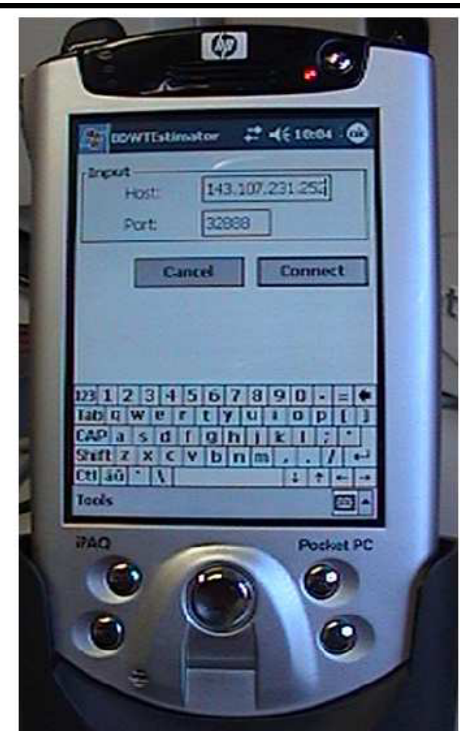

(b)

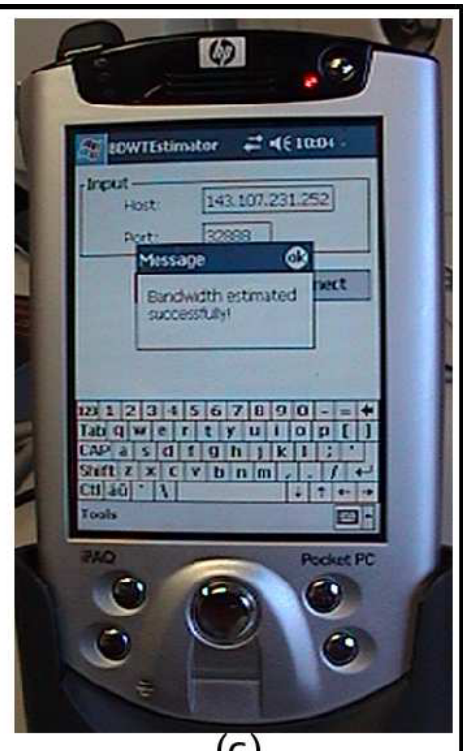

(c)

Figura 4.3: Estimativa da largura de banda utilizando a aplicação cliente no Windows CE.

Analogamente, a Figura 4.4 (a) ilustra a tela de abertura da aplicação para Windows XP e inserção do endereço IP e porta do servidor; e (b) ilustra o fim do processo de estimativa de largura de banda.

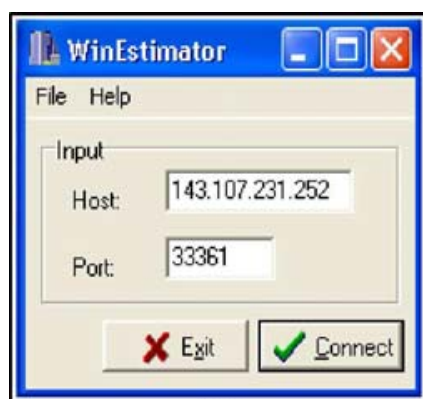

(a)

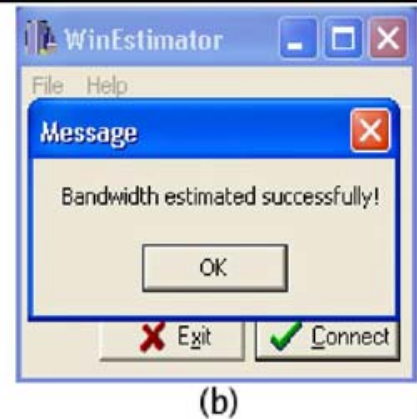

(b)

Figura 4.4: Estimativa da largura de banda utilizando a aplicação cliente no Windows XP.

\subsection{Representação de Dispositivos}

Tendo capturado as informações de contexto relevantes para se definir o estado atual da entidade contextual, no caso um dispositivo, é necessário utilizar um meio de se representar 
tais informações e o dispositivo em si. Essa representação, em última instância, é que será compartilhada pelas aplicações cientes de contexto, propiciando tomadas de decisões mais ajustadas às necessidades dos usuários.

Vários trabalhos referentes à representação e descrição de dispositivos estão disponíveis na literatura. Um dos mais conhecidos e utilizados é o CC/PP (Capacidades Compostas/Perfil de Preferências - do Inglês, Composite Capabilities/Preferences Profile) (W3C, 2000), que descreve capacidades de dispositivos e preferências de usuários. Diversos trabalhos exploram o CC/PP, como por exemplo, o sistema DELI (Biblioteca de Entrega de Contexto para CC/PP e UAProf - do Inglês, Delivery Context Library for $C C / P P$ and UAProf $)^{5}$, que define uma biblioteca em código-aberto que utiliza servlets JAVA para processar requisições HTTP. Essas informações podem incluir informações de contexto enviadas por um dispositivo, as quais são compatíveis com o CC/PP. Outro trabalho que utiliza o CC/PP foi desenvolvido por Lemlouma \& Layaida (2003), que combina a especificação UPS (Esquema de Perfil Universal - do Inglês, Universal Profile Schema) (baseada em CC/PP) com SMIL (Linguagem de Integração Multimídia Sincronizada - do Inglês, Synchronized Multimedia Integration Language), a fim de adaptar conteúdo para dispositivos móveis.

No entanto, a utilização de CC/PP não é adequada para representar contexto. Indulska et al. (2003) argumentam que embora o CC/PP possa ser utilizado na representação contextual, incluindo relacionamentos e dependências, suas limitações impedem que ele seja apropriado para esse tipo de tarefa. Uma limitação imposta pelo CC/PP refere-se a ele não representar composição de dispositivos, permitindo, no máximo, uma árvore de um nível apenas (elemento raiz e seus filhos). Outra limitação está relacionada à geração de inconsistência na definição de atributos em vocabulários e perfis diferentes.

Informações mais detalhadas sobre vantagens e desvantagens do CC/PP e de outros trabalhos, tais como o WURFL (Arquivo Universal de Recursos Sem Fio - do Inglês, Wireless Universal Resource File) (PASSANI; TRASATTI, 2002) e aqueles que exploram ontologias (WANG et al., 2004; CHEN; FININ, 2003; CHEN; FININ; JOSHI, 2003), podem ser encontradas em (EISINGER; MANZATO; GOULARTE, 2005).

\subsubsection{Modelo para Descrição de Dispositivos}

Na Seção 3.5 foi apresentado um modelo desenvolvido por Goularte (2003) para representação de contexto. Foram definidos meios de se criar entidades contextuais classificando-as de acordo com o modelo contextual, e um conjunto extensível de elementos formando a biblioteca de contexto. Essa biblioteca inclui uma série de tipos que referenciam características relacionadas ao domínio Usuário. Modelos para outros domínios, tais como Aplicação, Rede, Dispositivos e Serviços (ver Figura 3.1), não foram

\footnotetext{
${ }^{5}$ http://delicon.sourceforge.net/
} 
definidos, tendo sido deixados para trabalhos futuros.

Desse modo, com base nos problemas e desvantagens encontrados nos modelos propostos pela literatura para representação de dispositivos, e na oportunidade de oferecer uma contribuição para o trabalho realizado por Goularte, uma extensão de seu modelo contextual foi desenvolvida com a finalidade de se criar uma representação organizada e hierárquica de dispositivos.

O modelo de descrição de dispositivos é ilustrado pela Figura 4.5, que mostra uma representação criada em XML Schema (W3C, 2004). O elemento <Infrastructure>, correspondente ao componente Infra-Estrutura da Figura 3.1, é definido como sendo do tipo InfrastructureType, o qual é composto pelos elementos $<$ Network $>$, $<$ Services $>$ e $<$ Devices $>$, como mostra a Figura 4.5. Os retângulos pontilhados indicam que os elementos não são obrigatórios. O elemento <Devices $>$ representa o modelo de dispositivos proposto, sendo formado por um ou mais elementos $<$ Device $>$, que é composto pelo tipo abstrato PrimaryContext Type (representado na Figura 4.5 pelos elementos $<$ Identity $>$, $<$ Location $>$, $<$ Time $>$ e $<$ Activity $>$ ), e/ou por outros elementos $<$ Device $>$.

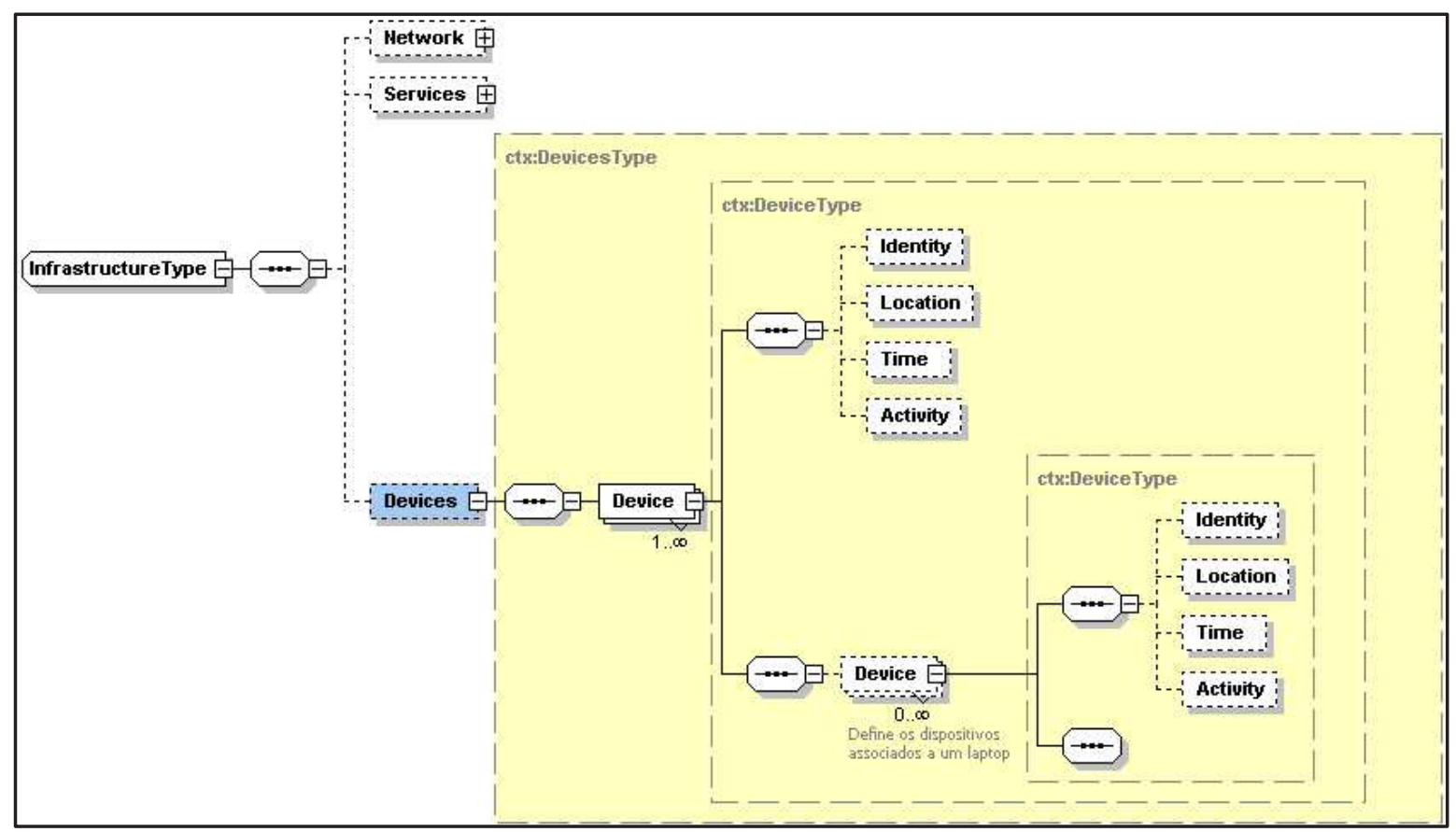

Figura 4.5: Representação de dispositivos.

Como visto anteriormente, uma das limitações do CC/PP é não permitir a descrição de dispositivos de maneira composta. O modelo proposto elimina essa limitação, fazendo com que a representação seja melhor estruturada, o que facilita a geração do documento descritor do dispositivo. Uma vez que dispositivos são formados por outros dispositivos, os quais contêm características específicas, é possível descrever um dispositivo por meio do tipo abstrato PrimaryContextType, ou por meio da descrição de seus componentes, os quais são vistos como dispositivos também. Como exemplo, um laptop pode ser 
representado por suas características básicas, tais como modelo, marca, etc., ou por outros dispositivos, tais como disco rígido, tela, memória, etc. O desenvolvedor é quem decide entre uma representação simplificada ou por uma representação específica de cada dispositivo.

\subsubsection{Biblioteca de Dispositivos}

Uma vez definido o modo em que um dispositivo é representado no modelo conceitual, o próximo passo é definir a biblioteca básica de dispositivos. Assim como foi feito por Goularte (2003) para o contexto Usuário, dispositivos são definidos com base nos quatro tipos abstratos: identidade, que descreve características básicas do dispositivo, tais como modelo, marca, número de série, etc.; localização, que pode ser real ou virtual, tais como endereço IP, laboratório, sala, etc.; tempo, que descreve, por exemplo, o período em que um dispositivo é geralmente usado; e atividade, referindo-se, por exemplo, às atividades ou tarefas realizadas normalmente por um dispositivo.

As características de cada dispositivo foram especificadas por meio de uma pesquisa dos principais vendedores de dispositivos da atualidade (IBM, Intel, Samsung e HP), extraindo informações tais como modelo, linha de produto, marca e número serial. Essa pesquisa não definiu uma lista exaustiva, contendo, a princípio, apenas informações que são validadas pelos equipamentos sendo utilizados. No entanto, o modelo de dispositivos permite que novos tipos sejam inseridos conforme a necessidade da aplicação.

Com base nos descritores contextuais primários utilizados para descrever a identidade, a localização, o tempo e a atividade de um dispositivo, a informação mais relevante para o acesso multimídia está relacionada à identidade, pois é por meio dela que o sistema sabe que tipo de dispositivo está sendo usado no momento. A fim de armazenar informações de identidade de um dispositivo, utiliza-se o elemento $<$ DevicelD $>$; no entanto, é necessário descrever também as características de um dispositivo. Essas características, as quais são agrupadas por semelhança, são definidas da seguinte maneira: primeiramente, para cada característica básica são criados tipos básicos, tais como StorageType (armazenamento), SpeedType (velocidade), ConnectorType (conector), entre outros, e a partir desses tipos básicos, são criados os tipos SpecTypes, os quais indicam as características específicas do dispositivo, como por exemplo, disco rígido, memória, etc. Desse modo, é possível reutilizar os tipos criados, combinando-se dois ou mais tipos básicos. A Figura 4.6 ilustra a definição do tipo DeviceldentityType, que é composto pelo elemento <DevicelD $>$ mais alguns SpecTypes criados. A Tabela 4.1 fornece uma lista completa dos SpecTypes com seus respectivos componentes associados aos tipos básicos.

\subsubsection{Extensão da Biblioteca}

A extensão da biblioteca é realizada usando XML Schema (W3C, 2004) a fim de facili- 


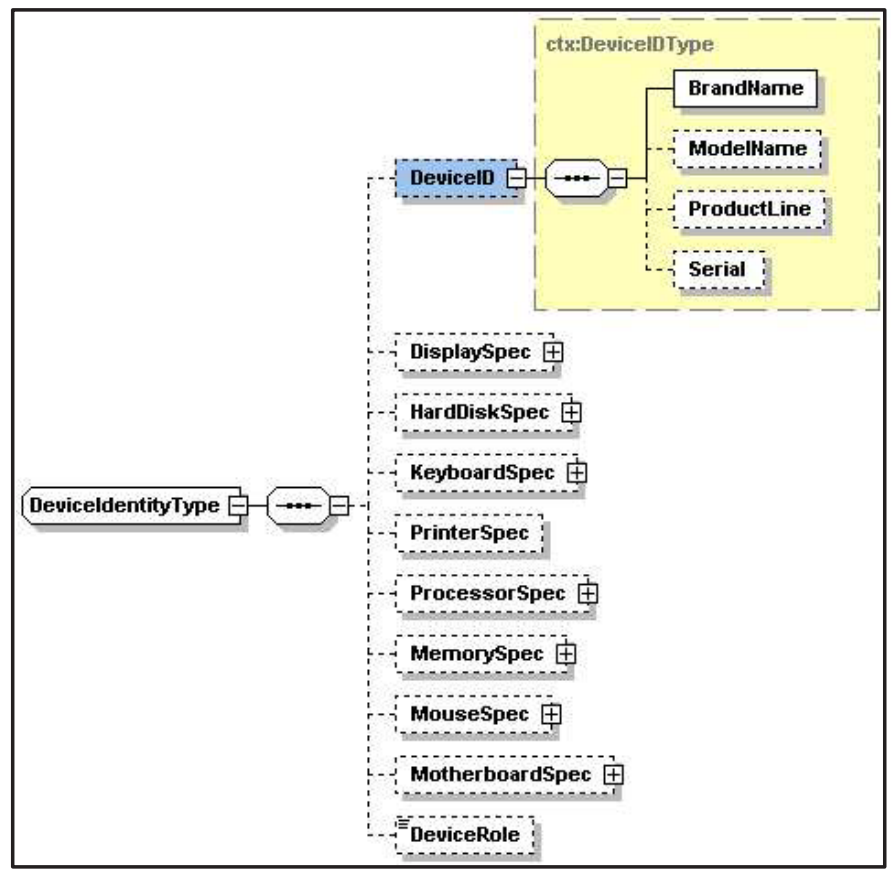

Figura 4.6: Definição do tipo DeviceldentityType.

tar a validação dos documentos que descrevem dispositivos novos ou existentes. Um novo dispositivo é definido, primeiramente, como sendo uma extensão do tipo abstrato DeviceType, conforme ilustra a Figura 4.7, que cria um novo tipo para o dispositivo memória.

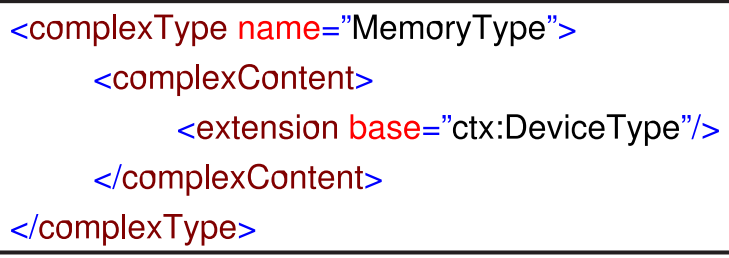

Figura 4.7: Extensão da biblioteca de dispositivos por meio da criação do tipo MemoryType.

Em seguida, é necessário especificar as características do dispositivo. Isso é feito definindo-se um SpecType, que contém uma ou mais definições de um tipo básico. A Figura 4.8 ilustra a definição do tipo MemorySpecType, o qual contém a definição do tipo básico MemType.

Por meio da Figura 4.8 é possível visualizar que o tipo básico MemType é restrito a um conjunto fixo de valores. Desse modo, usuários podem inserir novos valores somente pela especificação do novo item no esquema XML (Linguagem de Marcação Extensiva - do Inglês, Extensible Markup Language). Essa restrição tem a finalidade de prevenir que usuários especifiquem diferentes valores a uma mesma funcionalidade, o que gera inconsistência, conforme explanado em uma das limitações do CC/PP.

Na definição do tipo MemorySpecType, também foram utilizados tipos básicos existentes, como é o caso do tipo SpeedType, usado para definir o elemento $<$ MemSpeed $>$, o 
Tabela 4.1: Lista dos SpecTypes e seus componentes.

\begin{tabular}{|c|c|}
\hline SpecTypes & Componentes \& Tipos Básicos \\
\hline DisplaySpec & $\begin{array}{l}\text { ScreenModel (string), ColorResolution (string), } \\
\text { ScreenResolution (ResolutionType), } \\
\text { ScreenSize (ResolutionType),MaxResolution (ResolutionType), } \\
\text { Connector (ConnectorType) }\end{array}$ \\
\hline HardDiskSpec & $\begin{array}{l}\text { Storage (StorageType), Speed (SpeedType), } \\
\text { SeekTime (SpeedType), Interface (InterfaceType), } \\
\text { Type (string), SMARTSupport (boolean) }\end{array}$ \\
\hline KeyboardSpec & $\begin{array}{l}\text { KeyFormat (string), Wireless (boolean), } \\
\text { Connector (ConnectorType) }\end{array}$ \\
\hline PrinterSpec & $\begin{array}{l}\text { MonoSpeed (SpeedType), ColorSpeed (SpeedType), } \\
\text { MaxResolution (ResolutionType), Type (string), } \\
\text { OSCompatibility (string) }\end{array}$ \\
\hline ProcessorSpec & $\begin{array}{l}\text { OSCompatibility (string), ProcessorSpeed (SpeedType), } \\
\text { BusSpeed (SpeedType), InternalCache (MemorySpecType) }\end{array}$ \\
\hline MemorySpec & $\begin{array}{l}\text { MemType (string), MemSpeed (SpeedType), } \\
\text { MemSize (StorageType) }\end{array}$ \\
\hline MouseSpec & $\begin{array}{l}\text { Connector (ConnectorType), Wireless (boolean), } \\
\text { Scroll (boolean), NumButton (string), } \\
\text { Type (string) }\end{array}$ \\
\hline MotherboardSpec & $\begin{array}{l}\text { Chipset (string), Cache (MemorySpecType), } \\
\text { ConnectorSupport (string), MaxMemSizeSupported (StorageType) } \\
\text { NumMemorySlots (string), UsedMemorySlots (string), } \\
\text { ProcessorSocketType (string), NumProcessors (string), } \\
\text { OverClockCapability (boolean), InternalSlot (SlotType) }\end{array}$ \\
\hline
\end{tabular}

qual especifica informações relacionadas à velocidade de acesso à memória. A definição do tipo básico SpeedType é ilustrada pela Figura 4.9.

Por fim, o novo SpecType deve ser referenciado no tipo DeviceldentityType, de modo que ele possa ser utilizado pelo usuário durante a identificação do novo dispositivo. Essa operação é ilustrada pela Figura 4.10, que relaciona o tipo MemorySpecType ao elemento $<$ MemorySpec $>$. Esse elemento é definido, juntamente com o elemento $<$ DevicelD $>$, dentro da definição do tipo DeviceldentityType, o qual é derivado por extensão do tipo primário IdentityType.

A Figura 4.11 ilustra um exemplo que descreve um novo dispositivo, nesse caso, uma memória. Nota-se que o elemento < ldentity $>$, definido como tipo abstrato no modelo de Goularte (2003), referencia a extensão do tipo primário IdentityType, por meio do atributo xsi:type, de modo que as novas modificações possam ser utilizadas.

O Apêndice A contém o modelo de representação de dispositivos implementado em XML Schema, o qual inclui todas as definições, inclusive a definição do tipo básico StorageType referenciado na Figura 4.8, que foi utilizado para definir o elemento $<$ MemSize $>$. 


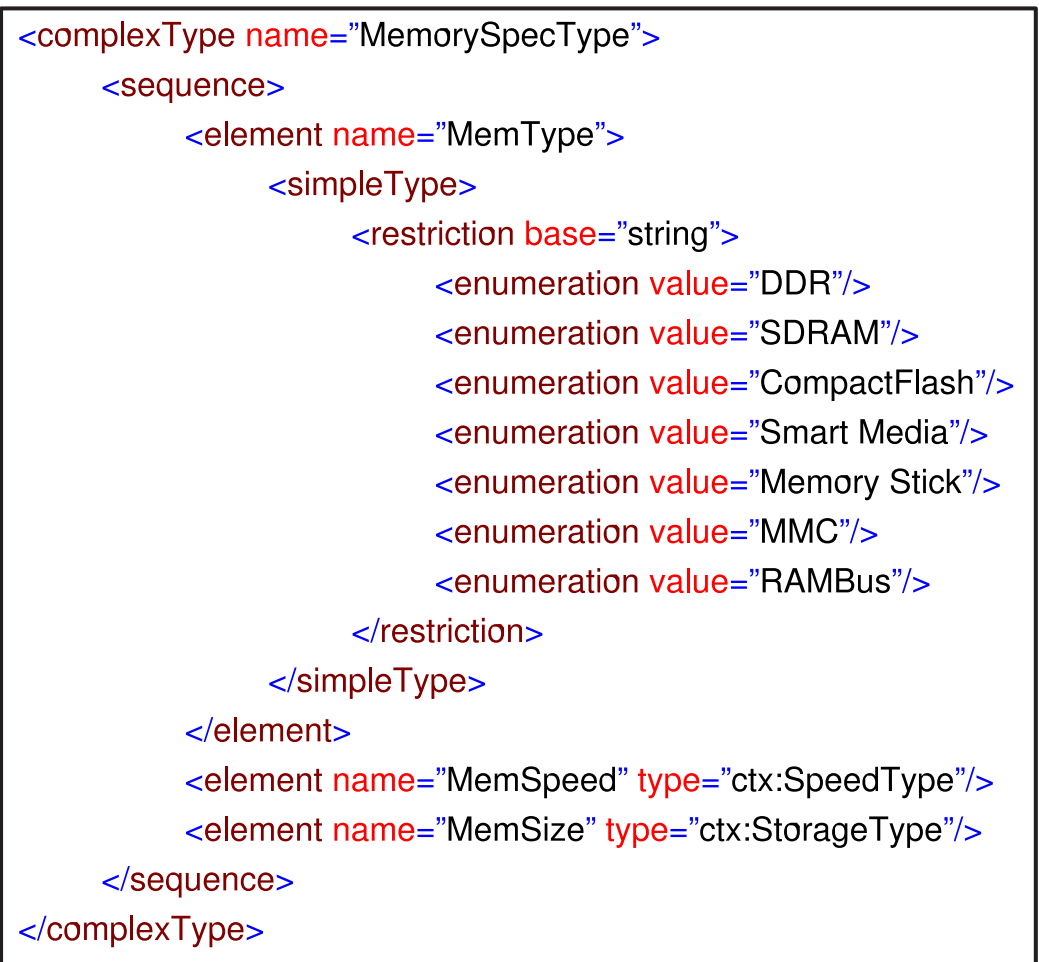

Figura 4.8: Definição de um novo tipo SpecType.

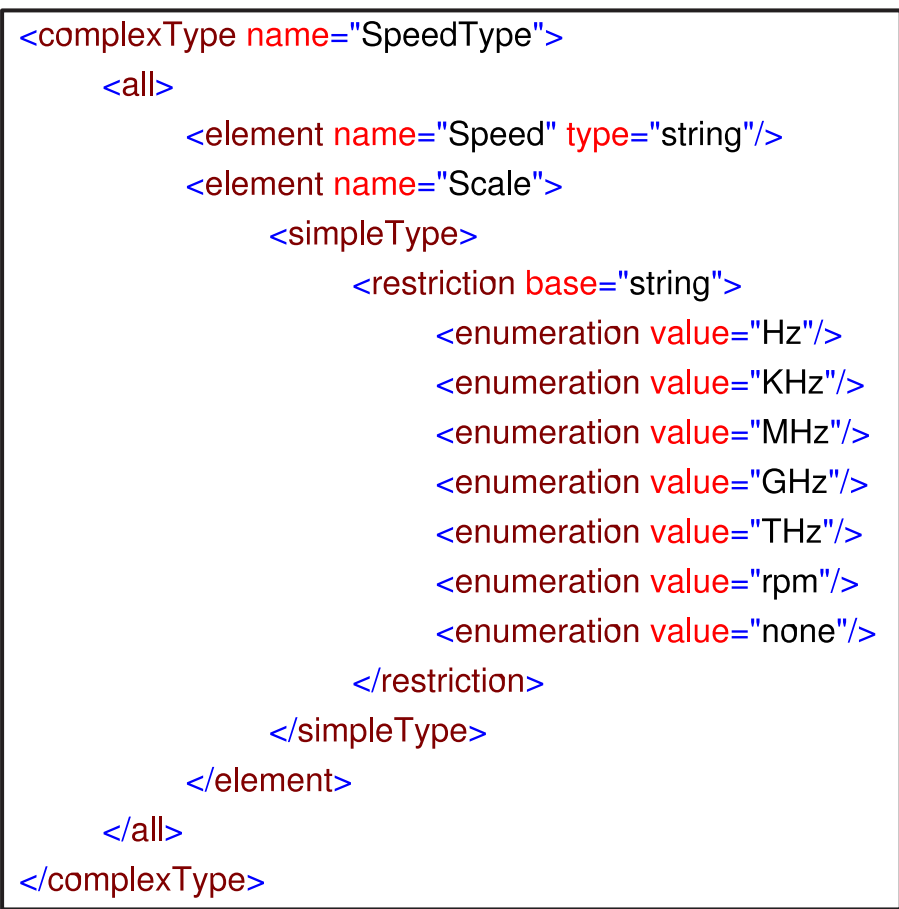

Figura 4.9: Definição do tipo SpeedType.

\subsection{Processamento de Informações de Contexto}

Uma vez que informações de contexto foram capturadas do ambiente computacional e armazenadas na forma de metadados utilizando o modelo de representação de dispo- 


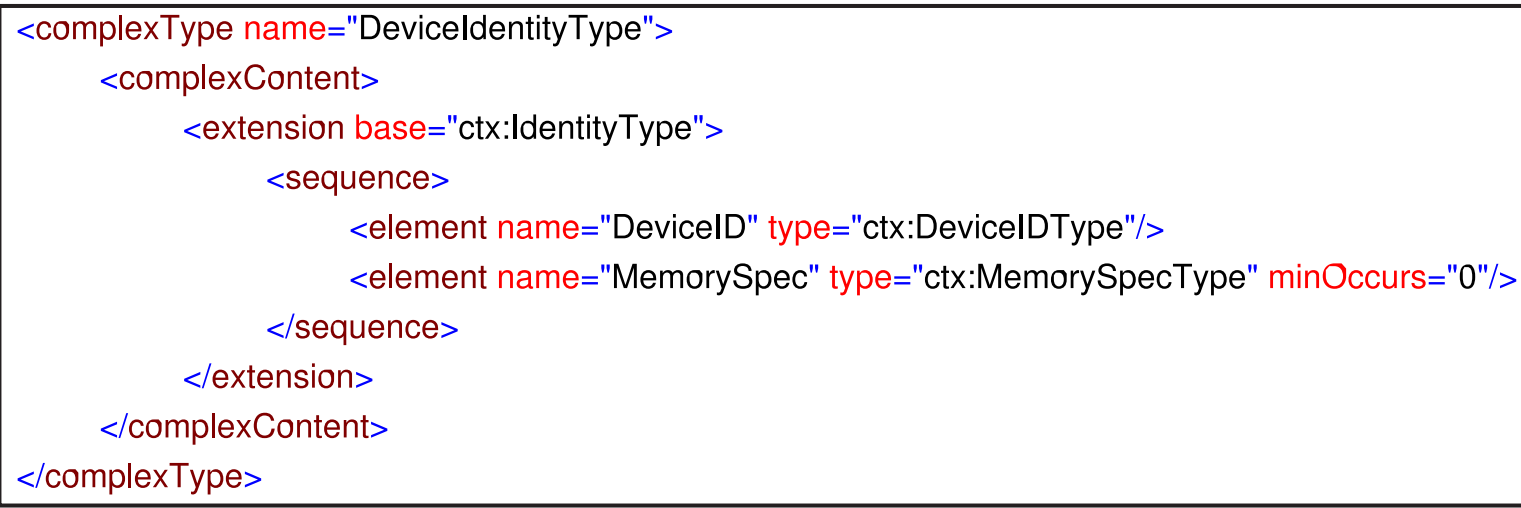

Figura 4.10: Exemplo de definição do tipo DeviceldentityType.

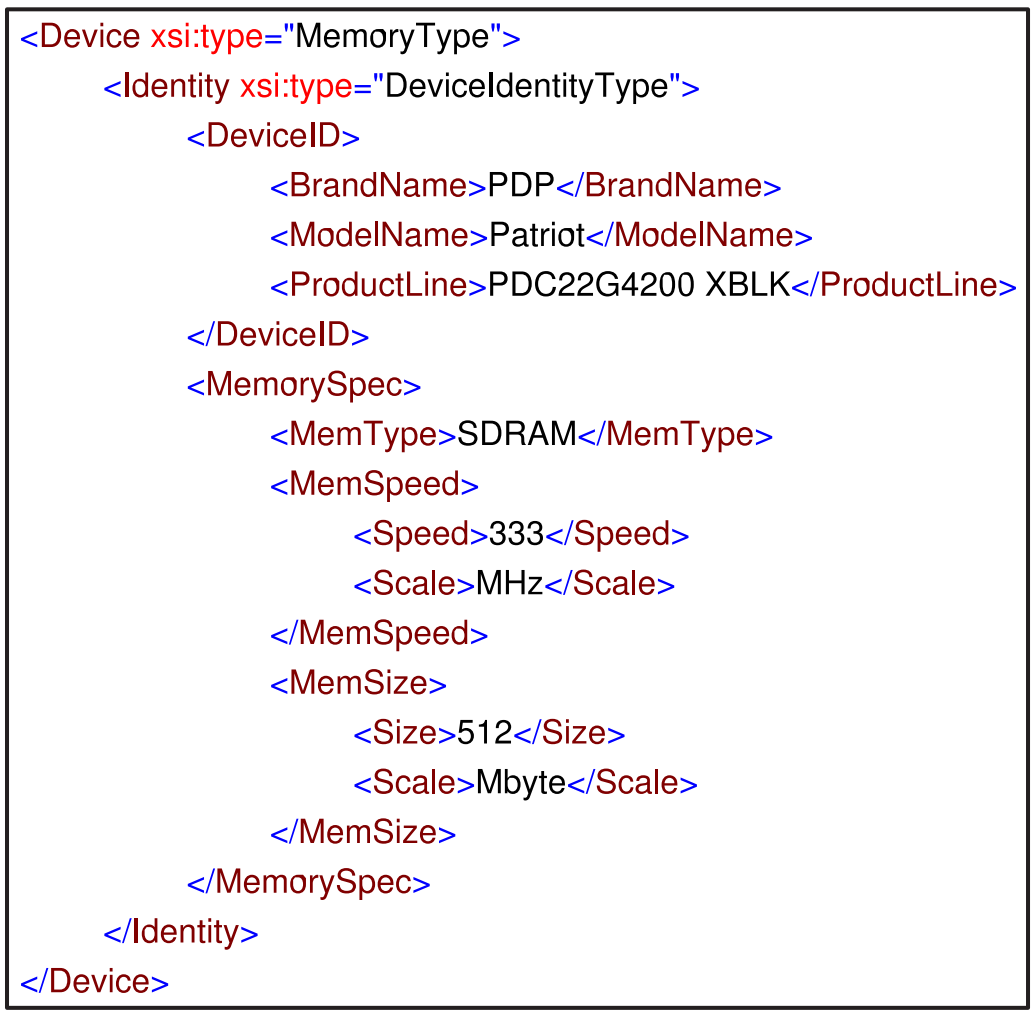

Figura 4.11: Exemplo de uso do tipo SpecType criado.

sitivos, é necessário processá-las para que os parâmetros do recodificador (taxa de bits, resolução espacial, resolução temporal, padrão de codificação, etc.) sejam recuperados. Esses parâmetros são submetidos ao recodificador, que irá adaptar o fluxo de vídeo original para que o mesmo seja acessado satisfatoriamente pelo usuário utilizando um dispositivo específico.

Conforme foi visto na Seção 4.3, duas informações de contexto são capturadas pelo sistema: resolução do dispositivo, que é capturada utilizando a linguagem JavaScript ou cabeçalhos HTTP, e largura de banda, capturada a partir do modelo LogP (CULLER et al., 1993; FERREIRA; MELLO, 2004). A resolução do dispositivo está diretamente relacionada à resolução do vídeo, ou seja, se um pocket pc, que geralmente é configurado a 
uma resolução de 240x320 fizer uma requisição de um vídeo configurado a uma resolução espacial de 640x480, o dispositivo não será capaz de acessar o conteúdo satisfatoriamente, podendo ocorrer alguns erros, tais como visualização de apenas uma parte do vídeo, latência na decodificação dos dados por decorrência da limitação do processador, etc. Desse modo, o processamento da informação de contexto resolução do dispositivo é realizado de modo direto, por meio de simples comparações entre as coordenadas $\mathrm{x}$ e y das resoluções do vídeo e do dispositivo. É importante ressaltar que a redução é feita proporcionalmente em ambas as coordenadas da resolução do vídeo, de modo que não ocorram distorções na imagem.

A informação de contexto largura de banda refere-se à quantidade de bits que podem ser transmitidos pela rede em um determinado segundo. Ela está relacionada à taxa de bits do fluxo de vídeo, uma vez que essa taxa indica quantos bits existem em um segundo de vídeo. Conseqüentemente, a taxa de bits do vídeo não pode ser maior do que largura de banda disponível, pois isso pode gerar problemas de transmissão do fluxo, tais como latência, perda de pacotes e congestionamento.

A taxa de bits é influenciada por diversas características do vídeo, tais como resolução espacial, resolução temporal, etc. Uma vez especificada a taxa de bits do recodificador, ele tentará mantê-la independentemente das resoluções espacial e temporal especificadas, mesmo que para isso seja necessário diminuir a qualidade da imagem. Isso pode ocorrer no caso em que uma baixa taxa de bits é especificada, com resoluções espacial e temporal muito grandes. Por outro lado, se a modificação das resoluções é realizada de modo a reduzir seus valores (um vídeo não é recodificado a uma resolução maior do que a do fluxo original), então a taxa de bits real será menor do que a taxa de bits especificada, a qual é calculada a partir da largura de banda.

É possível evitar que o usuário receba um vídeo com qualidade ruim no caso em que são especificadas baixas taxas de bits a resoluções muito grandes. Considerando uma resolução temporal constante, na ordem de 30 quadros/s, pode-se especificar valores mínimos aceitáveis para a taxa de bits de acordo com a resolução espacial do vídeo. Desse modo, depois de a taxa de bits e a resolução terem sido calculadas com base na largura de banda e na resolução do dispositivo, respectivamente, a resolução espacial pode ser reajustada, fazendo com que a relação taxa de bits/resolução espacial satisfaça os valores especificados na Tabela 4.2, que lista a escala de valores para as taxas de bits permitidas em cada resolução. Esses valores foram especificados a partir de uma análise subjetiva da qualidade da imagem em diferentes configurações de taxa de bits e resolução espacial. Vale ressaltar que esse reajuste é válido somente nos casos em que a taxa de bits calculada é menor do que a escala de valores da resolução espacial da Tabela 4.2; caso contrário, a resolução poderia ser reajustada com um valor maior, e o vídeo não ser acessado devido à limitação da resolução do dispositivo.

A Figura 4.12 ilustra o algoritmo de processamento das informações de contexto re- 
Tabela 4.2: Taxas de bits permitidas para cada resolução espacial.

\begin{tabular}{|l|l|}
\hline Taxas de bits & Resolução Espacial \\
\hline Até $120 \mathrm{kbits} / \mathrm{s}$ & $160 \times 120$ \\
\hline de $120 \mathrm{kbits} / \mathrm{s}$ até $600 \mathrm{kbits} / \mathrm{s}$ & $320 \times 240$ \\
\hline de $600 \mathrm{kbits} / \mathrm{s}$ até $12 \mathrm{Mbits} / \mathrm{s}$ & $640 \times 480$ \\
\hline A patir de $12 \mathrm{Mbits} / \mathrm{s}$ & $1280 \times 960$ \\
\hline
\end{tabular}

solução do dispositivo (screenResolution) e largura de banda (bandwidth), de modo a extrair os parâmetros resolucaoEspacial e taxa_de_bits.

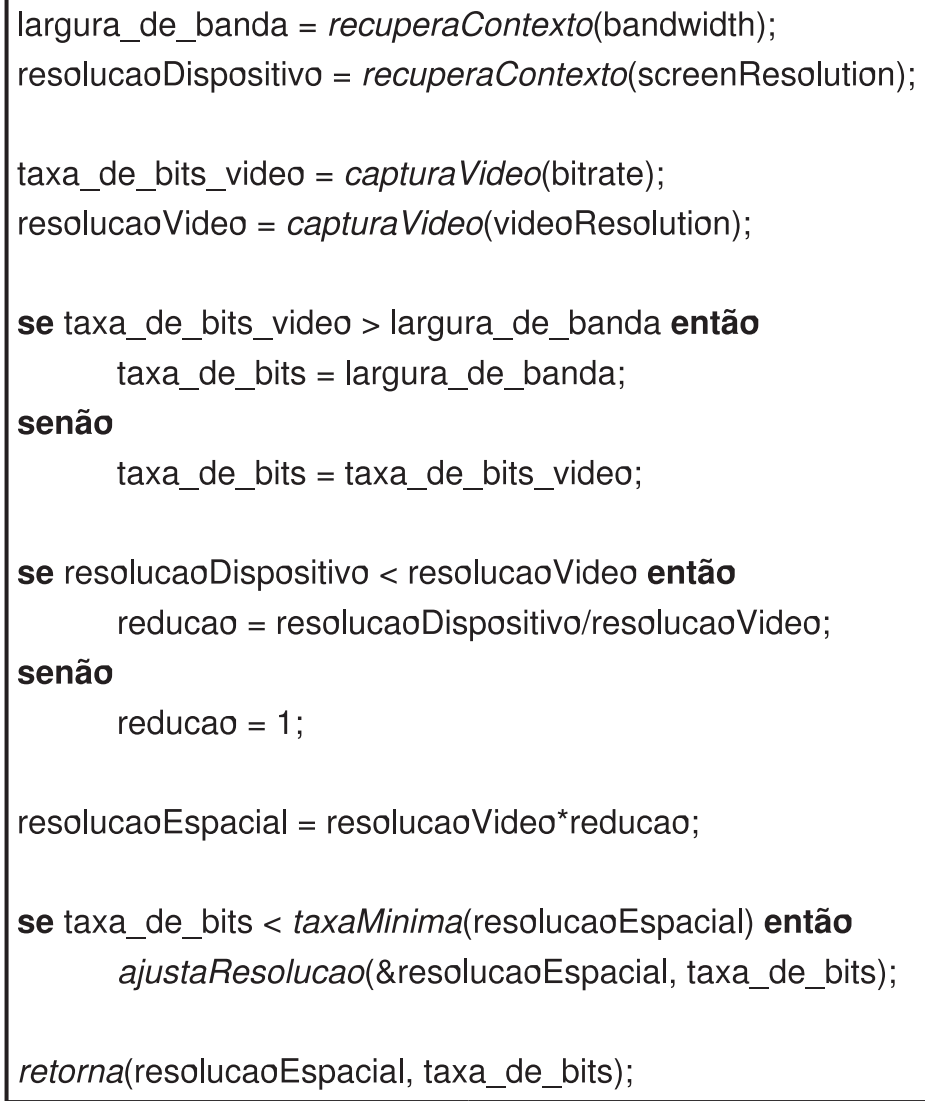

Figura 4.12: Algoritmo de processamento de informações de contexto.

\subsection{Recodificação de Vídeo}

Após as informações de contexto terem sido processadas, identificando-se os parâmetros de recodificação, eles são submetidos ao recodificador através de uma conexão TCP entre o servidor de acesso e o recodificador a fim de que este possa iniciar a tarefa de adaptação de conteúdo. Entre os parâmetros taxa de bits e resolução espacial, também são submetidos a taxa de quadros, o padrão de codificação, a taxa de bits do áudio, o nome e local do arquivo SDP, o endereço do servidor de vídeo, etc. 
Conforme foi visto na Seção 4.2, a recodificação é realizada pela aplicação VLC, que utilizando a biblioteca de codificação ffmpeg, decodifica o vídeo original e recodifica-o no formato e configurações desejados. Apesar de essa técnica ser a mais simples e a que envolve maior poder de processamento dos dados (ver Seção 2.4), ela tem a vantagem de não degradar a qualidade da imagem devido à reutilização de informações referentes ao vídeo codificado, tais como vetores de movimento e coeficientes DCT.

Do mesmo modo que o acesso é feito por clientes com capacidades suficientes para receber o conteúdo original, o VLC emite uma requisição RTSP ao servidor de vídeo, acessando o arquivo SDP, e à medida que os dados são recebidos pelo recodificador, eles são recodificados de acordo com os parâmetros especificados. O vídeo adaptado pode ser reenviado ao servidor de vídeo, no caso de o usuário realizar o acesso por RTSP; ou pode-se deixar o conteúdo disponível no próprio VLC, para que o usuário realize o acesso por HTTP.

\subsection{Interface de Acesso}

Com o objetivo de facilitar o processo de criação e visualização do conteúdo, foi criada uma interface de acesso que permite configurar e iniciar uma nova sessão de captura de vídeo, e acessar o conteúdo original ou adaptado de acordo com a rede e dispositivo utilizados por meio de links fornecidos pela interface. Tendo sido implementada em linguagem JSP, a interface é disponibilizada a partir do servidor web de acesso; ambos atuam em conjunto a fim de oferecer interação com o usuário, ao mesmo tempo que as informações de contexto são capturadas e as tarefas do recodificador são gerenciadas.

Optou-se por desenvolver a interface com enfoque na captura e acesso em salas de aula, uma vez que outras aplicações desenvolvidas no ICMC-USP, como por exemplo, o iClass (CATTELAN et al., 2003), estão em constante utilização pelos professores, e não permitem o acesso de vídeo e áudio ao vivo, além de não fornecerem suporte à adaptação de conteúdo. Assim, o professor inicia a sessão de captura de vídeo e áudio, e os alunos assistem à aula ao vivo e remotamente, recebendo o fluxo de vídeo original ou recodificado. Funcionalidades de interação do sistema de adaptação de vídeo com as aplicações existentes, como por exemplo, sincronização de vídeo e áudio ao vivo com as anotações produzidas pelo professor por meio da lousa eletrônica, poderão ser implementadas em trabalhos futuros.

Nas próximas Subseções é apresentada a interface de acesso, que se divide em duas partes: criação de uma aula, realizada pelo professor, e acesso pela interface, realizado pelos alunos. 


\subsubsection{Criação de uma Aula}

A criação de uma aula é realizada pelo professor mediante o seu login/senha informados ao sistema. A configuração permite especificar as seguintes opções: o título da aula, as resoluções espacial e temporal do vídeo, as taxas de bits do vídeo e do áudio, a opção de armazenamento dos dados, o endereço e as portas do servidor de vídeo, o valor de TTL (Tempo de Sobrevivência - do Inglês, Time To Live), o local de armazenamento do arquivo SDP e o local de instalação do software de difusão. Essas informações podem ser visualizadas pela Figura 4.13.

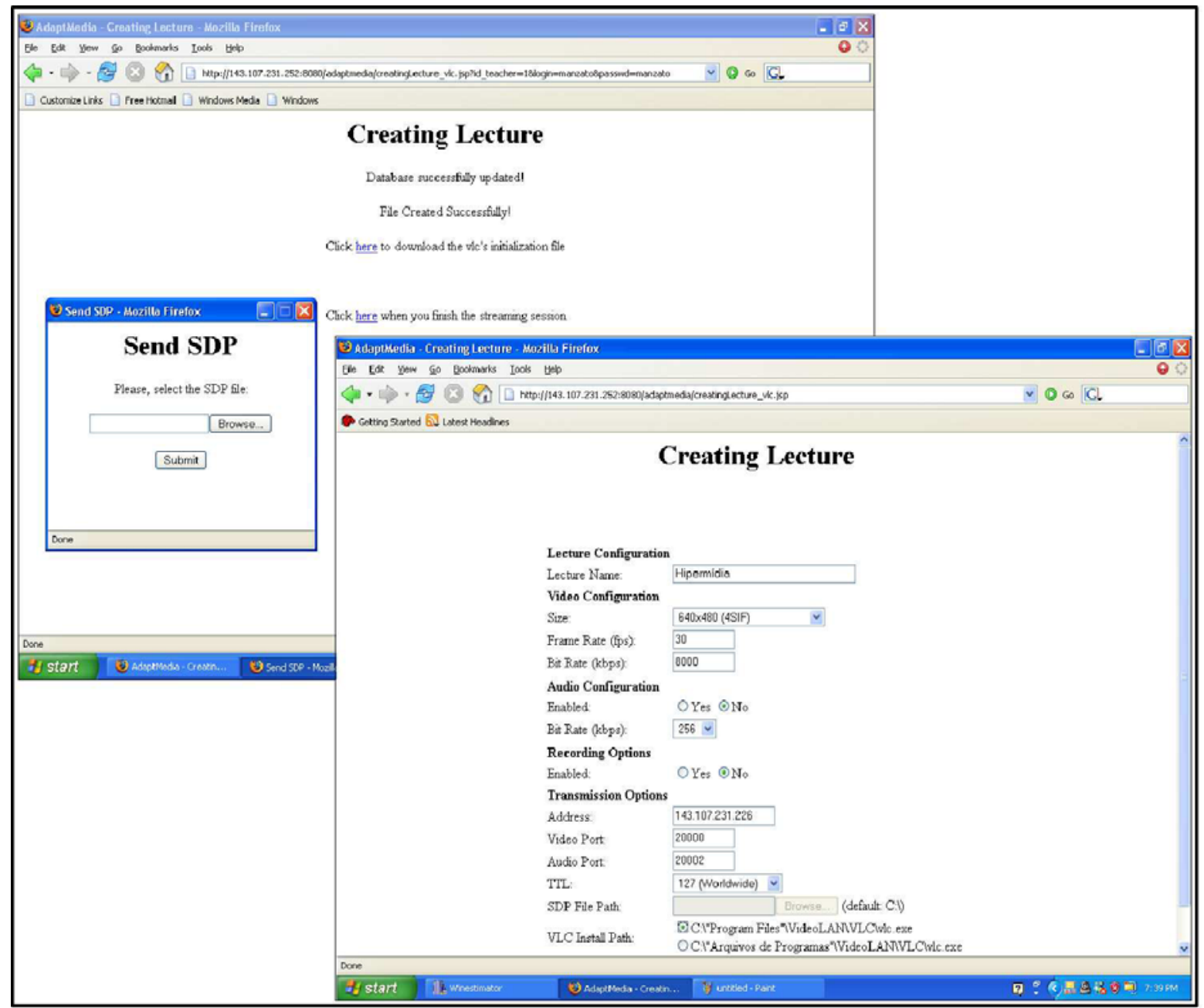

Figura 4.13: Criação de uma aula pelo professor.

Após o professor ter configurado a aula, ele recebe um arquivo de inicialização do software de difusão contendo todas as informações necessárias para que a captura, codificação e transmissão ao servidor sejam realizadas conforme a configuração especificada. O professor, em seguida, inicia a sessão de captura, gerando, conseqüentemente, o arquivo SDP, que poderá ser transmitido ao servidor de vídeo por meio da interface (ver Figura 4.13). 


\subsubsection{Acesso pela Interface}

Os alunos podem visualizar o conteúdo utilizando a interface de acesso. Primeiramente, são listadas todas as sessões de captura em andamento, e o aluno escolhe qual aula ele deseja acessar (ver Figura 4.14). Em seguida, o sistema detecta algumas informações do dispositivo utilizado - entre elas, a resolução do dispositivo -, conforme ilustra a Figura 4.14. Essas informações podem ser atualizadas pelo aluno, as quais serão armazenadas em um documento XML utilizando-se o modelo de descrição de dispositivos proposto. Feito isso, o cálculo da largura de banda é realizado, e por fim, o link para acessar o conteúdo (original ou recodificado) é informado ao aluno (ver Figura 4.14), que é livre para escolher o player de sua preferência para assistir à aula.

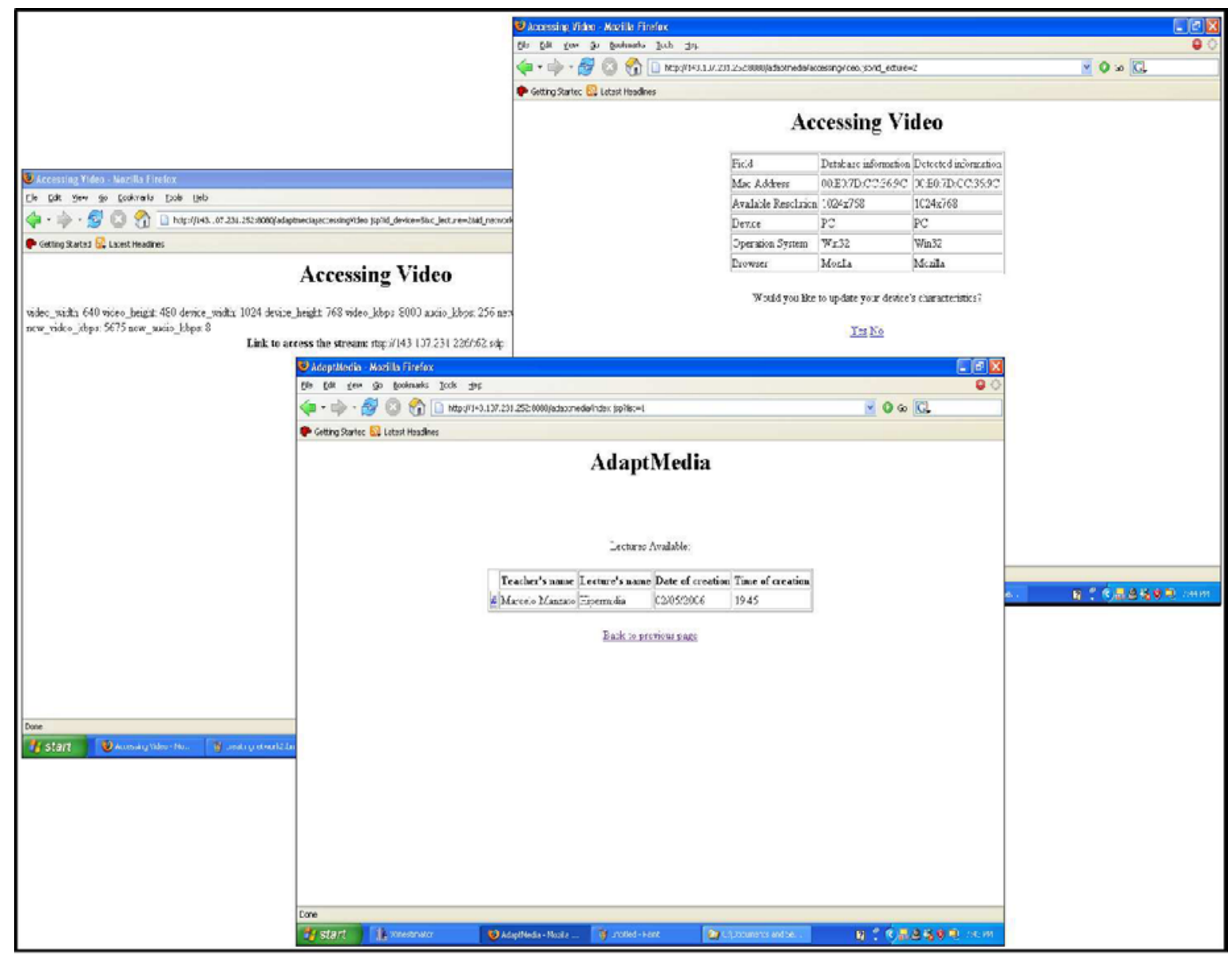

Figura 4.14: Acesso ao conteúdo utilizando a interface.

A recuperação das informações do dispositivo é realizada por meio de um simples parsing do documento XML, que retorna a informação de contexto resolução do dispositivo, que é formada pelos componentes $<$ Width $>$ (largura) e $<$ Height $>$ (altura). O Apêndice B lista três documentos XML que descrevem um laptop, um pocket pc e um computador pessoal. 


\subsection{Considerações Finais}

O auxílio da computação ciente de contexto no processo de adaptação de conteúdo pode facilitar a definição da melhor configuração de vídeo para ser visualizado por determinado usuário. Utilizando informações de contexto, que são capturadas do ambiente computacional, as técnicas de adaptação podem obter subsídios que indiquem quais modificações um vídeo deverá sofrer para que ele seja acessado satisfatoriamente por usuários em situações diversas.

Este Capítulo apresentou um sistema para adaptar vídeo ao vivo com base nas informações de contexto resolução do dispositivo e largura de banda. A partir desses subsídios, os parâmetros do recodificador são identificados, possibilitando adaptar o vídeo para ser acessado por dispositivos com pequena área de visualização de tela, além de canais de comunicação com pouca largura de banda. A arquitetura desenvolvida também foi apresentada, assim como um modelo de descrição de dispositivos, o qual foi estendido do modelo de representação de contexto proposto por Goularte (2003). Com a utilização desse modelo, as tarefas de representar e descrever dispositivos podem ser realizadas de maneira organizada e hierárquica, permitindo o compartilhamento dessas informações com outras aplicações que tenham suporte ao processamento de documentos XML.

No entanto, a utilização da técnica de recodificação na adaptação do vídeo gera latência durante o acesso aos dados. Essa latência pode provocar problemas durante a visualização do vídeo, principalmente se o acesso for realizado ao vivo, e/ou em sistemas com suporte à interatividade. Assim, o próximo Capítulo apresenta uma análise realizada no sistema de adaptação proposto, de modo a identificar quais influências são provocadas pela recodificação durante o acesso ao conteúdo modificado. 


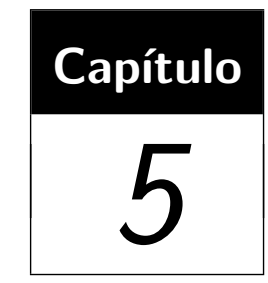

\section{Análise do Sistema}

\subsection{Considerações Iniciais}

A utilização da técnica de recodificação traz vantagens para o sistema de adaptação de vídeo, conforme foi apresentado no Capítulo 2. No entanto, sua estratégia pode gerar conseqüências para usuários durante o acesso ao conteúdo adaptado, principalmente se esse acesso é realizado ao vivo. Uma vez que vídeos em altas resoluções espacial e temporal são submetidos ao recodificador, que necessita decodificá-los e codificá-los antes de serem transmitidos para o usuário, o processo de recodificação pode provocar latência no acesso aos dados, devido à sua alta demanda de processamento e/ou por problemas de transmissão entre os componentes do sistema.

A latência gerada pela recodificação pode dificultar ou mesmo impossibilitar a utilização dessa técnica em certas aplicações. Sistemas de videoconferência, por exemplo, onde existe uma troca constante de informações audiovisuais, requerem que os dados sejam enviados e recebidos com o mínimo de atraso, pois a latência na ordem de alguns segundos é suficiente para dificultar a comunicação entre os usuários. Outras aplicações restringem mais a tolerância a atrasos no acesso aos dados, como por exemplo, sistemas com suporte à interatividade, aplicações que trabalham com análise de experimentos em organismos vivos, telemedicina, etc.

Além do processamento realizado pela recodificação, a transmissão dos dados entre os componentes do sistema também pode causar latência no acesso aos dados ao vivo. Uma vez que servidor e recodificador estão situados em máquinas diferentes, conforme ilustrado pela Figura 4.1, sucessivos empacotamentos e desempacotamentos realizados pelos protocolos de transmissão requerem um tempo de processamento extra, a fim de que os dados sejam enviados ou recebidos do canal de comunicação. 
Desse modo, é importante analisar o impacto provocado pela recodificação em sistemas de adaptação de vídeo, a fim de que seja possível prever as vantagens e desvantagens da utilização dessa técnica, e conseqüentemente, se a técnica é adequada em certos tipos de aplicações. Adicionalmente, por meio de uma análise de cada componente do sistema, é possível identificar qual ou quais componentes ou mecanismos estão provocando um atraso maior no acesso aos dados, permitindo, assim, melhorar o desempenho do sistema estudando-se possíveis alternativas à arquitetura desenvolvida.

Este Capítulo apresenta uma análise do atraso de recodificação realizada no sistema de adaptação de vídeo proposto no Capítulo 4. Na Seção 5.2 é apresentada a infra-estrutura utilizada na análise, incluindo os componentes em hardware, tais como computadores, hubs, câmeras, etc., e componentes em software, tais como as aplicações de captura, codificação, recodificação, etc. Na Seção 5.3 dois cenários são propostos para a análise; o primeiro realiza o acesso por RTSP e o segundo realiza o acesso utilizando o protocolo HTTP. Na Seção 5.4 a metodologia de coleta e medição dos dados é apresentada. Por fim, na Seção 5.5 os resultados da análise são identificados.

\subsection{Infra-estrutura Utilizada}

A Figura 5.1 ilustra a infra-estrutura utilizada na análise do sistema de adaptação. Uma câmera web foi conectada a um computador pessoal contendo o software de difusão, responsável pela captura, codificação e transmissão do vídeo para o servidor, passando por um $h u b$ de $100 \mathrm{Mbits} / \mathrm{s}$. Esse hub também conecta um computador pessoal (desktop 1), o qual acessa o vídeo sem adaptação, e um roteador wireless, que transmite os dados recodificados a um laptop. O servidor, além de estar conectado ao hub de $100 \mathrm{Mbits} / \mathrm{s}$, também foi ligado ao recodificador por um cabo cross-over, a fim de que a transmissão dos dados sem adaptação e com adaptação ocorra sem causar interferência na largura de banda dos usuários. O recodificador foi conectado a um hub de $10 \mathrm{Mbits} / \mathrm{s}$, o qual transmite os dados para um roteador wireless (no caso do acesso aos dados recodificados pelo pocket pc), ou para um computador pessoal (desktop 2), que acessa os dados sem adaptação.

Nas próximas Seções são apresentadas as configurações dos computadores e dispositivos utilizados, bem como os aplicativos adotados nas tarefas de captura, codificação, recodificação, atendimento, acesso e medição do atraso.

\subsubsection{Componentes em Hardware}

Durante a análise do sistema, utilizou-se três computadores distintos responsáveis pela captura, codificação, recodificação e atendimento às requisições dos usuários. O acesso ao vídeo original foi realizado por dois computadores pessoais (desktop 1 e desktop 2), e 


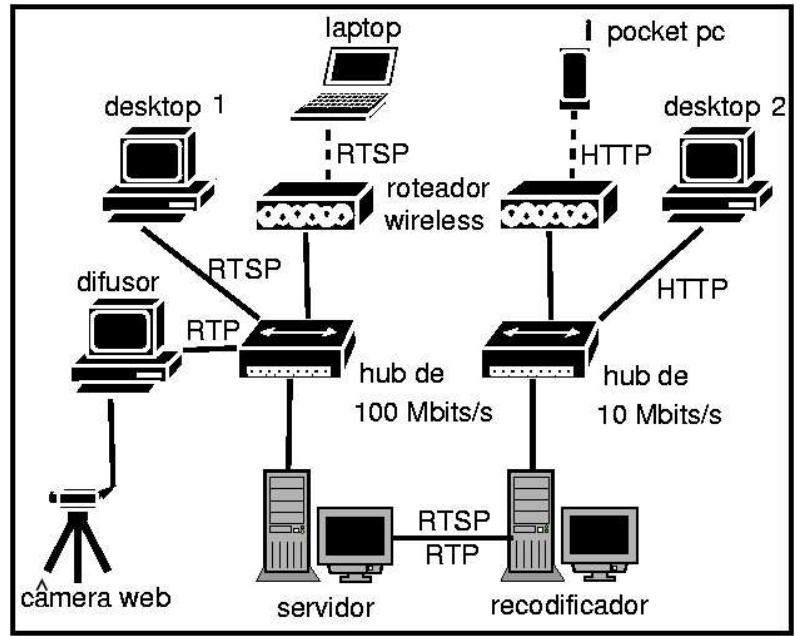

Figura 5.1: Arquitetura da análise do sistema de adaptação.

o acesso ao vídeo recodificado foi realizado por um laptop e por um pocket pc. A Tabela 5.1 lista as configurações em hardware dos computadores utilizados; identifica-se cada computador da Figura 5.1 por meio da coluna Nome dessa Tabela.

Tabela 5.1: Computadores utilizados na análise do atraso de recodificação.

\begin{tabular}{|l|l|l|}
\hline Nome & Papel & Configuração \\
\hline difusor & $\begin{array}{l}\text { Captura, codificação e transmissão } \\
\text { ao servidor de vídeo }\end{array}$ & $\begin{array}{l}\text { Intel Pentium 4, 3 GHz, } \\
1024 \text { Mbytes de RAM }\end{array}$ \\
\hline recodificador & $\begin{array}{l}\text { Recodificação e atendimento às } \\
\text { requisições HTTP }\end{array}$ & $\begin{array}{l}\text { Intel Pentium 4, 3 GHz, } \\
1024 \text { Mbytes de RAM }\end{array}$ \\
\hline servidor & Servidor de streaming RTSP & $\begin{array}{l}\text { Intel Pentium } 4 \text { Xeon, 3 GHz, } \\
2048 \text { Mbytes de RAM }\end{array}$ \\
\hline desktop 1 e 2 & Acesso ao vídeo original & $\begin{array}{l}\text { Intel Pentium 4, 1.7 GHz, } \\
512 \text { Mbytes de RAM }\end{array}$ \\
\hline laptop & Acesso ao vídeo recodificado & $\begin{array}{l}\text { Intel Pentium 3, 646 MHz, } \\
192 \text { Mbytes de RAM }\end{array}$ \\
\hline pocket pc & Acesso ao vídeo recodificado & $\begin{array}{l}\text { Intel PXA255, 128 Mbytes } \\
\text { de RAM }\end{array}$ \\
\hline
\end{tabular}

Além dos computadores, foram utilizadas duas câmeras de vídeo: uma câmera web da Logitech, modelo QuickCam Pro 4000, ligada ao difusor para capturar o vídeo; e uma câmera digital Sony modelo DCR-TRV340 para auxiliar o processo de medição do atraso (ver Seção 5.4). Adicionalmente, foram incluídos na arquitetura: um hub da 3COM modelo Dual Speed Hub 8 de 100 Mbits/s; um hub da IBM modelo Stackable Ethernet $H u b$ de $10 \mathrm{Mbits} / \mathrm{s}$; e um roteador wireless da Linksys modelo Wireless-G 802.11g de $2.4 \mathrm{GHz}$ e $54 \mathrm{Mbits} / \mathrm{s}$. Todos os dispositivos foram conectados conforme a Figura 5.1 utilizando-se cabos de rede do tipo par trançado categoria 5 (100 Mbits/s). 


\subsubsection{Componentes em Software}

A fim de prover flexibilidade por meio do acesso ao código, além de facilitar a implantação do sistema pelos desenvolvedores com o mínimo de custo, foram utilizadas ferramentas de código-aberto na análise do sistema. A Tabela 5.2 lista o sistema operacional e o respectivo aplicativo em cada computador do sistema; analogamente, é possível identificar cada computador da Figura 5.1 por meio da coluna Nome dessa Tabela.

Tabela 5.2: Aplicativos utilizados na análise do atraso de recodificação.

\begin{tabular}{|l|l|l|}
\hline Nome & Sistema Operacional & Aplicativo \\
\hline difusor & Windows XP Service Pack 2 & VLC versão 0.8.4a \\
\hline recodificador & Fedora Core 3 kernel 2.6.9 & VLC versão 0.8.4a \\
\hline servidor & Fedora Core 2 kernel 2.6.5 & DSS versão 5.5.1 \\
\hline desktop 1 e 2 & Windows XP Service Pack 2 & VLC versão 0.8.4a \\
\hline laptop & Windows XP & VLC versão 0.8.4a \\
\hline pocket pc & Windows CE versão 4.2 & VLC versão 0.8.5 \\
\hline
\end{tabular}

A ferramenta VideoLan Client (VLC), utilizada na maioria dos componentes do sistema de adaptação, é um player multimídia para vários formatos de vídeo e áudio. Contém funcionalidades de codificação, recodificação e streaming, além de poder ser instalado em diversas plataformas. O Darwin Streaming Server (DSS) é um servidor de streaming que atende requisições RTSP dos usuários, podendo servir vídeo MPEG-4 capturado e codificado ao vivo (utilizando o difusor), ou vídeo MPEG-4 armazenado na forma de arquivos em uma pasta local.

Algumas ferramentas e funções também foram utilizadas a fim de auxiliar o processo de medição do atraso. No difusor foi criado um arquivo de lote (batch files) contendo a inicialização do software de difusão, e a sua finalização após 40 segundos de captura e transmissão de vídeo (ver Seção 5.4). No servidor e no recodificador foram utilizadas as funções clock() e gettimeofday(), ambas da biblioteca C padrão (Standard C Library) ${ }^{1}$ a fim de se obter os tempos da CPU (Unidade Central de Processamento - do Inglês, Central Processing Unit) e do sistema, respectivamente. Também foi utilizado o comando snice $^{2}$ para atribuir prioridade baixa a todos os processos em execução no sistema. Adicionalmente, utilizou-se a ferramenta ffmpeg para se obter o número de quadros de um vídeo local.

\subsection{Cenários Propostos}

A análise do atraso foi realizada em dois cenários distintos. Ambos foram configurados para que o vídeo fosse acessado sem recodificação e com recodificação, de modo

\footnotetext{
${ }^{1}$ http://www.utas.edu.au/infosys/info/documentation/C/CStdLib.html

${ }^{2}$ http://linuxcommand.org/man_pages/snice1.html
} 
que o tempo de atraso gerado pelo recodificador pudesse ter sido identificado por meio das técnicas adotadas. O primeiro cenário realiza o acesso ao vídeo por RTSP, e o segundo realiza o acesso por HTTP. Nas próximas Subseções cada cenário é apresentado detalhadamente.

\subsubsection{Cenário 1: Acesso por RTSP}

A Tabela 5.3 ilustra as configurações do vídeo sem adaptação e com adaptação. O difusor captura e codifica o vídeo na configuração sem adaptação indicada pela Tabela 5.3, e o acesso a esse conteúdo é realizado pelo desktop 1 (ver Figura 5.1), que emite uma requisição RTSP ao servidor. Desse modo, o difusor transmite o vídeo ao servidor, que disponibiliza um arquivo SDP descritivo do conteúdo para o acesso.

Tabela 5.3: Configuração do vídeo no cenário 1.

\begin{tabular}{|l|l|l|}
\hline & Sem adaptação & Com adaptação \\
\hline Resolução Espacial & $640 \times 480$ & $640 \times 480$ \\
\hline Resolução Temporal & 30 quadros/s & 30 quadros/s \\
\hline Taxa de bits & $12 \mathrm{Mbits} / \mathrm{s}$ & $1 \mathrm{Mbit} / \mathrm{s}$ \\
\hline
\end{tabular}

O acesso ao conteúdo com adaptação é realizado pelo laptop, que por usar uma rede wireless, onde a largura de banda é pequena, necessita acessar o vídeo a uma taxa de bits reduzida. A adaptação é realizada pelo recodificador, que emite uma requisição RTSP ao servidor, e à medida que recebe e recodifica os dados no formato com adaptação especificado pela Tabela 5.3, reenvia-os de volta ao servidor, para que sejam acessados pelo laptop. Vale ressaltar que a taxa de bits do vídeo adaptado foi especificada com base na medição da largura de banda do canal de comunicação entre o laptop e o servidor.

\subsubsection{Cenário 2: Acesso por HTTP}

A Tabela 5.4 ilustra as configurações do vídeo sem adaptação e com adaptação. O difusor captura e codifica o vídeo na configuração sem adaptação indicada na Tabela 5.4, transmitindo-o para o servidor. O recodificador emite uma requisição RTSP ao servidor, o qual envia os dados sem adaptação para ele. No caso do acesso pelo desktop 2 (ver Figura 5.1), o recodificador apenas disponibiliza o vídeo para o acesso por HTTP; e no caso do acesso pelo pocket $p c$, o recodificador recodifica o vídeo no formato com adaptação indicado pela Tabela 5.4 e disponibiliza o conteúdo modificado para o acesso por HTTP.

Vale também ressaltar que a taxa de bits do vídeo adaptado foi especificada com base na largura de banda entre o pocket pc e o recodificador, e a resolução espacial foi especificada com base na resolução máxima do dispositivo. 
Tabela 5.4: Configuração do vídeo no cenário 2.

\begin{tabular}{|l|l|l|}
\hline & Sem adaptação & Com adaptação \\
\hline Resolução Espacial & $640 \times 480$ & $320 \times 240$ \\
\hline Resolução Temporal & 30 quadros/s & 30 quadros $/ \mathrm{s}$ \\
\hline Taxa de bits & $8 \mathrm{Mbits} / \mathrm{s}$ & $500 \mathrm{Kbits} / \mathrm{s}$ \\
\hline
\end{tabular}

\subsection{Metodologia de Análise}

A análise do sistema de adaptação tem como objetivo principal identificar o atraso gerado pela recodificação, a partir do atraso total percebido pelo usuário. Essa análise foi realizada em ambos os cenários, possibilitando verificar o desempenho do sistema durante o acesso por RTSP, a partir de uma requisição ao servidor, bem como durante o acesso por HTTP, a partir de uma requisição ao recodificador.

O processo de medição do atraso gerado pelo recodificador pode ser sumarizado da seguinte maneira: primeiramente, o atraso total, fim-a-fim, percebido pelo usuário com a implantação da adaptação é identificado, e, a partir do tempo de execução do recodificador, obtém-se o atraso gerado somente pela recodificação.

A fim de facilitar o entendimento da metodologia de análise, o sistema de adaptação foi esquematizado conforme ilustra a Figura 5.2. A definição de cada variável utilizada está indicada na Tabela 5.5.

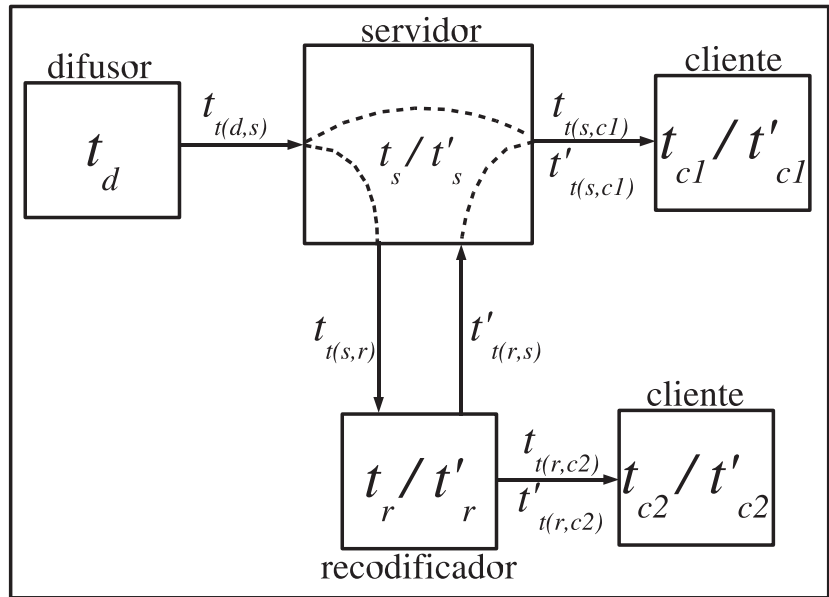

Figura 5.2: Esquema para análise do atraso de recodificação.

Considerando a Figura 5.2, é possível formular a seguinte equação, que indica o percurso realizado pelos dados do difusor até o cliente, durante o cenário 1, sem adaptação:

$$
P_{1}=t_{d}+t_{t(d, s)}+t_{s}+t_{t(s, c 1)}+t_{c 1}+B_{1}
$$

onde $P_{1}$ é o tempo total de percurso de um quadro sem adaptação e $B_{1}$ é o tempo de buferização dos dados no difusor, servidor e cliente. Analogamente, a equação que 
Tabela 5.5: Definição das varáveis utilizadas.

\begin{tabular}{|l|l|}
\hline Variável & Definição \\
\hline$t_{s}$ & $\begin{array}{l}\text { Tempo de processamento de um quadro no servidor, durante } \\
\text { o acesso sem adaptação }\end{array}$ \\
\hline$t_{s}^{\prime}$ & $\begin{array}{l}\text { Tempo de processamento de um quadro no servidor, durante } \\
\text { o acesso com adaptação }\end{array}$ \\
\hline$t_{r}$ & $\begin{array}{l}\text { Tempo de processamento de um quadro no recodificador, } \\
\text { sem adaptação }\end{array}$ \\
\hline$t_{r}^{\prime}$ & $\begin{array}{l}\text { Tempo de processamento de um quadro no recodificador, } \\
\text { com adaptação }\end{array}$ \\
\hline$t_{d}$ & $\begin{array}{l}\text { Tempo de codificação de um quadro no difusor } \\
\text { Tempo de transmissão de um quadro do difusor para o }\end{array}$ \\
\hline$t_{t(d, s)}$ & $\begin{array}{l}\text { Tempo de transmissão de um quadro do servidor para o } \\
\text { recodificador }\end{array}$ \\
\hline$t_{t(s, r)}$ & $\begin{array}{l}\text { Tempo de transmissão de um quadro adaptado do recodi- } \\
\text { ficador para o cliente }\end{array}$ \\
\hline$t_{t(r, s)}^{\prime}$ & $\begin{array}{l}\text { Tempo de transmissão de um quadro do servidor para o } \\
\text { cliente }\end{array}$ \\
\hline$t_{t(s, c 1)}$ \\
\hline$t_{t(s, c 1)}^{\prime}$ & $\begin{array}{l}\text { Tempo de transmissão de um quadro adaptado do servidor } \\
\text { para o cliente }\end{array}$ \\
\hline$t_{t(r, c 2)}$ & $\begin{array}{l}\text { Tempo de transmissão de um quadro do recodificador para } \\
\text { o cliente }\end{array}$ \\
\hline$t_{t(r, c 2)}^{\prime}$ & $\begin{array}{l}\text { Tempo de transmissão de um quadro adaptado do recodi- } \\
\text { ficador para o cliente }\end{array}$ \\
\hline$t_{c 1}$ e $t_{c 2}$ & $\begin{array}{l}\text { Tempo de decodificação de um quadro no player do cliente } \\
\text { Tempo de decodificação de um quadro adaptado no player }\end{array}$ \\
\hline$t_{c 1}^{\prime}$ e $t_{c 2}^{\prime}$ & \begin{tabular}{l} 
do cliente \\
\hline
\end{tabular} \\
\hline
\end{tabular}

representa o percurso realizado por um quadro do difusor até o cliente, durante o cenário 1, com adaptação, é a seguinte:

$$
P_{1}^{\prime}=t_{d}+t_{t(d, s)}+t_{s}^{\prime}+t_{t(s, r)}+t_{r}^{\prime}+t_{t(r, s)}^{\prime}+t_{t(s, c 1)}^{\prime}+t_{c 1}^{\prime}+B_{1}^{\prime}
$$

onde $P_{1}^{\prime}$ é o tempo total de percurso de um quadro com adaptação e $B_{1}^{\prime}$ é o tempo de buferização dos dados no difusor, servidor, recodificador e cliente.

Da mesma maneira, a equação que representa o percurso realizado por um quadro do difusor até o cliente, durante o cenário 2, sem adaptação, é a seguinte:

$$
P_{2}=t_{d}+t_{t(d, s)}+t_{s}+t_{t(s, r)}+t_{r}+t_{t(r, c 2)}+t_{c 2}+B_{2}
$$

onde $P_{2}$ é o tempo total de percurso de um quadro sem adaptação e $B_{2}$ é o tempo de buferização dos dados no difusor, servidor, recodificador e cliente. Analogamente, a equação que representa o percurso realizado pelos dados do difusor até o cliente, durante 
o cenário 2, com adaptação, é a seguinte ${ }^{3}$ :

$$
P_{2}^{\prime}=t_{d}+t_{t(d, s)}+t_{s}+t_{t(s, r)}+t_{r}^{\prime}+t_{t(r, c 2)}^{\prime}+t_{c 2}^{\prime}+B_{2}^{\prime}
$$

onde $P_{2}^{\prime}$ é o tempo total de percurso de um quadro com adaptação e $B_{2}^{\prime}$ é o tempo de buferização dos dados no difusor, servidor, recodificador e cliente.

Em todas as configurações, realizou-se 30 transmissões do vídeo para que o intervalo de confiança fosse atingido. Desse modo, para o cenário 1, por exemplo, o desktop 1 acessou 30 vezes o vídeo original por RTSP, e em seguida, o laptop acessou 30 vezes o vídeo modificado, também por RTSP. Em cada transmissão, o tempo de execução do software de difusão foi de 40 segundos, o que foi controlado pelo arquivo de lote (ver Subseção 5.2.2); e o tempo de acesso dos dispositivos foi de aproximadamente 40 segundos, considerando que existe um período para inicialização da câmera e dos módulos do difusor. Nas próximas Subseções, são apresentados os mecanismos realizados para se obter os dados necessários para a análise.

\subsubsection{Cálculo do Atraso Total}

O atraso total pode ser retratado como sendo o tempo adicional percebido pelo usuário durante o acesso ao vídeo adaptado, comparando-se os tempos de percursos dos dados sem adaptação e com adaptação. Considerando o cenário 1 , o atraso total $\left(A T_{1}\right)$ é definido pela seguinte equação:

$$
A T_{1}=P_{1}^{\prime}-P_{1}
$$

onde $P_{1}^{\prime}$ e $P_{1}$ são definidos pelas equações 5.2 e 5.1 , respectivamente. O valor de $A T_{1}$ representa: a) a diferença dos tempos de processamento dos dados com e sem adaptação no servidor; b) a transmissão dos dados entre servidor e recodificador; c) a diferença entre as transmissões dos dados com e sem adaptação entre servidor e cliente; d) a diferença entre os tempos de decodificação dos dados com e sem adaptação no player do cliente; e) o atraso de recodificação; e f) o tempo de buferização dos dados no recodificador.

Analogamente, o atraso total $\left(A T_{2}\right)$, no cenário 2, pode ser definido pela seguinte equação:

$$
A T_{2}=P_{2}^{\prime}-P_{2}
$$

onde $P_{2}^{\prime}$ e $P_{2}$ são definidos pelas equações 5.4 e 5.3, respectivamente. $\mathrm{O}$ valor de $A T_{2}$ representa: a) a diferença dos tempos de processamento dos dados com e sem adaptação

\footnotetext{
${ }^{3}$ Uma vez que os dados passam apenas uma vez pelo servidor, durante o cenário 2, com adaptação, pode-se dizer que o tempo de processamento do servidor será o mesmo para os casos sem adaptação do cenário 1 e sem adaptação do cenário 2 , ou seja, $t_{s}$.
} 
no recodificador; b) a diferença entre as transmissões dos dados com e sem adaptação entre recodificador e cliente; e c) a diferença entre os tempos de decodificação dos dados com e sem adaptação no player do cliente.

Os tempos de percursos $P_{1}, P_{1}^{\prime}, P_{2}$ e $P_{2}^{\prime}$ foram obtidos da seguinte maneira: uma câmera web foi conectada ao software de difusão, sendo projetada a filmar um monitor exibindo um vídeo específico com duração de 40 segundos e um cronômetro. Assim, foi possível calcular o tempo total de percurso de um quadro no sistema, tirando-se simples fotografias do monitor filmado e do dispositivo de acesso e a subtração dos valores em cada cronômetro. O momento de tirar cada fotografia foi variável para cada teste; conseqüentemente, a média dos 30 valores referentes aos 30 testes representa o tempo de cada quadro do vídeo total. A Figura 5.3 ilustra um dos testes realizados com o laptop e com o pocket pc, cujo vídeo capturado e codificado pelo difusor foi configurado conforme o cenário 1 e o cenário 2 , respectivamente.

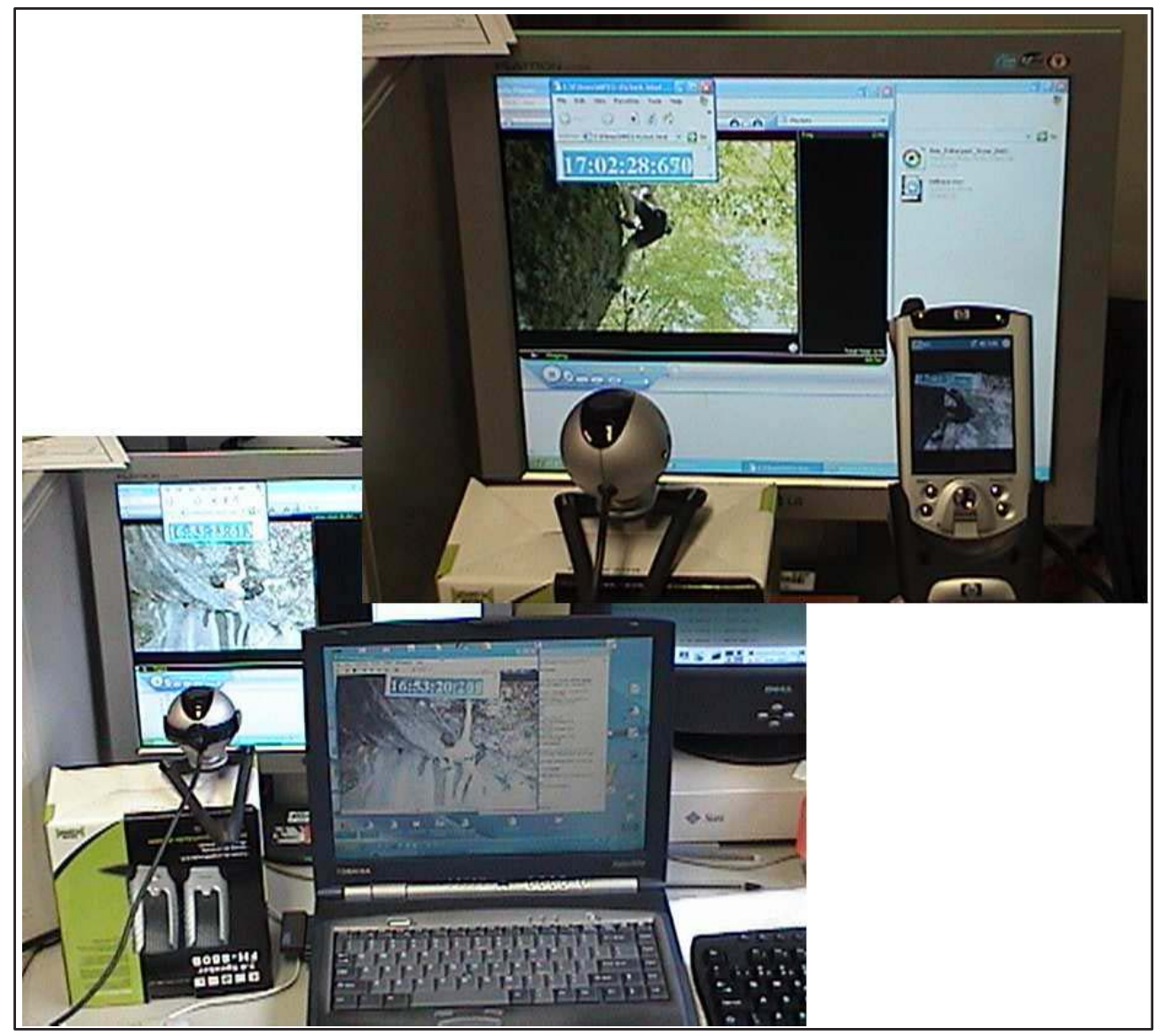

Figura 5.3: Captura do tempo total utilizando um laptop e um pocket pc.

Além de permitir a obtenção dos tempos de percursos, essa estratégia possibilitou que uma mesma taxa de bits fosse transmitida em cada teste. Considerando que o sistema transmite vídeo ao vivo, e que cenas em diferentes níveis de movimentação podem provocar uma variação considerável na taxa de bits, garantiu-se que em cada medição a mesma quantidade de dados fosse processada pelos módulos do sistema. 


\subsubsection{Instrumentalização do Recodificador}

Além do tempo total, foi possível coletar informações do recodificador por meio da inserção das funções clock() e gettimeofday() no código do VLC. Essas informações descrevem, respectivamente, o tempo de processamento e tempo de execução gastos durante a transmissão do vídeo todo, e foram nomeadas e classificadas da seguinte maneira:

- $\Delta R$ e $\Delta R^{\prime}$ : equivalem aos tempos de execução do recodificador sem adaptação (no caso do acesso via desktop 2 no cenário 2) e com adaptação, respectivamente.

- $\Delta R_{c p u}$ e $\Delta R_{c p u}^{\prime}$ : são os tempos efetivos de processamento da CPU no recodificador sem adaptação e com adaptação, respectivamente.

- $\Delta R_{i / o}$ e $\Delta R_{i / o}^{\prime}$ : são os tempos efetivos de entrada e saída dos dados no recodificador sem adaptação e com adaptação, respectivamente. São calculados por meio da subtração do tempo de execução $\left(\Delta R\right.$ e $\left.\Delta R^{\prime}\right)$ pelo tempo de processamento $\left(\Delta R_{c p u}\right.$ e $\left.\Delta R_{c p u}^{\prime}\right)$.

Com o propósito de calcular essas informações, as funções clock() e gettimeofday() foram inseridas em regiões do VLC onde ocorrem a entrada dos pacotes da rede e a saída dos pacotes para a rede. O primeiro valor obtido pela função clock(), indicando o primeiro pacote que entrou no recodificador, foi subtraído pelo último valor obtido pela mesma função, que indica o último pacote que saiu do recodificador. Analogamente, foram realizadas as mesmas subtrações com os valores obtidos pela função gettimeofday().

\subsubsection{Cálculo do Número de Quadros}

Uma vez que o tempo total de percurso do vídeo calculado por meio do cronômetro é referente a cada quadro, e que os tempos obtidos pelas funções clock() e gettimeofday() são referentes ao vídeo todo, é necessário converter os valores para que todos indiquem o tempo de cada quadro. Isso é feito dividindo-se cada delta (indicado na Subseção anterior) pelo número total de quadros.

O número total de quadros $(\alpha)$ foi obtido da seguinte maneira: configurou-se o recodificador para que ele armazenasse o vídeo provindo do servidor no disco local. Em seguida, utilizou-se uma funcionalidade estatística da ferramenta ffmpeg para se obter o número de quadros do vídeo armazenado. Esse experimento foi realizado 30 vezes para cada configuração da taxa de bits do vídeo (12 Mbits/s e $8 \mathrm{Mbits} / \mathrm{s}$ ), e a média foi calculada (ver valores na próxima Seção). Vale destacar que o vídeo recebido do servidor foi capturado e codificado pelo difusor da mesma maneira que se realizou nos testes anteriores.

Com base no número de quadros obtidos, e os valores calculados por meio da instrumentalização do recodificador, é possível calcular os valores de $t_{r}$ e $t_{r}^{\prime}$ pela simples divisão de $\Delta R$ e $\Delta R^{\prime}$ por $\alpha$, obtendo-se o tempo de recodificação para cada quadro. 


\subsubsection{Cálculo do Atraso de Recodificação}

O cálculo do atraso de recodificação é realizado com base nos valores obtidos a partir da instrumentalização do recodificador. Uma vez que $t_{r}$ e $t_{r}^{\prime}$ equivalem ao tempo de recodificação, o atraso gerado por um único quadro é igual à diferença entre $t_{r}$ ou $t_{r}^{\prime}$ pelo período em que um quadro é mostrado na tela para o usuário, o que está relacionado à taxa de quadros do vídeo. Desse modo, se um vídeo, por exemplo, está configurado a 30 quadros/s, e o tempo de recodificação é de 0,035 segundos, então o atraso gerado por um único quadro será de 0,002 segundos (0,035-0,033).

No entanto, a recodificação sucessiva de múltiplos quadros pode gerar latência acumulativa, no caso em que o tempo de processamento de um quadro é maior que o período em que um quadro é mostrado na tela. Teoricamente, um quadro $i$ recodificado é entregue ao cliente a um atraso de $i\left(t_{r}-\frac{1}{f p s}\right)$ segundos $^{4}$, onde $f p s$ é a taxa de quadros do vídeo. Porém, esse atraso acumulativo é mascarado pelo processo de buferização dos dados no recodificador, servidor e player do cliente.

A fim de se obter o atraso gerado pela recodificação em ambos os cenários, é possível calcular uma média do atraso acumulativo. Essa média pode ser expressa da seguinte maneira:

$$
\begin{gathered}
A R_{1}=\sum_{i=1}^{\alpha} \frac{i\left(t_{r}^{\prime}-\frac{1}{f p s}\right)}{\alpha} \\
=\frac{\left(t_{r}^{\prime}-\frac{1}{f p s}\right)}{\alpha} \frac{(1+\alpha) \alpha}{2} \\
A R_{1}=\frac{\alpha\left(t_{r}^{\prime}-\frac{1}{f p s}\right)+t_{r}^{\prime}-\frac{1}{f p s}}{2}
\end{gathered}
$$

onde $A R_{1}$ é o atraso gerado pela recodificação no cenário 1 e $\alpha$ é o número de quadros do vídeo. Analogamente, a média do atraso acumulativo no cenário 2 pode ser expressa da seguinte maneira:

$$
\begin{gathered}
A R_{2}=\sum_{i=1}^{\alpha} \frac{i\left[\left(t_{r}^{\prime}-\frac{1}{f p s}\right)-\left(t_{r}-\frac{1}{f p s}\right)\right]}{\alpha} \\
=\frac{\left(t_{r}^{\prime}-\frac{1}{f p s}-t_{r}+\frac{1}{f p s}\right) \frac{(1+\alpha) \alpha}{\alpha}}{2} \\
A R_{2}=\frac{\alpha\left(t_{r}^{\prime}-t_{r}\right)+t_{r}^{\prime}-t_{r}}{2}
\end{gathered}
$$

onde $A R_{2}$ é o atraso gerado pela recodificação no cenário 2 e $\alpha$ é o número de quadros do vídeo.

\footnotetext{
${ }^{4} \mathrm{Ou} i\left(t_{r}^{\prime}-\frac{1}{f p s}\right)$ segundos.
} 
As equações formuladas foram propostas para que os resultados possam ser identificados aplicando-se os dados coletados em cada equação. A próxima Seção apresenta os resultados da análise, os quais foram baseados no conjunto de dados obtidos conforme explicado nesta Seção.

\subsection{Resultados Obtidos}

Utilizando a infra-estrutura de hardware e software apresentada na Seção 5.2, as configurações de vídeo definidas nos cenários 1 e 2 descritos na Seção 5.3, e a metodologia de análise apresentada na Seção anterior, foram obtidos dados referentes aos experimentos realizados no sistema de adaptação de vídeo.

Conforme explicado na Seção anterior, o número de quadros $(\alpha)$ foi calculado por meio da média das configurações de taxa de bits de $8 \mathrm{Mbits} / \mathrm{s}$ e $12 \mathrm{Mbits} / \mathrm{s}$, obtendo-se o valor de 1117 quadros, que foram transmitidos e processados em cada experimento. Considerando o cenário 1, a Tabela 5.6 indica os tempos de percursos $\left(P_{1}\right.$ e $\left.P_{1}^{\prime}\right)$, assim como os tempos de execução $\left(\Delta R^{\prime}\right)$, processamento $\left(\Delta R_{c p u}^{\prime}\right)$ e entrada e saída $\left(\Delta R_{i / o}^{\prime}\right)$ do recodificador. Aplicando os valores de $P_{1}$ e $P_{1}^{\prime}$ na equação 5.5, obtém-se o valor de $A T_{1}$, que é de 1,496 segundos, indicando o atraso total percebido pelo usuário com a implantação da recodificação no sistema.

Tabela 5.6: Resultados do cenário 1.

\begin{tabular}{|l|l|l|l|l|l|}
\hline \multicolumn{5}{|c||}{ Sem adaptação } & \multicolumn{1}{|c|}{ Com adaptação } \\
\hline & $P_{1}$ & $P_{1}^{\prime}$ & $\Delta R^{\prime}$ & $\Delta R_{c p u}^{\prime}$ & $\Delta R_{i / o}^{\prime}$ \\
\hline Média & 1,927 & 3,423 & 39,360 & 12,191 & 27,170 \\
\hline Variância & 0,001 & 0,015 & 0,021 & 0,013 & 0,011 \\
\hline Desvio Padrão & 0,031 & 0,122 & 0,145 & 0,114 & 0,105 \\
\hline
\end{tabular}

$\mathrm{O}$ valor de $A T_{1}$ inclui o atraso gerado somente pelo processo de recodificação. Esse atraso pode ser calculado com base no tempo de execução do recodificador, ou seja, $\Delta R^{\prime}$. Dividindo-se $\Delta R^{\prime}$ por $\alpha$ obtém-se a variável $t_{r}^{\prime}$, que é de 0,03523 segundos, representando o tempo de recodificação de um quadro no recodificador. Esse tempo pode ser decomposto em processamento, calculado pela divisão de $\Delta R_{c p u}^{\prime}$ por $\alpha$, obtendo-se o valor de 0,01091 segundos, e entrada e saída, calculado pela divisão de $\Delta R_{i / o}^{\prime}$ por $\alpha$, obtendo-se o valor de 0,02432 segundos.

Além do atraso gerado pela recodificação, o valor de $A T_{1}$ contém ainda o tempo de buferização do recodificador, que é de 0,600 segundos. Subtraindo os tempos de recodificação e buferização no recodificador do atraso total, obtém-se o valor de 0,861 segundos, que indica o atraso gerado pela transmissão dos dados, diferença de processamento e buferização no servidor e diferença de decodificação no player do cliente. Apesar de o tempo de recodificação ser pequeno à primeira vista, a não utilização de buferização pode gerar um atraso acumulativo de 1,24657 segundos, o qual foi obtido por meio da equação 5.7. 
Cálculos similares podem ser aplicados no cenário 2. A Tabela 5.7 indica os tempos de percursos $\left(P_{2}\right.$ e $\left.P_{2}^{\prime}\right)$, assim como os tempos de execução $\left(\Delta R\right.$ e $\left.\Delta R^{\prime}\right)$, processamento $\left(\Delta R_{c p u}\right.$ e $\left.\Delta R_{c p u}^{\prime}\right)$ e entrada e saída $\left(\Delta R_{i / o}\right.$ e $\left.\Delta R_{i / o}^{\prime}\right)$ do recodificador. Aplicando os valores de $P_{2}$ e $P_{2}^{\prime}$ na equação 5.6, obtém-se o valor de $A T_{2}$, que é de 0,131 segundos, indicando o atraso total percebido pelo usuário com a implantação da recodificação no sistema.

Tabela 5.7: Resultados do cenário 2.

\begin{tabular}{|l|l|l|l|l|l|l|l|l|}
\hline & \multicolumn{6}{|l|}{ Sem adaptação } & \multicolumn{4}{|c|}{ Com adaptação } \\
\hline & $P_{2}$ & $\Delta R$ & $\Delta R_{c p u}$ & $\Delta R_{i / o}$ & $P_{2}^{\prime}$ & $\Delta R^{\prime}$ & $\Delta R_{c p u}^{\prime}$ & $\Delta R_{i / o}^{\prime}$ \\
\hline Média & 2,759 & 39,302 & 1,242 & 38,060 & 2,890 & 39,311 & 9,762 & 29,549 \\
\hline Variância & 0,014 & 0,031 & 0,003 & 0,036 & 0,027 & 0,024 & 0,003 & 0,017 \\
\hline Desvio Padrão & 0,118 & 0,176 & 0,055 & 0,190 & 0,164 & 0,155 & 0,055 & 0,130 \\
\hline
\end{tabular}

$\mathrm{O}$ valor de $A T_{2}$ inclui a diferença dos atrasos gerados pelo recodificador, no caso do processamento de um quadro com e sem adaptação. Dividindo-se $\Delta R$ por $\alpha$ obtém-se a variável $t_{r}$, que é de 0,03518 segundos, representando o tempo gasto pelo recodificador para disponibilizar o conteúdo original para o acesso por HTTP. Da mesma maneira, dividindo-se $\Delta R^{\prime}$ por $\alpha$, obtém-se a variável $t_{r}^{\prime}$, que é de 0,03519 segundos, representando o tempo de recodificação de um quadro no recodificador, e a disponibilização do conteúdo para o acesso por HTTP. Analogamente ao cenário 1, esses tempos podem ser decompostos em processamento, calculado pelas divisões de $\Delta R_{c p u}$ e $\Delta R_{c p u}^{\prime}$ por $\alpha$, obtendo-se os valores de 0,00111 e 0,00873 segundos, respectivamente, e entrada e saída, calculado pelas divisões de $\Delta R_{i / o}$ e $\Delta R_{i / o}^{\prime}$ por $\alpha$, obtendo-se os valores de 0,03407 e 0,02645 segundos, respectivamente.

Considerando que a taxa de quadros foi também configurada em 30 quadros/s no cenário 2, o atraso gerado pela recodificação, no caso da não utilização de buferização, pode ser obtido aplicando-se os valores de $\alpha, t_{r}$ e $t_{r}^{\prime}$ na equação 5.8 , o que resulta em 0,00559 segundos. Uma vez que o recodificador realiza um processamento dos dados em ambos os casos do cenário 2 (com e sem adaptação), o atraso gerado apenas pela adaptação é consideravelmente pequeno, quando comparado ao cenário 1.

\subsection{Considerações Finais}

Este Capítulo apresentou uma análise do atraso de recodificação realizada no sistema. A partir dos resultados obtidos, conclui-se que o agente principal causador de latência durante o acesso ao vídeo é a buferização dos dados.

Esses resultados foram obtidos a partir do atraso total percebido pelo usuário, cuja medição identificou um valor de 1,496 segundos para o cenário 1 e 0,131 segundos para o cenário 2. Apesar de o cenário 2 apresentar um atraso total consideravelmente menor do que o cenário 1 , o tempo de percurso de um quadro sem adaptação no cenário 2 é maior do que o tempo de percurso de um quadro sem adaptação no cenário 1. 
Além disso, calculou-se o tempo necessário para recodificar um quadro no formato MPEG-4, que é de 0, 035 segundos. Esse tempo equivale ao processo de total decodificação dos dados seguida da codificação. De acordo com a Recomendação G.114 da ITU-T (União de Telecomunicação Internacional - do Inglês, International Telecommunication Union) (1996), um atraso ponto-a-ponto de até 0, 150 segundos é aceitável para a maioria das aplicações interativas ou não. Desse modo, o tempo gerado somente pela recodificação é satisfatório no contexto de um sistema de adaptação com suporte à interatividade.

Por outro lado, a buferização é um fator limitante, uma vez que a sua não utilização pode gerar latência acumulativa. Considerando que os tempos de buferização do codificador, servidor, recodificador e player adotados pela análise são os valores padrões das respectivas aplicações, pode-se diminuir o atraso por meio da redução dos tempos de buferização. No entanto, o desenvolvedor deve estar ciente das conseqüências que essa medida poderá trazer para o sistema, principalmente se nenhuma providência for tomada para reduzir o atraso acumulativo, bem como se a transmissão de dados for muito suscetível a erros de comunicação. 


\section{Capítulo \\ 6}

\section{Conclusões}

\subsection{Considerações Iniciais}

A utilização da recodificação traz algumas vantagens quando comparada a outros métodos de adaptação de vídeo. Ao contrário do modelo de distribuição por difusão simultânea, a recodificação não necessita ter várias versões de um mesmo conteúdo armazenadas no servidor. Além disso, a adaptação na taxa de bits, de acordo com a largura de banda, pode ser realizada mais eficientemente, uma vez que o recodificador é livre para especificar taxas de bits ótimas para a situação atual do canal de comunicação. Diferenciando-se, por sua vez, do modelo de mídia escalável, a recodificação não requer nenhuma funcionalidade adicional por parte dos decodificadores presentes nos dispositivos para acessar os dados, como por exemplo, suporte a múltiplas camadas. Tendo em vista que o vídeo é adaptado antes de ser transmitido para os usuários, problemas de interdependência entre camadas, assim como limitações de entrega de vídeo personalizado devido às restrições de rede e dispositivos podem ser evitadas.

Não obstante, a recodificação traz obstáculos que podem dificultar a sua utilização. Uma vez que o vídeo necessita ser decodificado, e em seguida, codificado novamente em um novo formato, a latência provocada pelo processamento dos dados no recodificador pode influenciar significativamente o acesso ao vivo por parte dos usuários. Esse atraso pode inviabilizar a utilização desse método, principalmente em aplicações onde ocorre interatividade, tais como TV interativa, e-learning, videoconferência e telemedicina.

Outro problema enfrentado por aplicações com suporte à recodificação e outros métodos de adaptação de conteúdo relaciona-se a como obter, representar e processar informações vindas do sistema computacional, que forneçam subsídios para proceder a recodificação de modo automático e personalizado. 
Este trabalho desenvolveu um sistema de adaptação de vídeo ao vivo utilizando a técnica da recodificação. Foram utilizados conceitos da área de computação ciente de contexto para se obter, automaticamente, subsídios para permitir adaptação de vídeo de modo a atender às necessidades de acesso em situações específicas.

\subsection{Contribuições}

Dentre as principais contribuições deste trabalho, pode-se destacar:

- Proposta de um modelo para representação contextual de dispositivos.

- Desenvolvimento de um sistema de adaptação de vídeo ao vivo.

- Avaliação do atraso imposto pela recodificação durante o acesso ao vídeo.

O modelo para representação de dispositivos foi desenvolvido de modo a oferecer uma descrição organizada, hierárquica e extensível de informações de contexto relacionadas às características de dispositivos. A partir desse modelo, aplicações cientes de contexto podem compartilhar informações sobre dispositivos, uma vez que a representação é realizada de modo padronizado por meio de esquemas XML. A biblioteca de dispositivos, que pode ser estendida conforme a necessidade de aplicações, facilitou o trabalho de representação, uma vez que a descrição de dispositivos específicos foi projetada anteriormente no esquema XML.

Depois de capturadas as informações de contexto, o sistema de adaptação de vídeo desenvolvido armazena esses dados utilizando o modelo proposto. Esse armazenamento é realizado por meio de documentos XML, que serão acessados pelo próprio sistema, ou poderão ser compartilhados com outras aplicações.

Com a definição desse modelo, alguns problemas existentes no CC/PP foram eliminados: a) a limitação de não permitir a descrição de dispositivos de maneira composta foi resolvida, fazendo com que a representação seja melhor estruturada, e conseqüentemente, permitindo que um número maior de aplicações utilizem o modelo proposto; b) a inconsistência gerada pela definição de diferentes valores a uma mesma funcionalidade em vocabulários diferentes foi resolvida por meio da obrigatoriedade de especificar novos itens no esquema XML, sendo que esses itens são restritos a um conjunto fixo de valores.

Além da representação, foram desenvolvidos métodos de captura automática e semiautomática das informações de contexto resolução do dispositivo e largura de banda, respectivamente. Mostrou-se como essas informações podem ser processadas de modo a especificar automaticamente a melhor configuração do vídeo para o acesso por determinado dispositivo e condição de rede.

O sistema de adaptação de vídeo ao vivo, desenvolvido utilizando-se ferramentas de código-aberto disponíveis na literatura, permite a sua implantação com o mínimo de custo 
em software, havendo apenas a necessidade de máquinas capazes de realizar a recodificação e atendimento aos clientes. A interface de acesso, a qual foi implementada com enfoque para aplicações de captura e acesso em salas de aula, permite a recodificação automática, e facilita a sua integração com outras aplicações existentes. Além disso, por meio dela, o usuário pode configurar rapidamente o vídeo a ser capturado, e outros usuários podem acessar o conteúdo original ou modificado de acordo com a situação atual do sistema.

A análise do atraso de recodificação realizada no sistema mostrou que, de fato, a recodificação impõe um atraso durante o acesso aos dados ao vivo. O atraso total medido foi de 1,496 segundos para o cenário 1 e 0,131 segundos para o cenário 2, dos quais apenas 0,035 segundos foram gastos com a recodificação. Por meio desse tempo gerado pelo recodificador, conclui-se que uma latência acumulativa de cerca de 0,002 segundos pode prejudicar o acesso em longo prazo. Estratégias alternativas para se reduzir o atraso foram propostas, de modo que o sistema de adaptação possa ser usado em aplicações com suporte à interatividade.

\subsection{Limitações}

Este trabalho apresenta as seguintes limitações:

- A captura da informação de contexto largura de banda é realizada com intervenção do usuário, o qual necessita ter instalado a aplicação cliente, desenvolvida com base na implementação de Ferreira \& Mello (2004) do modelo LogP (CULLER et al., 1993). Essa aplicação é necessária para que o usuário se conecte ao servidor, o qual irá calcular a largura de banda com base em troca de mensagens.

- A adaptação de vídeo do sistema é realizada de modo estático, ou seja, as informações de contexto largura de banda e resolução do dispositivo são capturadas apenas no momento do acesso ao vídeo pelo usuário. Desse modo, se a largura de banda for alterada após a recodificação ter sido inicializada, o recodificador não ajusta as configurações do vídeo sendo transmitido, havendo a necessidade de o usuário realizar nova requisição ao servidor.

- Informações de contexto relacionadas ao poder de processamento e capacidade de memória do dispositivo são importantes para se determinar em que nível de qualidade o vídeo poderá ser decodificado pelo dispositivo sem prejudicar o desempenho do mesmo. Apesar de o sistema proposto não capturar essas informações, a informação de contexto resolução do dispositivo pode contribuir indiretamente para se evitar esse problema. Como exemplo, a partir de baixas resoluções, que normalmente são configuradas em pocket pcs, pode-se inferir que o dispositivo utilizado contém baixo poder de processamento e capacidade de memória. No entanto, 
essa inferência nem sempre é verdadeira, pois computadores pessoais podem estar configurados a altas resoluções e serem compostos por processador e memória limitados.

\subsection{Trabalhos Futuros}

Com a conclusão do presente trabalho, algumas direções de trabalhos futuros foram identificadas. Um primeiro ponto a ser aprimorado no sistema é permitir a adaptação dinâmica de vídeo, de acordo com as oscilações da largura de banda durante a transmissão dos dados. Tal estratégia requer um mecanismo de ajuste automático da taxa de bits no recodificador, assim como medições periódicas da largura de banda no canal de comunicação. Utilizando-se, atualmente, a aplicação VLC como recodificador, o ajuste na taxa de bits só seria possível por meio da inicialização de uma nova tarefa de recodificação, contendo os novos valores. Essa limitação poderia ser sobreposta implementando-se um chaveamento dinâmico entre os vídeos recodificados. No entanto, o problema maior está na aplicação cliente do modelo $\log P$ (CULLER et al., 1993), o qual necessita intervenção do usuário para se conectar ao servidor para se determinar a largura de banda atual.

Um segundo ponto a ser aprimorado é desenvolver métodos de captura das informações de contexto poder de processamento e capacidade de memória. Essas informações poderiam ser coletadas por meio de scripts sendo executados no dispositivo do usuário, implementados, por exemplo, em JavaScript. Uma vez adquiridas essas informações, um algoritmo para processamento de todas as informações de contexto disponíveis se faz necessário, de modo que a nova configuração do vídeo adaptado seja especificada.

Um terceiro ponto identificado como trabalho futuro é o aprimoramento da interface de acesso, de modo que questões de segurança e robustez sejam consideradas em seu desenvolvimento. Adicionalmente, pretende-se integrar o sistema com aplicações já existentes, tal como o iClass (CATTELAN et al., 2003); essa integração deverá ser realizada por meio da implementação de um módulo de sincronização entre as aplicações, e ajustes na interface de acesso desenvolvida.

Um quarto ponto a ser considerado como trabalho futuro é a avaliação de desempenho com base no número de tarefas de recodificação realizadas ao mesmo tempo pelo recodificador. Questões como a carga máxima suportada pelo recodificador, a latência provocada pelos acessos simultâneos e desempenho do servidor deverão ser esclarecidas com essa avaliação.

O último ponto que poderá ser explorado a partir deste trabalho é o suporte a vídeo interativo. Uma vez que o formato de codificação é MPEG-4, o qual especifica meios de se interagir com objetos de vídeo, seria possível realizar a adaptação com base na personalização de conteúdo, o qual conteria funcionalidades de interação disponíveis para o usuário. No entanto, as estratégias propostas pela análise do sistema, com o objetivo 
de diminuir a latência durante o acesso ao vivo, deverão ser consideradas e estudadas. 


\section{Anexo A}

Este anexo apresenta todas as medições realizadas no sistema de adaptação, cujas médias calculadas foram utilizadas no capítulo cinco.

Tabela A1: Medições realizadas no cenário 1.

\begin{tabular}{|l|l|l|l|l|l|l|}
\hline Teste & $P_{1}$ & $P_{1}^{\prime}$ & $\Delta R^{\prime}$ & $\Delta R_{c p u}^{\prime}$ & $\Delta R_{i / o}^{\prime}$ & $\alpha$ \\
\hline $\mathbf{1}$ & 1,875 & 3,536 & 39,477 & 12,120 & 27,357 & 1119 \\
\hline $\mathbf{2}$ & 1,938 & 3,396 & 39,548 & 12,280 & 27,268 & 1113 \\
\hline $\mathbf{3}$ & 1,921 & 3,506 & 39,643 & 12,200 & 27,443 & 1119 \\
\hline $\mathbf{4}$ & 1,907 & 3,500 & 39,218 & 12,110 & 27,108 & 1119 \\
\hline $\mathbf{5}$ & 1,871 & 3,495 & 39,095 & 11,960 & 27,135 & 1119 \\
\hline $\mathbf{6}$ & 1,953 & 3,153 & 39,109 & 11,990 & 27,119 & 1119 \\
\hline $\mathbf{7}$ & 1,937 & 3,556 & 39,540 & 12,190 & 27,350 & 1119 \\
\hline $\mathbf{8}$ & 1,922 & 3,448 & 39,258 & 12,130 & 27,128 & 1119 \\
\hline $\mathbf{9}$ & 1,948 & 3,249 & 39,452 & 12,260 & 27,192 & 1113 \\
\hline $\mathbf{1 0}$ & 1,922 & 3,391 & 39,444 & 12,310 & 27,134 & 1119 \\
\hline $\mathbf{1 1}$ & 1,896 & 3,549 & 39,154 & 11,940 & 27,214 & 1113 \\
\hline $\mathbf{1 2}$ & 1,921 & 3,406 & 39,442 & 12,180 & 27,262 & 1113 \\
\hline $\mathbf{1 3}$ & 1,922 & 3,061 & 39,321 & 12,200 & 27,121 & 1113 \\
\hline $\mathbf{1 4}$ & 1,947 & 3,468 & 39,397 & 12,380 & 27,017 & 1119 \\
\hline $\mathbf{1 5}$ & 1,922 & 3,469 & 39,303 & 12,160 & 27,143 & 1113 \\
\hline $\mathbf{1 6}$ & 1,923 & 3,391 & 39,558 & 12,210 & 27,348 & 1119 \\
\hline $\mathbf{1 7}$ & 1,938 & 3,433 & 39,276 & 12,120 & 27,156 & 1113 \\
\hline $\mathbf{1 8}$ & 1,922 & 3,447 & 39,292 & 12,180 & 27,112 & 1119 \\
\hline $\mathbf{1 9}$ & 1,938 & 3,399 & 39,101 & 12,080 & 27,021 & 1113 \\
\hline $\mathbf{2 0}$ & 1,937 & 3,471 & 39,370 & 12,240 & 27,130 & 1119 \\
\hline $\mathbf{2 1}$ & 2,002 & 3,386 & 39,366 & 12,380 & 26,986 & 1107 \\
\hline $\mathbf{2 2}$ & 1,926 & 3,390 & 39,397 & 12,160 & 27,237 & 1119 \\
\hline $\mathbf{2 3}$ & 1,906 & 3,244 & 39,208 & 12,090 & 27,118 & 1113 \\
\hline $\mathbf{2 4}$ & 1,915 & 3,397 & 39,441 & 12,290 & 27,151 & 1113 \\
\hline $\mathbf{2 5}$ & 1,922 & 3,636 & 39,492 & 12,350 & 27,142 & 1113 \\
\hline $\mathbf{2 6}$ & 1,969 & 3,368 & 39,336 & 12,170 & 27,166 & 1119 \\
\hline $\mathbf{2 7}$ & 1,907 & 3,422 & 39,473 & 12,360 & 27,113 & 1113 \\
\hline $\mathbf{2 8}$ & 1,918 & 3,463 & 39,448 & 12,290 & 27,158 & 1113 \\
\hline $\mathbf{2 9}$ & 1,938 & 3,480 & 39,250 & 12,140 & 27,110 & 1119 \\
\hline $\mathbf{3 0}$ & 1,937 & 3,594 & 39,403 & 12,250 & 27,153 & 1134 \\
\hline Média & 1,927 & 3,423 & 39,360 & 12,191 & 27,170 & 1116,5 \\
\hline Vari- & 0,001 & 0,015 & 0,021 & 0,013 & 0,011 & 22,4 \\
$\mathbf{a n c i a}$ & & & & & & \\
\hline $\mathbf{D e s v i o}$ & 0,031 & 0,122 & 0,145 & 0,114 & 0,105 & 4,732 \\
$\mathbf{P a d r a ̃ o}$ & & & & & & \\
\hline & & & & & & \\
\hline
\end{tabular}


Tabela A2: Medições realizadas no cenário 2.

\begin{tabular}{|c|c|c|c|c|c|c|c|c|c|}
\hline Teste & $P_{2}$ & $\Delta R$ & $\Delta R_{c p u}$ & $\Delta R_{i / o}$ & $P_{2}^{\prime}$ & $\Delta R^{\prime}$ & $\Delta R_{c p u}^{\prime}$ & $\Delta R_{i / o}^{\prime}$ & $\alpha$ \\
\hline 1 & 2,772 & 39,206 & 1,230 & 37,976 & 2,753 & 39,575 & 9,850 & 29,725 & 1113 \\
\hline 2 & 2,989 & 39,332 & 1,140 & 38,192 & 2,913 & 39,207 & 9,730 & 29,477 & 1113 \\
\hline 3 & 2,782 & 39,442 & 1,240 & 38,202 & 2,800 & 39,272 & 9,750 & 29,522 & 1113 \\
\hline 4 & 2,709 & 39,176 & 1,260 & 37,916 & 2,770 & 39,178 & 9,800 & 29,378 & 1119 \\
\hline 5 & 2,771 & 39,300 & 1,230 & 38,070 & 2,250 & 39,616 & 9,790 & 29,826 & 1113 \\
\hline 6 & 2,813 & 39,342 & 1,290 & 38,052 & 3,047 & 39,181 & 9,800 & 29,381 & 1105 \\
\hline 7 & 2,688 & 39,069 & 1,220 & 37,849 & 2,875 & 39,444 & 9,840 & 29,604 & 1119 \\
\hline 8 & 2,766 & 38,974 & 1,280 & 37,694 & 2,871 & 39,339 & 9,730 & 29,609 & 1106 \\
\hline 9 & 2,716 & 39,560 & 1,290 & 38,270 & 2,828 & 39,484 & 9,840 & 29,644 & 1119 \\
\hline 10 & 2,782 & 39,341 & 1,190 & 38,151 & 2,904 & 39,385 & 9,850 & 29,535 & 1119 \\
\hline 11 & 2,823 & 39,408 & 1,210 & 38,198 & 2,922 & 39,102 & 9,750 & 29,352 & 1119 \\
\hline 12 & 2,750 & 39,609 & 1,250 & 38,359 & 3,094 & 39,342 & 9,760 & 29,582 & 1119 \\
\hline 13 & 2,797 & 38,971 & 1,250 & 37,721 & 3,025 & 39,181 & 9,760 & 29,421 & 1119 \\
\hline 14 & 2,750 & 39,597 & 1,190 & 38,407 & 3,031 & 39,045 & 9,690 & 29,355 & 1119 \\
\hline 15 & 2,812 & 39,473 & 1,170 & 38,303 & 2,843 & 39,304 & 9,730 & 29,574 & 1119 \\
\hline 16 & 2,688 & 39,264 & 1,200 & 38,064 & 3,047 & 39,361 & 9,770 & 29,591 & 1113 \\
\hline 17 & 2,754 & 39,173 & 1,250 & 37,923 & 2,823 & 39,181 & 9,690 & 29,491 & 1113 \\
\hline 18 & 2,708 & 39,393 & 1,310 & 38,083 & 2,730 & 39,451 & 9,780 & 29,671 & 1119 \\
\hline 19 & 2,832 & 39,237 & 1,150 & 38,087 & 2,906 & 39,148 & 9,770 & 29,378 & 1113 \\
\hline 20 & 2,797 & 39,440 & 1,220 & 38,220 & 2,902 & 39,339 & 9,660 & 29,679 & 1119 \\
\hline 21 & 2,257 & 39,135 & 1,240 & 37,895 & 2,922 & 39,208 & 9,700 & 29,508 & 1119 \\
\hline 22 & 2,766 & 39,201 & 1,180 & 38,021 & 3,028 & 39,209 & 9,710 & 29,499 & 1119 \\
\hline 23 & 2,786 & 39,295 & 1,300 & 37,995 & 3,031 & 39,609 & 9,780 & 29,829 & 1119 \\
\hline 24 & 2,819 & 39,199 & 1,230 & 37,969 & 3,096 & 39,179 & 9,770 & 29,409 & 1126 \\
\hline 25 & 2,667 & 39,437 & 1,240 & 38,197 & 3,019 & 39,177 & 9,690 & 29,487 & 1113 \\
\hline 26 & 2,859 & 39,564 & 1,290 & 38,274 & 3,000 & 39,346 & 9,690 & 29,656 & 1119 \\
\hline 27 & 2,718 & 39,099 & 1,340 & 37,759 & 2,703 & 39,508 & 9,850 & 29,658 & 1113 \\
\hline 28 & 2,912 & 39,479 & 1,260 & 38,219 & 2,812 & 39,371 & 9,820 & 29,551 & 1119 \\
\hline 29 & 2,645 & 39,137 & 1,360 & 37,777 & 2,875 & 39,448 & 9,820 & 29,628 & 1113 \\
\hline 30 & 2,838 & 39,205 & 1,250 & 37,955 & 2,890 & 39,150 & 9,690 & 29,460 & 1126 \\
\hline Média & 2,759 & 39,302 & 1,242 & 38,060 & 2,890 & 39,311 & 9,762 & 29,549 & 1116,57 \\
\hline $\begin{array}{l}\text { Vari- } \\
\text { ância }\end{array}$ & 0,014 & 0,031 & 0,003 & 0,036 & 0,027 & 0,024 & 0,003 & 0,017 & 22,25 \\
\hline $\begin{array}{l}\text { Desvio } \\
\text { Padrão }\end{array}$ & 0,118 & 0,176 & 0,055 & 0,190 & 0,164 & 0,155 & 0,055 & 0,130 & 4,716 \\
\hline
\end{tabular}




\section{Anexo B}

Este anexo apresenta os resumos dos artigos publicados e submetidos durante o desenvolvimento deste trabalho:

Artigo 1: "Device Descriptions for Context-Based Content Adaptation".

Abstract: Nowadays, networks can be accessed by multiple devices with different characteristics. Some of these characteristics such as low processing power and memory capacity restrict the access to multimedia content. Researchers have then focused on making automatic system adaptations in order to present content according to devices' capabilities. Most of the works on this area include the description of hardware and software devices' features using the $\mathrm{CC} / \mathrm{PP}$ specification. However, the indiscriminate and direct use of $\mathrm{CC} / \mathrm{PP}$ makes it difficult to generate consistent descriptions when using the same device into different contexts. The novel of this paper is an alternative method to describe devices' features. This method aims to facilitate context-based content adaptation decisions to be made before content delivery. This paper also presents an application for content adaptation that uses our method.

Referência: EISINGER, R.; MANZATO, M. G.; GOULARTE, R. Device Descriptions for Context-Based Content Adaptation. In: LATIN AMERICAN WEB CONGRESS (LA-WEB). 2005, Buenos Aires. Proceedings. Los Alamitos: IEEE, 2005, p. 121-129.

Artigo 2: "Live Video Adaptation: A Context-Aware Approach".

Abstract: Nowadays, networks can be accessed by multiple devices with different characteristics. Some of these characteristics, such as low processing power and memory capability, restrict the access to multimedia content. Researchers have then focused on developing automatic content adaptations in order to present the data according to devices' capabilities. One method that can be used to achieve content adaptation is the transcoding model. This paper presents a method of exploring context-aware computing in order to adapt video content in a way to be successfully accessed by users with different devices capabilities. It also presents an implementation of the transcoding model using efficient open source tools available in the literature. Finally, the adaptation mechanism is applied in the iClass system, a capture \& access application used in lectures.

Referência: MANZATO, M. G.; GOULARTE, R. Live Video Adaptation: A ContextAware Approach. In: BRAZILLIAN SYMPOSIUM ON MULTIMEDIA AND THE WEB (WEBMEDIA). 11., 2005, P. Caldas. Proceedings. N. York: ACM Press, 2005, p. 1-8.

Artigo 3: "Captura e Transmissão de Vídeo em Sistemas Ubíquos". 
Resumo: A utilização de vídeo e áudio em sistemas multimídia e/ou ubíquos tem facilitado a visualização e assimilação de informação por parte dos usuários. Um exemplo é o iClass, um sistema de captura e acesso a dados produzidos em salas de aula, que realiza a captura, transmissão, armazenamento e acesso a vídeo, áudio, slides e anotações produzidas pelo professor. No entanto, é necessário que o professor finalize a sessão de captura para que vídeo e áudio sejam disponibilizados para o acesso. Além disso, a utilização de diferentes tipos de dispositivos pode prejudicar o acesso, uma vez que dados multimídia geralmente são projetados para serem acessados por computadores pessoais. O propósito do trabalho é fornecer métodos alternativos de captura, transmissão, processamento e armazenamento de vídeo e áudio de modo que esses dados possam ser acessados pelos alunos em tempo real. Além disso, o trabalho visa também o desenvolvimento de métodos de adaptação de conteúdo com base em informações de contexto provenientes do sistema computacional.

Referência: MANZATO, M. G.; GOULARTE, R. Captura e Transmissão de Vídeo em Sistemas Ubíquos. In: SIMPÓSIO BRASILEIRO DE SISTEMAS MULTIMÍDIA E WEB (WEBMÍDIA), 11., 2005, P. Caldas. Anais. P. Alegre: SBC, 2005, p. 245-248.

Artigo 4: "Transcoding Evaluation in Live Video Adaptation".

Abstract: The video adaptation has been developed as the objective to enable the access by devices with limitant characteristics. One way to adapt the video is the transcoding technique, which can be applied in a large range of applications. However, it is known that the transcoding process has a high computational cost, which it is thought to be the main generator of delay. In this paper we present a transcoding evaluation in live video adaptation. As a result, the measures obtained can help researchers and developers to choose the best adaptation mechanism or system archietacture for their specific applications.

Referência: MANZATO, M. G.; GOULARTE, R. Transcoding Evaluation in Live Video Adaptation. In: LATIN AMERICAN WEB CONGRESS (LA-WEB). 2006, Puebla/Cholula. Proceedings. (to appear). 


\section{Referências Bibliográficas}

ABOWD, G. D.; MYNATT, E. D. Charting Past, Present, and Future Research in Ubiquitous Computing. ACM Transactions on Conputer-Human Interaction, v. 7, n. 1, p. 29-58, 2000.

ABOWD, G. D.; MYNATT, E. D.; RODDEN, T. The Human Experience. IEEE Pervasive Computing, v. 1, n. 1, p. 48-57, 2002.

AHMAD, I. et al. Video Transcoding: An Overview of Various Techniques and Research Issues. IEEE Transactions on Multimedia, v. 7, n. 5, p. 793-804, 2005.

ANDREOPOULOS, Y. et al. Fully-Scalable Wavelet Video Coding Using In-Band Motion Compensated Temporal Filtering. In: IEEE INTERNATIONAL CONFERENCE ON ACCOUSTICS, SPEECH AND SIGNAL PROCESSING. 2003, [S.l.]. Proceedings. [S.l.: s.n.], 2003. p. 417-420.

ARRUDA JÚNIOR, C. R. E. Context Kernel: Um Web Service Baseado nas Dimensões de Informação de Contexto. 85p p. Dissertação (Mestrado) - ICMC-USP, São Carlos, 2003.

ASSUNÇÃO, P. A. A.; GHANBARI, M. A Frequency-Domain Video Transcoder for Dynamic Bitrate Duction of MPEG-2 Bit Streams. IEEE Transactions on Circuits and Systems for Video Technology, v. 8, n. 8, p. 953-967, 1998.

BJORK, N.; CHRISTOPOULOS, C. Transcoder Architecture for Video Coding. IEEE Transactions on Consumer Eletronics, v. 44, p. 88-98, 1998.

BROWN, P. J. Triggering Information by Context. Personal Technologies, v. 2, n. 1, p. 1-9, 1998.

BROWN, P. J.; BOVEY, J. D.; CHEN, X. Context-Aware Applications: From the Laboratory to the Marketplace. IEEE Personal Communications, v. 4, n. 5, p. 58-64, 1997.

BUTLER, M. H. CC/PP and UAProf: Issues, Improvements and Future Directions. W3C Workshop on Delivery Context, Hewlett-Packard, Sophia-Antipolis, 2002.

CATTELAN, R. G. et al. iClass: Um sistema para captura e acesso de sessões em ambiente educacional. Revista Eletrônica de Iniciação Científica da Sociedade Brasileira de Computação (REIC-SBC), 19p, Março 2003. 
CHALMERS, D. Contextual Mediation to Support Ubiquitous Computing. Tese (Doutorado) - Imperial College of Science, Technology and Medicine-London University, Londres, 2002.

CHEN, H.; FININ, T. An Ontology for Context-Aware Pervasive Computing Environments. Workshop on Ontologies and Distributed Systems, Acapulco, 2003.

CHEN, H.; FININ, T.; JOSHI, A. Semantic Web in Pervasive Context-Aware Architecture. Artificial Intelligence in Mobile Systems, Seattle, p. 33-40, 2003.

CHEN, M. J.; CHU, M. C.; PAN, C. W. Efficient Motion-Estimator Algorithm for Reduced Frame-Rate Video Transcoder. IEEE Transactions on Circuits and Systems for Video Technology, v. 12, n. 4, p. 269-275, 2002.

CHEOK, A. D. et al. Touch-Space: Mixed Reality Game Space Based on Ubiquitous, Tangible, and Social Computing. Personal and Ubiquitous Computing, Springer-Verlag London, v. 6, n. 5-6, p. 430-442, 2002.

CONKLIN, G. J. et al. Video Coding for Streaming Media Delivery on the Internet. IEEE Transactions on Circuits and Systems for Video Technology, v. 11, n. 3, p. 269-281, 2001.

CROWLEY, J. L. et al. Perceptual Components for Context Aware Computing. In: BORRIELO, G.; HOLMQUIST, L. E. UbiComp 2002: Ubiquitous Computing. Heidelberg: Springer-Verlag Berlin, 2002. p. 117-134. (Lecture Notes in Computer Science, 2498).

CULLER, D. et al. LogP Performance Assessment of Fast Network Interfaces. IEEE Micro, 1996.

CULLER, D. E. et al. LogP: Towards a Realistic Model of Parallel Computation. In: ACM SIGPLAN SYMPOSIUM ON PRINCIPLES AND PRACTICE OF PARALLEL PROGRAMming. 4., 1993, San Diego. Proceedings. N. York: ACM Press, 1993.

DEY, A. Undersating and Using Context. Personal and Ubiquitous Computing Journal, v. 1, n. 5, p. $4-7,2001$.

DEY, A. K.; ABOWD, G. D. Towards a Better Understanding of Context and Context-Awareness. Atlanta, 1999. (Relatório Técnico).

DIX, A. et al. Exploring Space and Location as a Design Framework for Interactive Mobile Systems. ACM Transactions on Computer-Human Interaction, v. 7, n. 3, p. 285-321, 2000.

DOGAN, S. et al. Error-Resilient Video Transcoding for Robust Internetwork Communications Using GPRS. IEEE Transactions on Circuits and Systems for Video Technology, v. 12, n. 6, p. 453-464, 2002.

DOGAN, S. et al. Video Content Adaptation Using Transcoding for Enabling UMA over UMTS. 5th International Workshop on Image Analysis for Multimedia Interactive Services, Lisboa, 2004. 
EISINGER, R.; MANZATO, M. G.; GOULARTE, R. Device Descriptions for ContextBased Content Adaptation. In: LATIN AMERICAN WEB CONGRESS (LA-WEB). 2005, Buenos Aires. Proceedings. Los Alamitos: IEEE, 2005. p. 121-129.

ELLIS, D. P. W.; LEE, K. Minimal-Impact Audio-Based Personal Archives and Retrieval of Personal Experiences. In: ACM WORKSHOP ON CONTINUOUS ARCHIVAL. 1., 2004, [S.l.]. Proceedings. N. York: ACM Press, 2004. p. 39-47.

FERREIRA, E. A.; MELLO, R. F. Avaliação de Desempenho de Protocolos e Bibliotecas de Comunicação entre Processos. In: INTERNATIONAL INFORMATION AND TECHNOLOGIES SYMPOSIUM. 3., 2004, S. Carlos. Proceedings. Upper Saddle River: [s.n.], 2004.

FIELDING, R. et al. Hypertext Transfer Protocol - HTTP/1.1. Network Working Group, RFC 2616, Junho de 1999.

GOULARTE, R. Personalização e adaptação de conteúdo baseadas em contexto para TV Interativa. Tese (Doutorado) - ICMC-USP, São Carlos, 2003.

GOUlARTE, R.; PIMENTEL, M. G. C.; MOREIRA, E. S. Context-Aware Support in Structured Documents for Interactive-TV. Multimedia Systems, v. 11, n. 4, p. 367-382, 2006.

HANDLEY, M.; JACOBSON, V. SDP: Session Description Protocol. Internet Engineering Task Force, RFC 2327, Abril de 1998.

HARTER, A. et al. The Aanatomy of a Context-Aaware Application. In: ACM/IEEE INTERNATIONAL CONFERENCE ON MOBILE COMPUTING AND NETWORKING. 5., 1999, Seatle. Proceedings. N. York: ACM, 1999. p. 59-68.

HELAL, S. et al. The Gator Tech Smart House: A Programmable Pervasive Space. Computer, IEEE Computer Society, v. 38, n. 3, p. 50-60, 2005.

HORN, U.; GIROD, B. Scalable Video Transmission for the Internet. Computer Networks and ISDN Systems, v. 29, n. 15, p. 1833-1842, 1997.

HULL, R.; NEAVES, P.; BEDFORD-ROBERTS, J. Towards Situated Computing. In: IEEE INTERNATIONAL SYMPOSIUM ON WEARABLE COMPUTERS. 1., 1997, Cambridge. Proceedings. Los Alamitos: IEEE, 1997. p. 146-153.

HWANG, J. N.; WU, T. D. Motion Vectior Re-Estimation and Dynamic Frame-Skipping for Video Transcoding. Conference on Signals, System $\&$ Computer, v. 2, p. 1606-1610, 1998.

INDULSKA, J. et al. Experiences in Using CC/PP in Context-Aware Systems. In: INTERNATIONAL CONFERENCE ON MOBILE DATA MANAGEMENT. 4., 2003, Melbourne. Proceedings. Heidelberg: Springer-Verlag, 2003. p. 247-261. (Lecture Notes in Computer Science, 2574).

ITU-T RECOMENDATION G.114. One-Way Transmission Time. 1996.

KEESMAN, G. et al. Transcoding of MPEG bitstreams. Signal Processing: Image Communication, v. 8, n. 6, p. 481-500, 1996. 
KIM, T.; AMMAR, M. H. Optimal Quality Adaptation for MPEG-4 Fine-Grained Scalable Video. 22nd IEEE Infocom, p. 641-651, 2003.

KINDBERG, T. et al. People, Space, Things: Web Presence for the Real World. In: IEEE WORKSHOP ON MOBILE COMPUTING SYSTEMS AND APPLICATIONS. 3., 2000, Monterey. Proceedings. Los Alamitos: IEEE, 2000. p. 19-30.

KORTEUM, G.; SEGSLL, Z.; BAUER, M. Context-Aware, Adaptive Wearable Computers as Remote Interfaces to "Intelligent" Environments. In: IEEE INTERNATIONAL SYMPOSIUM ON WEARABLE COMPUTERS. 2., 1998, Pittsburgh. Proceedings. Los Alamitos: IEEE, 1998. p. 58-65.

LEMLOUMA, T.; LAYAIDA, N. SMIL Content Adaptation for Embebbed Devices. SMIL Europe 2003, 2003.

LI, W. Overview of Fine Granularity Scalability in MPEG-4 Video Standard. IEEE Transactions on Circuits Systems Video Technology, v. 11, n. 3, p. 301-317, 2001.

LIPPMAN, A. Video coding for multiple target audiences. In: T/SPIE CONFERENCE ON VISUAL COMMUNICATIONS AND IMAGE PROCESSING. 1999, San Jose. Proceedings. [S.l.: s.n.], 1999. p. 780-784.

LIU, J.; LI, B.; ZHANG, Y. Q. Adaptive Video Multicast Over the Internet. IEEE Multimedia, v. 10, n. 1, p. 22-33, 2003.

LIU, J.; LI, B.; ZHANG, Y. Q. An End-to-End Adaptation Protocol for Layered Video Multicast Using Optimal Rate Allocation. IEEE Transactions on Multimedia, v. 6, n. 1, p. 87-102, 2004.

LORENZEN, J. Darwin Streaming Server: Open, Functional and Free. 2001. Disponível em: <http://www.streamingmedia.com/article.asp?id=7705\&c=6>. Acesso em: Junho de 2006.

LUM, W. Y.; LAU, F. C. M. A Context-Aware Decision Engine for Context Adaptation. IEEE Pervasive Computing, v. 1, n. 3, p. 41-49, 2002.

MAnZATO, M. G.; GOUlARTE, R. Live Video Adaptation: A Context-Aware Approach. In: BRAZILLIAN SYMPOSIUM ON MULTIMEDIA AND THE WEB (WEBMEDIA). 11., 2005, P. Caldas. Proceedings. N. York: ACM Press, 2005. p. 1-8.

MAYER, R. E. Multimedia Learning. [S.1.]: Cambridge University Press, 2001.

MOHAN, R.; SMITH, J. R.; LI, C. S. Adapting Multimedia Internet Content for Uuniversal Access. IEEE Transactions on Multimedia, v. 1, n. 1, p. 104-114, 1999.

OHM, J. R. Advances in Scalable Video Coding. IEEE, v. 93, n. 1, p. 42-56, 2005.

PASCOE, J. Adding Generic Contextual Capabilities to Wearable Computers. In: INTERNATIONAL SYMPOSIUM ON WEARABLE COMPUTERS. 2., 1998, Pittsburgh. Proceedings. Los Alamitos: IEEE, 1998. p. 92-99.

PASSANI, L.; TRASATTI, A. WURFL. 2002. Disponível em: $<$ http://wurfl.sourceforge.net/>. Acesso em: Abril de 2006. 
PENUSOPONE, K.; CHEN, X.; LING, F. Logo insertion in MPEG transcoder. In: IEEE INTERNATIONAL CONFERENCE ON ACCOUSTICS, SPEECH AND SIGNAL PROCESSING. 2001, [S.l.]. Proceedings. Salt Lake City: [s.n.], 2001. v. 2, p. 981-984.

REYES, G. D. L. et al. Error-Resilient Transcoding for Video Over Wireless Channels. IEEE J. Select. Areas Communication, v. 18, n. 6, p. 1063-1074, 2000.

SALBER, D.; DEY, A. K.; ABOWD, G. D. The Context Toolkit: Aiding the Development of Context-Enabled Applications. In: CONFERENCE ON HUMAN FACTORS AND COMPUTING SYSTEMS. 17., 1999, Pittsburgh. Proceedings. N. York: ACM, 1999. p. 434-441.

SAlBER, D. A.; DEY, A. K.; ABOWD, G. D. Ubiquitous Computing: Defining and HCI Research Agenda for an Emerging Interaction Paradigm. Atlanta, 1998. (Relatório Técnico).

SANTOS JÚNIOR, J. B. Modelagem de ambientes interativos conscientes de contexto: uma abordagem baseada nos padrões MPEG-4 e MPEG-7. Tese (Doutorado) ICMC-USP, São Carlos, 2002.

SANTOS JÚNIOR, J. B. et al. The Modeling of Structured Context-Aware Interactive Environments. Transactions of the SDPS - Journal of Integrated Design and Process Science, v. 5, n. 4, p. 77-93, 2001.

SCHILIT, B. N.; ADAMS, N.; WANT, R. Context-Aware Computing Applications. In: IEEE WORKSHOP ON MOBILE COMPUTING SYSTEMS AND APPLICATIONS. 1., 1994, Santa Cruz. Proceedings. Los Alamitos: IEEE, 1994. p. 85-90.

SCHILIT, B. N.; THEIMER, M. Disseminating Active Map Information to Mobile Hosts. IEEE Network, v. 8, n. 5, p. 22-32, 1994.

SCHILIT, W. N. A System Architecture for Context-Aware Mobile Computing. Tese (Doutorado) - Graduate School of Arts and Sciences-Columbia University, Columbia, 1995 .

SCHMIDT, A. et al. Advanced Interaction in Context. In: GELLERSEN, H. W. International Symposium on Handheld and Ubiquitous Computing. Heidelberg: Springer-Verlag Berlin, 1999. p. 89-101. (Lecture Notes in Computer Science, 1707).

SCHULZRINNE, H. et al. RTP: A Transport Protocol for Real-Time Applications. Internet Engineering Task Force, RFC 1889, Janeiro de 1996.

SCHULZRINNE, H.; RAO, A.; LANPHIER, R. Real Time Streaming Protocol (RTSP). Internet Engineering Task Force, RFC 2326, Abril de 1998.

SHANABLEH, T.; GHANBARI, M. Heterogeneous Video Transcoding to Lower Spatial-Temporal Resolutions and Different Encoding Formats. IEEE Transactions on Multimedia, v. 2, n. 2, p. 101-110, 2000.

SHEN, B.; SETHI, I. K.; VASUDEV, B. Adaptive Motion-Vector Resampling for Compressed Video Down Scaling. IEEE Transactions on Circuits and Systems for Video Technology, v. 9, n. 6, p. 929-936, 1999. 
STANDARDISATION, I. O. for. Short MPEG-2 Description. 2000. Disponível em: $<$ http://www.chiariglione.org/mpeg/standards/mpeg-2/mpeg-2.htm>. Acesso em: Abril de 2006.

STANDARDISATION, I. O. for. MPEG-4 Overview. 2002. Disponível em: $<$ http://www.chiariglione.org/mpeg/standards/mpeg-4/mpeg-4.htm $>$. Acesso em: Abril de 2006.

STANDARDISATION, I. O. for. MPEG-7 Overview. 2004. Disponível em: $<$ http://www.chiariglione.org/MPEG/standards/mpeg-7/mpeg-7.htm>. Acesso em: Maio de 2006.

SU, Y. C. Fine Granularity Video Compression Technique and Its Application to Robust Video Transmission over Wireless Internet. Tese (Doutorado) - Computer Science and Engineering, National Sun Yat-Sen University, 2003.

TAPIA, E. M.; INTILLE, S. S.; LARSON, K. Activity Recognition in the Home Using Simple and Ubiquitous Sensors. In: FERSCHA, A.; MATTERN, F. Pervasive Computing: Second International Conference, PERVASIVE 2004. Heidelberg: Springer-Verlag Berlin, 2004. p. 158-175. (Lecture Notes in Computer Science, 3001).

TRUONG, K.; ABOWD, G. INCA: A Software Infrastructure to Facilitate the Construction and Evolution of Ubiquitous Capture \& Access Applications. In: FERSCHA, A.; MATTERN, F. Pervasive Computing: Second International Conference, PERVASIVE 2004. Heidelberg: Springer-Verlag Berlin, 2004. p. 140-157. (Lecture Notes in Computer Science, 3001).

TRUONG, K.; ABOWD, G.; BROTHERTON, J. Who, What, When, Where, How: Design Issues of Capture \& Access Applications. International Conference on Ubiquitous Computing, p. 209-224, 2001.

Vetro, A.; CHRISTOPOUlOS, C.; SUN, H. Video Transcoding Architectures and Techniques: An Overview. IEEE Signal Processing Magazine, v. 20, n. 2, p. 18-29, 2003.

VIÉRON, J.; GUILLEMOT, C. M. Low-Rate FGS Video Coding Scheme Based on a Closed-Loop Motion-Compensated 2D+t Wavelet Decomposition. In: VISUAL COMMUNICATIONS AND IMAGE PROCESSING. 2003, [S.1.]. Proceedings. [S.l.: s.n.], 2003. p. $732-744$.

W3C. Composite Capabilities/Preferences Profile Public Home Page. 2000. Disponível em: <http://www.w3.org/Mobile/CCPP/>. Acesso em: Abril de 2006.

W3C. XML Schema Part 0: Primer Second Edition. 2004. Disponível em: <http://www.w3.org/TR/xmlschema-0/>. Acesso em: Abril de 2006.

WANG, Q. et al. Optimal Rate Allocation for Progressive Fine Granularity Scalable Video Coding. IEEE Signal Processing Letters, v. 9, n. 2, p. 33-39, 2002.

WANG, X. H. et al. Ontology Based Context Modeling and Reasoning Using OWL. In: WORKSHOP ON CONTEXT MODELING AND REASONING. 2004, Orlando. Proceedings. Los Alamitos: IEEE, 2004. 
WARD, A.; JONES, A.; HOPPER, A. A. A New Location Technique for the Active Office. IEEE Personal Communications, v. 4, n. 5, p. 42-47, 1997.

WEISER, M. The Computer of the 21st Century. Scientific American, v. 265, n. 3, p. 94-104, 1991.

WERNER, O. Requantization for Transcoding of MPEG-2 Intraframes. IEEE Transactions on Image Processing, v. 8, n. 2, p. 179-191, 1999.

WILKERSON, M.; GRISWOLD, G.; SIMON, B. Ubiquitous Presenter: Increasing Student Access and Control in a Digital Lecturing Environment. In: SIGCSE TECHNICAL SYMPOSIUM ON COMPUTER SCIENCE EDUCATION. 36., 2005, [S.l.]. Proceedings. St. Louis: ACM Press, 2005.

WU, D. et al. Streaming Video over the Internet: Approaches and Directions. IEEE Transactions on Circuits and Systems for Video Technology, v. 11, n. 3, p. 282-300, 2001.

XIN, J.; LIN, C. W.; SUN, M. T. Digital Video Transcoding. IEEE, v. 93, n. 1, p. 84-97, 2005 .

YOUN, J.; SUN, M. T.; LIN, C. W. Motion Vector Refinement for High-Performance Transcoding. IEEE Transactions on Multimedia, v. 1, n. 1, p. 30-40, 1999. 


\section{Apêndice A}

Este apêndice apresenta o código do esquema criado para representar informações de contexto relacionadas a dispositivos, conforme explicado na seção 4.4.

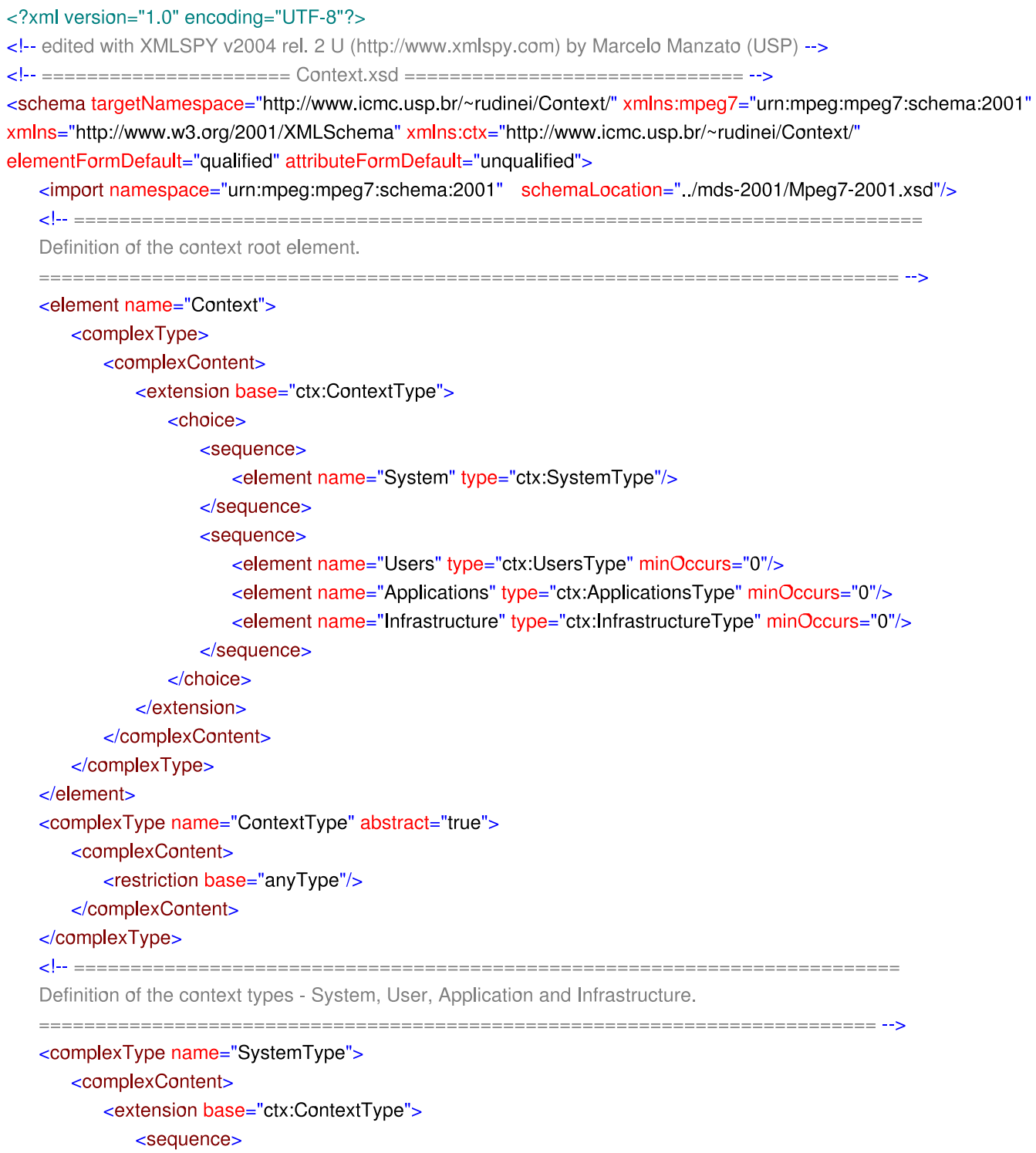




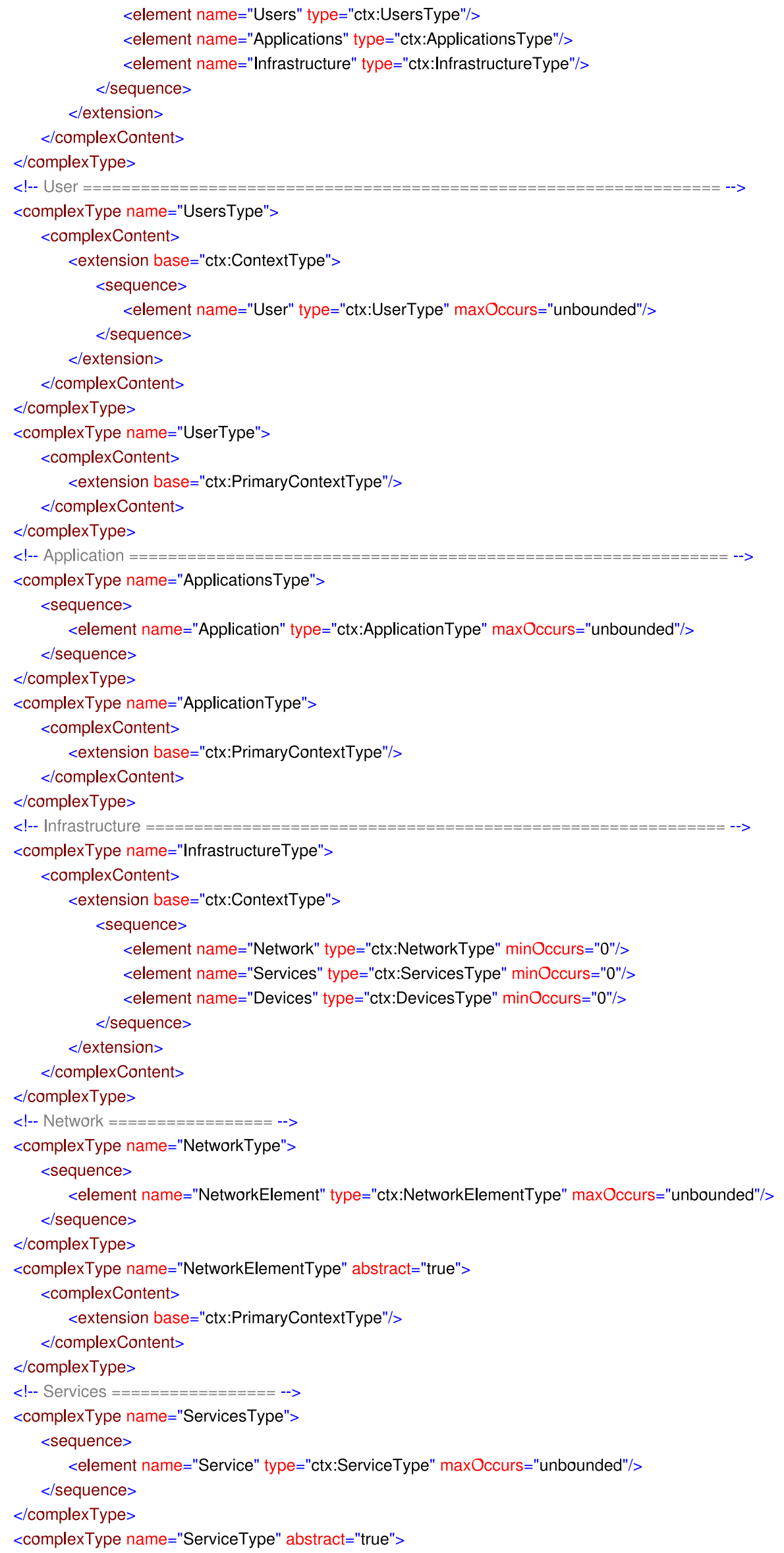




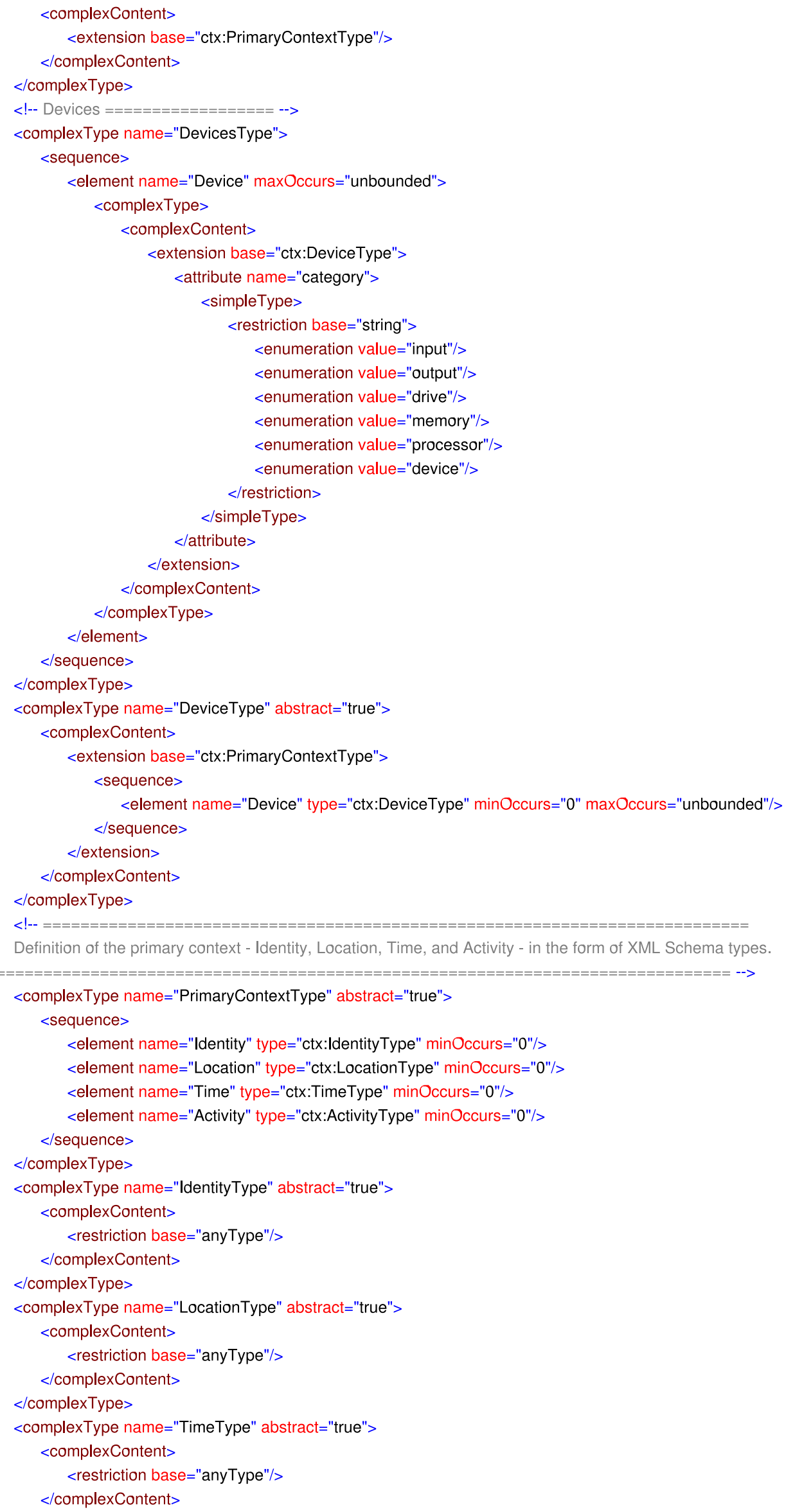




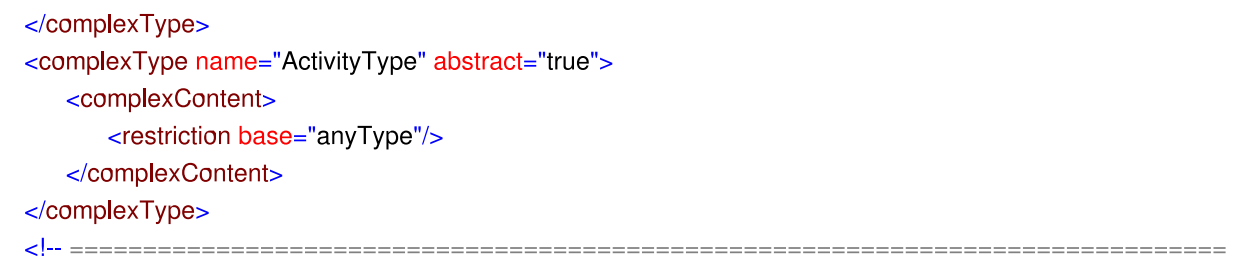

Examples of devices using the high level structures. These peices are used to characterize an entity.

Some are contrext library built-in, but users can write their own in a similar way.

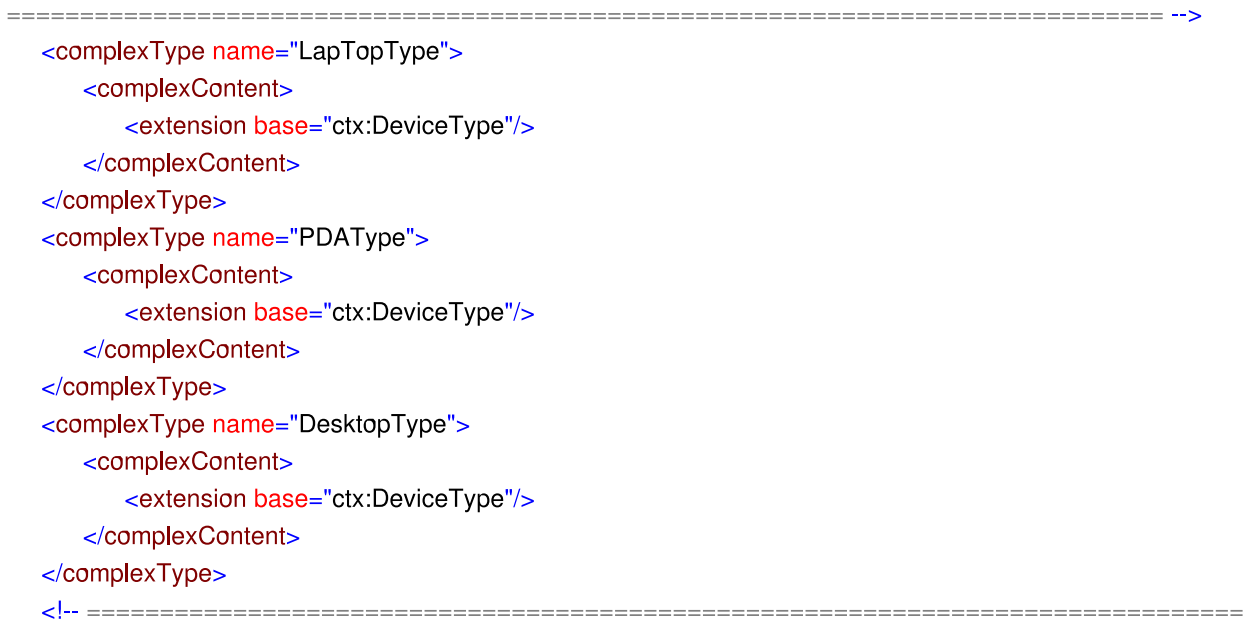

Examples of device's components using the high level structures. These peices are used to characterize an entity. Some are contrext library built-in, but users can write their own in a similar way.

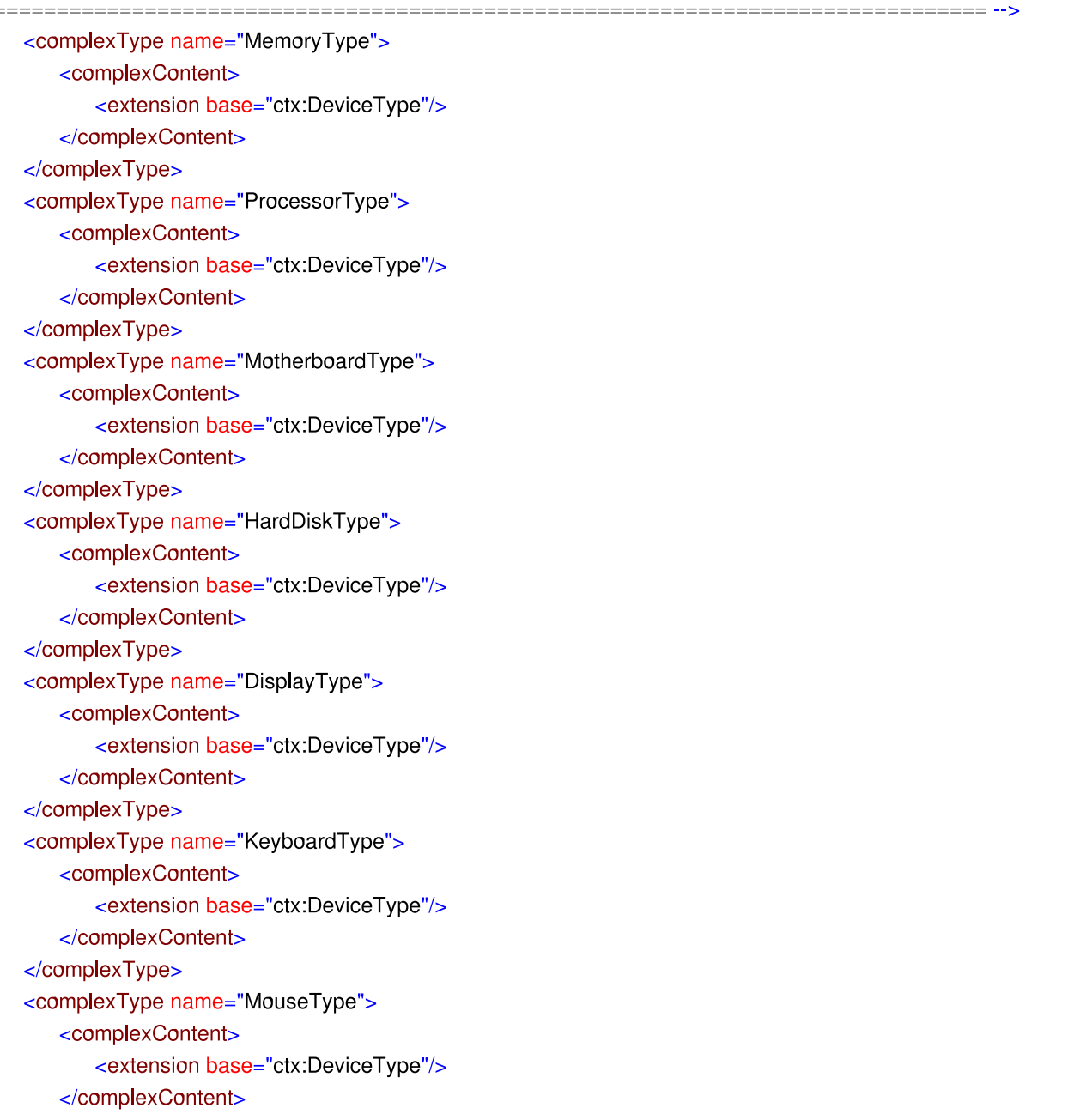




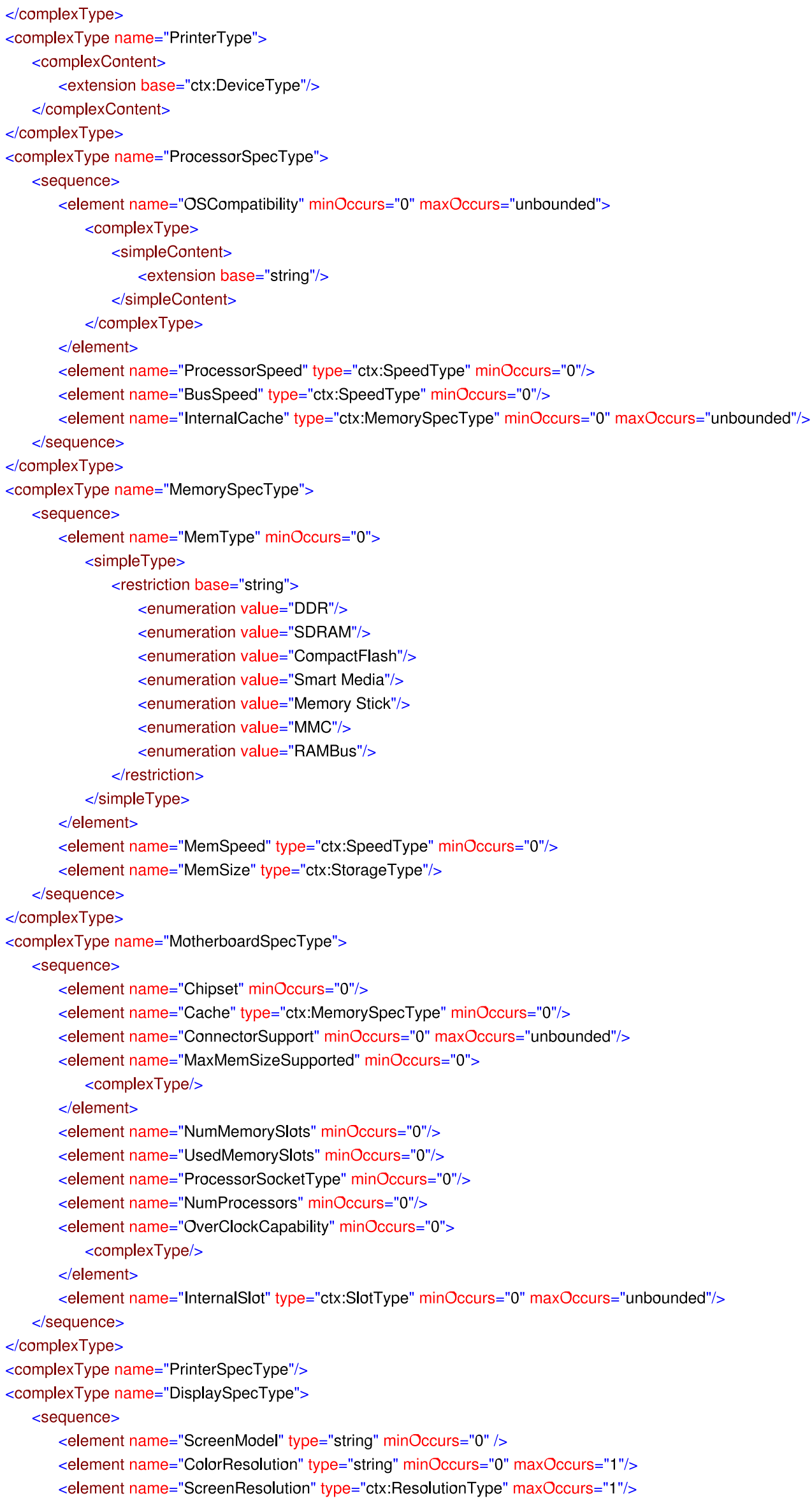


$<$ element name="ScreenSize" type="ctx:ResolutionType" minOccurs="0" /> <element name="MaxResolution" type="ctx:ResolutionType" minOccurs="0"/>

$<$ element name="Connector" minOccurs="0" maxOccurs="unbounded"/>

$<$ /sequences

$<$ complexType $>$

$<$ complexType name="HardDiskSpecType">

$<$ sequences

$<$ element name="Storage" type="ctx:StorageType" minOccurs="0"/>

$<$ element name="Speed" type="ctx:SpeedType" minOccurs="0"/>

$<$ element name="SeekTime" minOccurs="0">

$<$ complexType>

$<$ sequence>

$<$ element name="Scale">

$<$ simpleType>

$<$ restriction base="string">

$<$ enumeration value $=$ "seconds"/>

$<$ enumeration value $=$ "miliseconds" $/>$

$<$ enumeration value $=$ "microseconds"/>

$<$ enumeration value $=$ "minutes"/>

$<$ enumeration value="hours"/>

$<$ enumeration value $=$ "days" $/>$

$<$ restriction $>$

$<$ simpleType $>$

$<$ element>

$<$ element name="Time" type="string"/>

$</$ sequences

$<$ complexType $>$

$<$ element $>$

$<$ element name="Interface" type="ctx:InterfaceType" minOccurs="0"/>

$<$ element name="Type" minOccurs="0">

$<$ simpleType $>$

$<$ restriction base="string" $>$

$<$ enumeration value="internal"/>

$<$ enumeration value="external"/>

$<$ enumeration value="integrated"/>

$<$ restriction $>$

$<$ simpleType $>$

$<$ element>

$<$ element name="SMARTSupport" type="boolean" minOccurs="0"/>

$<$ /sequence $>$

$<$ complexType>

<complexType name="MouseSpecType">

<sequence>

$<$ element name="Connector" type="ctx:ConnectorType" minOccurs="0"/>

$<$ element name="Wireless" type="boolean" minOccurs="0"/>

$<$ element name="Scroll" type="boolean" minOccurs="0"/>

$<$ element name="NumButton" minOccurs="0"/>

$<$ element name="Type" minOccurs="0">

$<$ simpleType>

$<$ restriction base="string">

$<$ enumeration value $=$ "mechanical"/>

$<$ enumeration value $=$ "trackball" $/>$

$<$ enumeration value="optical"/>

$<$ enumeration value="integrated"/>

$<$ restriction $>$

$<$ simpleType $>$

$<$ /element>

$<$ /sequence $>$

$<$ complexType>

$<$ complexType name="KeyboardSpecType">

<sequence>

$<$ element name="KeyFormat" $>$

$<$ simpleType> 


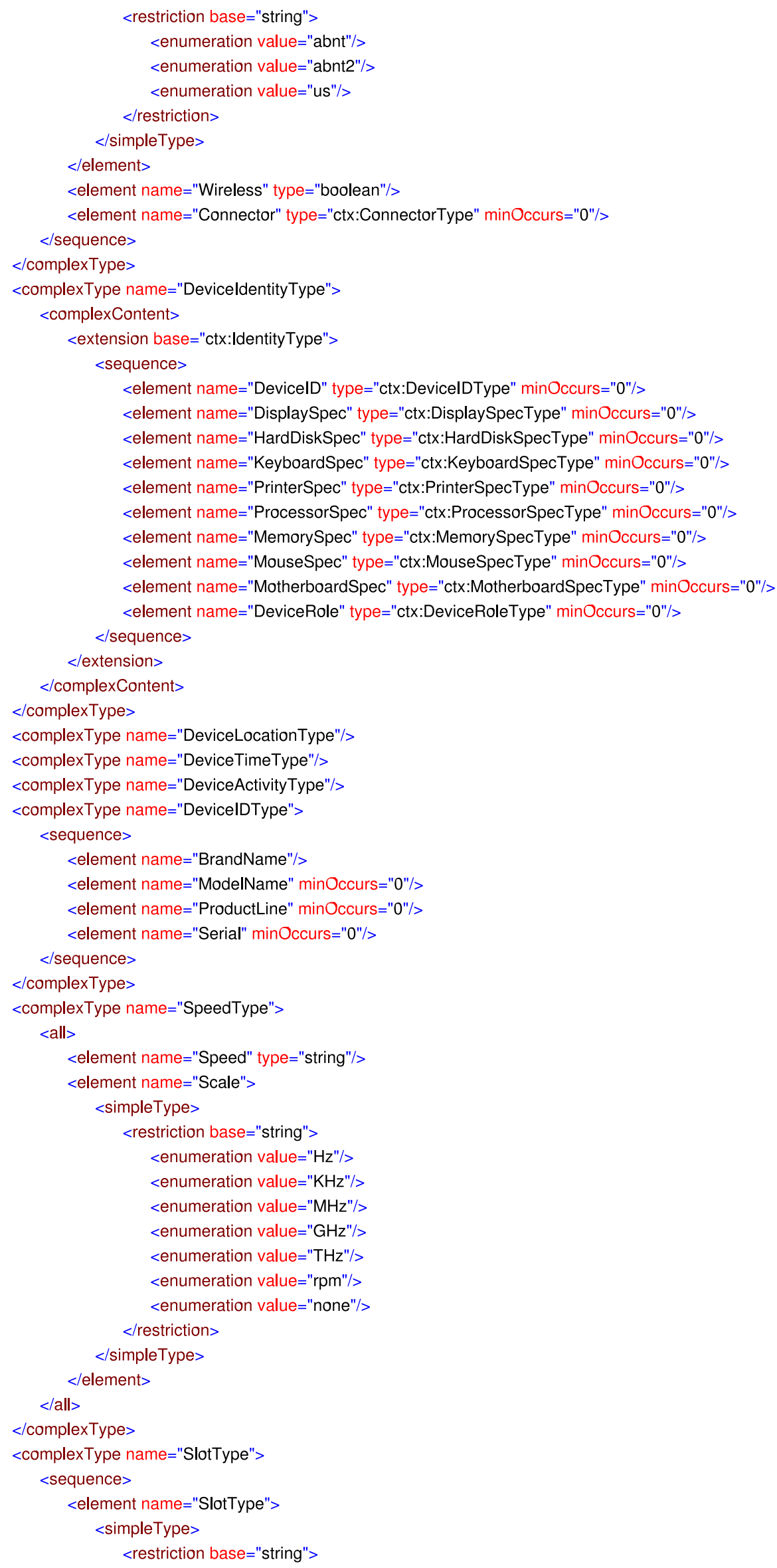




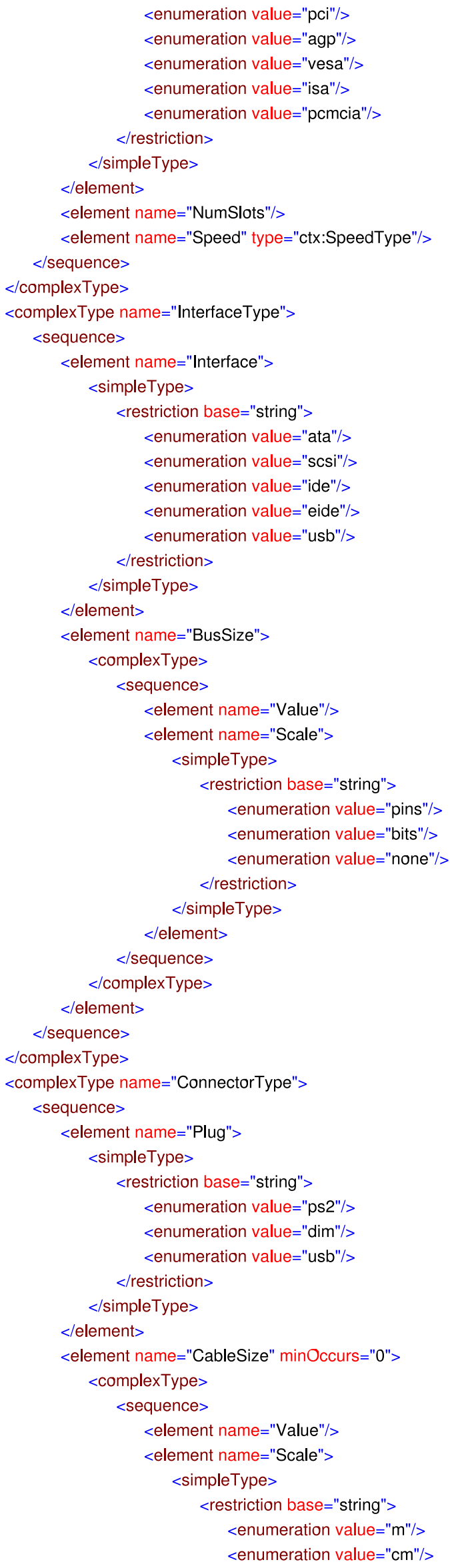


$<$ enumeration value="none"/>

$<$ restriction>

$<$ simpleType>

$<$ /element>

$</$ sequence $>$

$<$ <complexType>

$<$ element>

$<$ sequence $>$

$</$ complexType>

<complexType name="StorageType">

$<$ sequence>

$<$ element name="Size" type="string"/>

$<$ element name="Scale">

<simpleType>

$<$ restriction base="string">

$<$ enumeration value="byte"/>

$<$ enumeration value="Kbyte"/>

$<$ enumeration value="Mbyte"/>

$<$ enumeration value="Gbyte"/>

$<$ enumeration value="Tbyte"/>

$<$ enumeration value $=$ "minutes"/>

$<$ enumeration value="none"/>

$</$ restriction $>$

$<$ /simpleType $>$

$<$ /element>

$<$ /sequences

$<$ complexType $>$

$<$ complexType name="ResolutionType">

<sequence>

<element name="Width" type="string"/>

$<$ element name="Height" type="string"/>

$<$ /sequence $>$

$<$ complexType>

<simpleType name="DeviceRoleType">

$<$ restriction base="string">

$<$ enumeration value="server"/>

$<$ enumeration value $=$ "client"/>

$<$ enumeration value $=$ "intermediate" $/>$

$<$ restriction $>$

$<$ simpleType $>$

$<$ complexType name="OperationSystemType"/>

$<$ /schema $>$ 


\section{Apêndice B}

Este apêndice apresenta um documento XML que, por meio do modelo de representação proposto, descreve três dispositivos: um laptop, um pocket pc e um computador pessoal. Esses dispositivos foram utilizados na análise de desempenho.

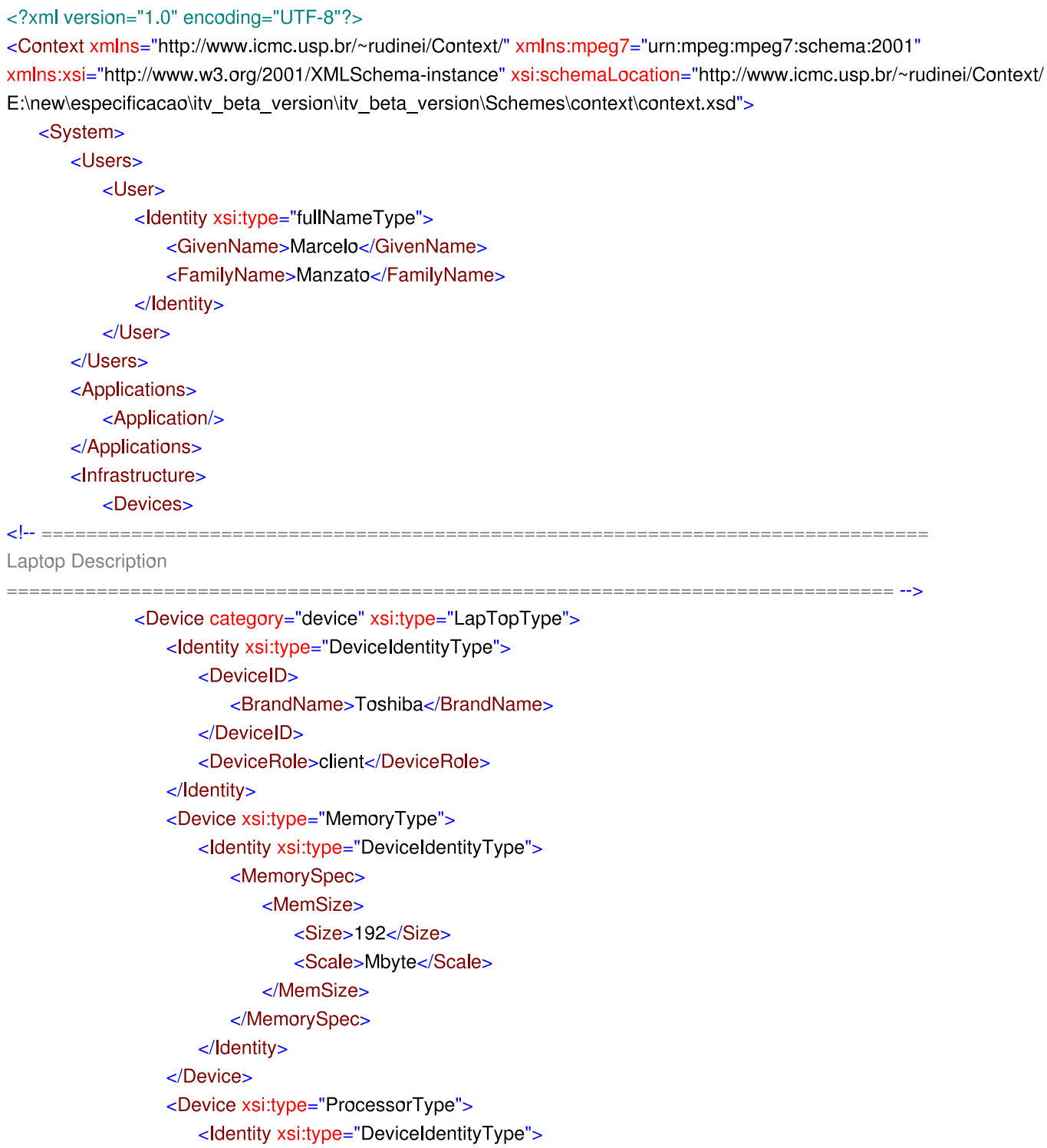




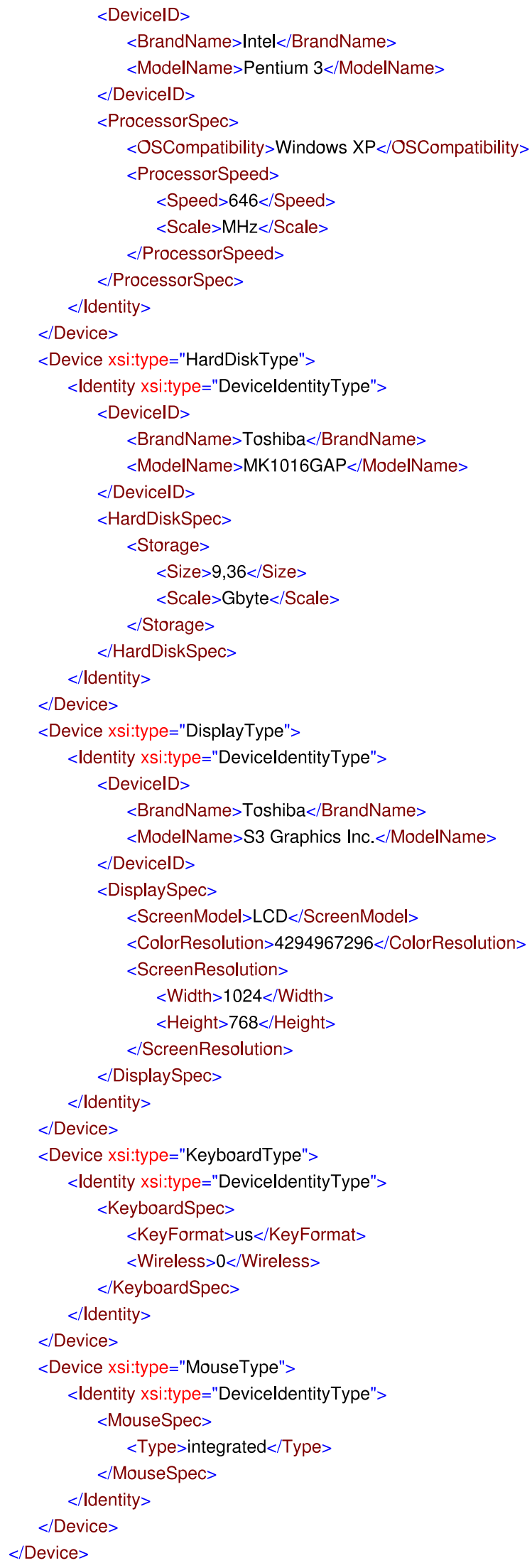




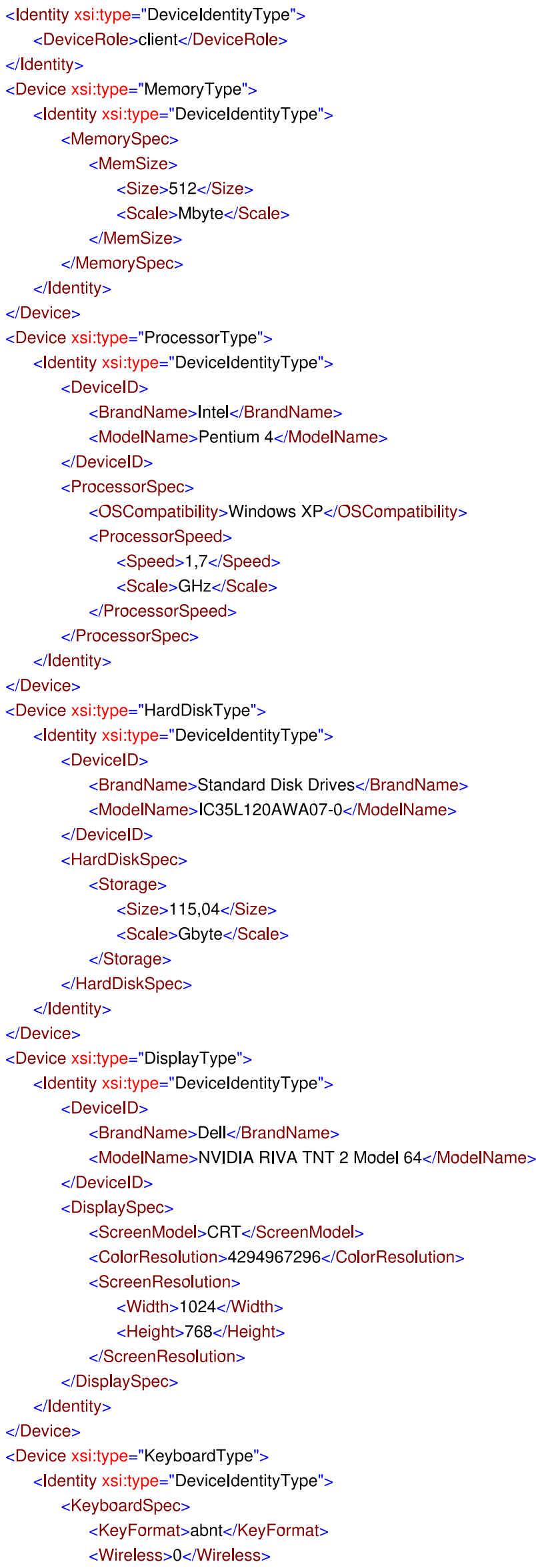




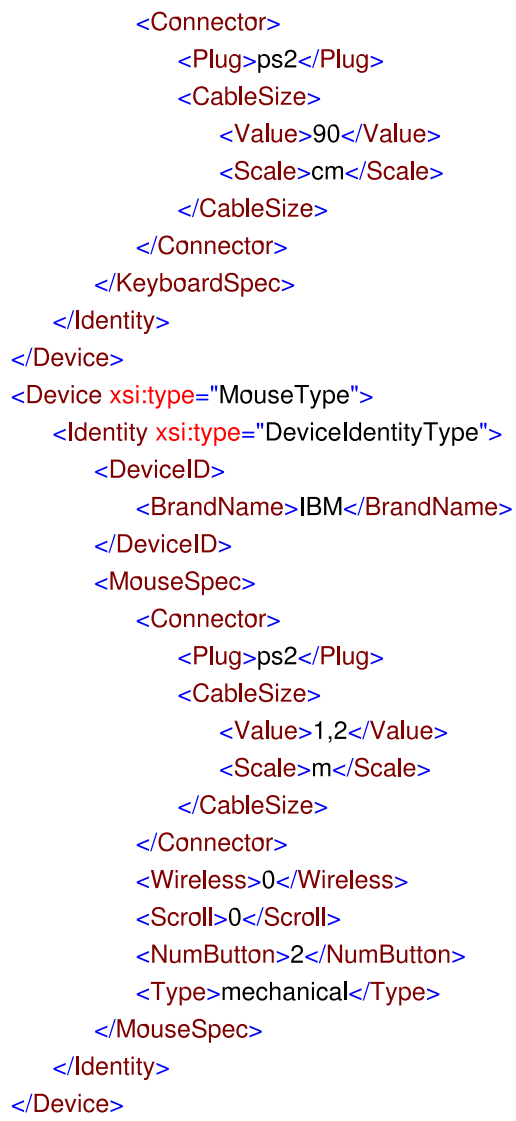


$<$ ProcessorSpec>

$<$ OSCompatibility >WinCE</OSCompatibility > </ProcessorSpec>

$</$ Identity $>$

$</$ Devices

$<$ Device xsi:type="DisplayType">

<Identity xsi:type="DeviceldentityType">

$<$ DisplaySpec>

$<$ ColorResolution>65536</ColorResolution>

<ScreenResolution>

$<$ Width $>240<$ /Width $>$

$<$ Height $>320<$ /Height $>$

$</$ ScreenResolution>

$</$ DisplaySpec $>$

$</$ Identity $>$

$</$ Device $>$

$</$ Device $>$

$</$ Devices $>$

$</$ Infrastructure $>$

$</$ System>

$</$ Context $>$ 


\section{Glossário}

Amostragem - Em telecomunicações e processamento de sinais, amostragem é o processo de discretização temporal de um sinal contínuo.

Bloco - Estrutura utilizada em compressão de imagens e vídeo. É formada por um conjunto de oito linhas, onde cada linha contém oito pixels, totalizando 64 pixels.

CC/PP -Composite Capabilities/Preferences Profile (Capacidades Compostas/Perfil de Preferências). E uma especificação criada pela W3C que descreve capacidades de dispositivos e preferências de usuários.

Codificação - Em processamento digital de sinais, codificação significa a modificação de características de um sinal para torná-lo mais apropriado para uma aplicação específica, como por exemplo, transmissão ou armazenamento de dados.

Codificador - Dispositivo que realiza o processo de codificação.

Decodificação - Decodificação é o processo contrário da codificação, ou seja, as características modificadas de um sinal são transformadas em seu formato original.

Decodificador - Dispositivo que realiza o processo de decodificação.

Difusão - Nome dado à prática de distribuir um sinal de uma fonte para vários destinos.

Difusor - Ver Software de Difusão.

Dispositivos Portáteis - São dispositivos que podem ser utilizados em qualquer lugar e a qualquer hora. São caracterizados pelo pequeno porte, e geralmente são projetados para atender uma certa funcionalidade. Exemplos de dispositivos portáteis são o telefone celular, PDA, tablet, etc.

Darwin Streaming Server. Versão código-aberto do QuickTime Streaming Server, ambos desenvolvidos pela Apple. É um servidor de vídeo para várias plataformas que contém algumas funcionalidades; entre elas, a capacidade de se realizar espelhamento e servir vídeo no formato MPEG-4.

Efeito de Blocagem - Gerado pelo processamento individual de cada bloco em uma imagem. Geralmente ocorre quando altos valores dos parâmetros de quantização são utilizados nos coeficientes DCT. Como resultado, a imagem é apresentada com efeitos de 
escada (proveniente dos blocos) nas bordas dos objetos.

Efeito de Tração - Ocorre quando existe inconsistência nos quadros de referência utilizados durante a estimativa e compensação de movimento. Com esse efeito, a imagem decodificada é apresentada com borrões em certas regiões, persistindo até que um quadro do tipo I seja decodificado.

Endereço MAC - Media Access Control (Controle de Acesso ao Meio). É o endereço físico da interface de rede. Composto por 48 bits, em hexadecimal, o protocolo é responsável pelo controle de acesso de cada estação à rede ethernet. Os três primeiros octetos são destinados à identificação do fabricante e os 3 posteriores são fornecidos pelo fabricante.

Espelhamento - Funcionalidade do servidor de vídeo de receber um fluxo de vídeo ao vivo e repassar para outros servidores ou usuários.

Estimativa e Compensação de Movimento - Técnica utilizada para eliminar a redundância temporal de um sinal de vídeo. O algoritmo compara quadros próximos uns dos outros e verifica quais áreas da imagem são equivalentes ou mesmo qual foi o movimento realizado pela área de um quadro para outro. Essas áreas equivalentes são eliminadas, e no lugar, são armazenadas no arquivo codificado apenas essas informações de controle, que serão mais tarde processadas pelo decodificador, para recostrução da imagem original.

Ethernet - É uma tecnologia de interconexão para redes locais baseada no envio de pacotes.

FGS - Fine Granular Scalability (Escalabilidade Granular Refinada). Especificação proposta pelo padrão MPEG-4 que realiza codificação escalável progressiva na taxa de bits dependendo da largura de banda disponível. A principal diferença entre a FGS e a codificação escalável é que, embora a FGS também codifique a seqüência de vídeo em duas camadas, o fluxo de bits adicional, independentemente de ter sido totalmente recebido pela aplicação, pode ser aplicado nos quadros da camada base a fim de fornecer melhorias na qualidade da imagem proporcionais à quantidade de dados recebidos.

Fluxo - Em computação, refere-se a um fluxo de dados.

Framework - Um framework provê uma solução para uma família de problemas semelhantes, usando um conjunto de classes e interfaces que mostra como decompor essa família de problemas, e como objetos dessas classes colaboram para cumprir suas responsabilidades. O conjunto de classes deve ser flexível e extensível para permitir a construção de várias aplicações com pouco esforço, especificando apenas as particularidades de cada aplicação.

Hipertexto - É uma maneira de representar informações textuais de forma não-linear, permitindo que, a partir de um documento, usuários acessem outros documentos.

HTML - HyperText Markup Language (Linguagem de Marcação de Hipertexto). Linguagem de marcação de texto utilizada para a apresentação de hiperdocumentos na Internet.

HTTP - Hypertext Transfer Protocol (Protocolo de Trasferência de Hipertexto). É um protocolo utilizado para transferência de dados hipermídia (imagens, sons, texto, etc.) e 
pela comunicação entre cliente e servidor na Internet.

IP - Internet Protocol (Protocolo de Internet). É um protocolo usado entre duas máquinas em rede para encaminhamento dos dados.

ISDN - Integrated Services Digital Network (Rede Digital de Integração de Serviços). É uma rede que utiliza o sistema telefônico comum para transmissão de dados. A conexão pode ser realizada até uma taxa de $128 \mathrm{Kbits} / \mathrm{s}$, através de duas linhas de até $64 \mathrm{Kbits} / \mathrm{s}$, que são usadas tanto para conexão com a Internet quanto para chamadas telefônicas de voz normais.

JavaScript - É uma linguagem de programação criada pela Netscape em 1995, que a princípio se chamava LiveScript, para atender, principalmente, as seguintes necessidades: a) validação de formulários no lado cliente (programa navegador); e b) interação com a página exibida por meio da Internet.

JSP - JavaServer Pages. Sendo processada no servidor, JSP é uma extensão da tecnologia Java servlet que foi desenvolvida pela Sun. É utilizada em conjunto com HTML para geração dinâmica de documentos na web.

Largura de Banda - Intervalo do espectro de freqüências disponível ou necessário para transmitir dados (imagens, áudio, pacotes digitais) sobre um meio, tal como cabo ou ar, ou sobre um dispositivo elétrico. Quanto maior é a largura de banda disponível, maior é a quantidade de dados que pode ser transmitida por segundo.

LogP - É um modelo de avaliação de interfaces de comunicação que visa servir de base para o estudo de técnicas de paralelização e, conseqüentemente, projeto de algoritmos paralelos. Esse modelo considera a rede como principal gargalo de sistemas paralelos e distribuídos, e utiliza mensagens de tamanho reduzido para buscar a extração de alguns parâmetros, tais como latência, overhead, gap e número de elementos de processamento do sistema.

Lousa Eletrônica - Substitui, em sala de aula, o tradicional quadro negro, possibilitando a digitalização dos traçados realizados manualmente pelo professor por meio de uma caneta eletrônica, bem como a interação com o computador, em substituição ao mouse, além da realização de anotações manuais sobre as imagens nela projetadas.

Macrobloco - Estrutura utilizada em compressão de imagens e vídeo. É formada por um conjunto de quatro blocos de luminância, mais um determinado número de blocos de crominância.

MTU - Maximum Transmission Unit (Unidade de Transmissão Máxima). Em redes de computadores, MTU se refere ao tamanho do maior datagrama que uma camada de um protocolo de comunicação pode transmitir.

Multicast - É a entrega de informação para múltiplos destinatários simultaneamente usando a estratégia mais eficiente onde as mensagens só passam por um link uma única vez e somente são duplicadas quando o link para os destinatários se divide em duas direções. Em comparação com o multicast, a entrega simples ponto-a-ponto é chamada de unicast, e a entrega para todos os pontos de uma rede chama-se broadcast.

Multimídia - É a utilização simultânea de vários tipos de mídia (texto, sons, imagens, 
gráficos, vídeos e animações).

Ontologia - Em computação, o termo ontologia tem como princípio básico: o que "existe" é o que pode ser representado. Nesse contexto, ontologia pode ser entendida como uma especificação formal e explícita de uma conceitualização consensual, a qual pode ser definida como uma estrutura composta por um domínio de conhecimento e um conjunto de relações sobre o mesmo.

PDA - Personal Digital Assistant (Assistente Digital Pessoal). É um dispositivo do tamanho de um bolso usado para gravar mensagens digitais ou escritas, que podem ser transportadas para um computador.

Quadro de Vídeo - É uma das inúmeras imagens que compõem um vídeo; ao tocar um vídeo, cada quadro é mostrado na tela por um tempo especificado pela taxa de quadros: se o vídeo está configurado a 25 quadros/s, então cada quadro será apresentado por um período de 0,040 segundos.

Quadro B - Na eliminação da redundância temporal, a estimativa de movimento utiliza quadros do tipo I ou $\mathrm{P}$ antecedentes ou posteriores a ele como referência para a codificação de seus dados.

Quadro I - É codificado eliminando apenas a redundância espacial. É o tipo de quadro que requer a maior quantidade de bits para representá-lo, pois uma vez que não é eliminada a redundância temporal, seu nível de codificação é baixo.

Quadro P - Na eliminação da redundância temporal, a estimativa de movimento utiliza quadros do tipo I ou P antecedentes a ele como referência para a codificação de seus dados.

Quantização - Consiste em converter um sinal de amplitudes contínuas em um número finito de amplitudes discretas. Todo sinal deve ser quantizado para ser armazenado ou transmitido na forma digital. Nesta técnica, a quantidade de bits que representa os dados é diminuída, provocando uma degradação na imagem. No entanto, se a quantidade de níveis de quantização, ou a taxa de bits for alta, a perda de qualidade pode ser imperceptível. Como exemplo clássico de quantização, pode-se citar o arredondamento de números no formato ponto-flutuante para números em formato inteiro.

Redundância Espacial - Algumas informações de cores presentes em uma imagem não são perceptíveis pelo olho humano, e podem ser eliminadas sem que a qualidade da imagem seja prejudicada. Essa eliminação é realizada pela aplicação da transformada discreta do cosseno, e em seguida, a quantização.

Redundância Temporal - São repetições de certas informações presentes em sinais de vídeo que podem ser eliminadas por codificadores sem a percepção do telespectador. Comparando-se quadros próximos uns dos outros, algumas áreas da imagem, tais como plano de fundo, objetos sem movimento, etc., são iguais, e podem, na codificação, ser eliminadas para diminuir o tamanho do arquivo. Assim, durante a decodificação, o decodificador, ao verificar que essas áreas foram eliminadas em um determinado quadro, irá "emprestar" essas informações de quadros próximos, a fim de recostruir a imagem original.

Resolução Espacial - Define o tamanho de um quadro de um vídeo, normalmente 
expressa em pixels.

Resolução Temporal - Define a taxa de quadros de um vídeo, normalmente expressa em quadros/s.

RTP - Real Time Protocol (Protocolo em Tempo Real). É um protocolo de redes utilizado em aplicações de tempo real, como por exemplo, entrega de dados de áudio ponto-aponto, como Voz sobre IP. Define como deve ser feita a fragmentação do fluxo de dados, adicionando a cada fragmento informação de seqüência e de tempo de entrega. Utiliza o UDP como protocolo de transporte, o qual não oferece qualquer garantia que os pacotes serão entregues num determinado intervalo.

RTSP - É um protocolo em nível de aplicação para controle na transferência de dados, como vídeo e áudio, com propriedades de tempo real. É utilizado para estabelecer e controlar um único ou vários fluxos sincronizados de mídias contínuas pertencentes a uma apresentação.

Script - São arquivos contendo linguagem interpretada, os quais precisam de programas especiais para interpretação, em tempo de execução, de blocos de códigos não compilados.

SDP - Session Description Protocol (Protocolo de Descrição de Sessão). É um protocolo que descreve sessões multimídia, ou seja, ele leva informações necessárias para que os clientes possam participar da sessão. É utilizado para anunciar antecipadamente os fluxos disponíveis na rede, carregando certas informações que são importantes para que as aplicações saibam que tipo de dados elas estão recebendo.

SNR - Signal-Noise Ratio (Razão Sinal-Ruído). Utilizada para medir o quanto de "ruído" (imagem granulada) uma imagem de vídeo contém, normalmente expressa em decibéis (dB). Essa medição é calculada por meio do valor da voltagem máxima atingida pelo sinal dividido pelo valor residual da voltagem que permanece quando o sinal é removido - ou seja, a quantidade de ruído no mesmo.

Software de Difusão - É um software cuja função é distribuir conteúdo por meio da difusão.

Streaming - É um fluxo de bits em tempo real contendo informação de áudio ou vídeo, que torna possível apresentar a informação antes que a transmissão tenha se completado. Pode ser contrastado ao proceso de downloading, que espera todos os dados chegarem para realizar a apresentação.

Tablets - É um tipo de notebook que contém tela em cristal líqüido no qual o usuário pode escrever utilizando uma caneta eletrônica. A escrita a mão é digitalizada e pode ser convertida em texto padrão por meio de reconhecimento de escrita, ou pode ser armazenada como escrita a mão na forma de figuras, ou um tipo de arquivo específico. Os tablets normalmente são compostos por um teclado e/ou um mouse para inserção de dados.

TCP - Transmission Control Protocol (Protocolo de Controle de Transmissão). É um protocolo amplamente utilizado na Internet atualmente, devido à sua versatilidade e robustez, permitindo, entre outras funcionalidades, saber se os dados estão sendo enviados de maneira correta, na seqüência apropriada e sem erros.

Transformada Discreta do Cosseno - Técnica utilizada na eliminação da redundância 
espacial de uma imagem. Ela transforma os dados do domínio espacial para o domínio de freqüências, onde quanto mais alta é uma freqüência, menos perceptível ela é para o olho humano. Após a transformação, os dados são submetidos à quantização, que é onde a eliminação da redundância é realizada.

Transformada Discreta do Cosseno Inversa - É a inversa da transformada discreta do cosseno. Ela transforma os dados do domínio de freqüências para o domínio espacial.

TTL - Time To Live (Tempo de Sobrevivência). Indica o número de máquinas que os pacotes podem demorar numa rede de computadores antes de serem descartados.

UMA - Universal Multimedia Access (Acesso Multimídia Universal). Conceito referente ao acesso a informações multimídia independentemente do dispositivo ou rede utilizados. O objetivo é disponibilizar diferentes formatos de um mesmo conteúdo personalizados para cada situação de rede, dispositivo ou preferências de usuário.

URL - Uniform Resource Locators (Localizadores de Recurso Uniformes). Define o endereço global de documentos e outros recursos na Internet. A primeira parte do endereço indica qual protocolo utilizar, a segunda parte especifica o endereço IP ou o domínio onde o recurso está localizado.

Vetor de Movimento - Termo utilizado em compressão de vídeo. Indica a translação espacial de um bloco para outro em quadros distintos, onde essa translação é especificada pela aplicação da técnica estimativa de movimento.

VideoLan Client - É um player multimídia, de código-aberto, com suporte a vários formatos de vídeo, como MPEG-1, MPEG-2, MPEG-4, DivX, DVD, VCDs, etc., e áudio, como MP3 e WAV. Além disso, suporta vários protocolos de streaming, podendo ser usado como servidor de vídeo em redes de alta velocidade. A transmissão pode ser realizada em unicast ou multicast, através redes IPv4 ou IPv6. Contém versões para vários sistemas operacionais, tais como Windows, Mac OS, FreeBSD, Linux, BeOS, dentre outros.

XML - Extensible Markup Language (Linguagem de Marcação Extensiva). É uma especificação desenvolvida pela W3C utilizada em documentos da web. Permite que projetistas criem suas próprias tags, disponibilizando a definição, transmissão, validação e interpretação de dados entre aplicações e organizações.

XML Schema - Linguagem criada pela W3C em 2001, e utilizado para definir esquemas XML. Um esquema define um conjunto de regras que um documento XML deve seguir para ser considerado válido.

Wavelet - Em compressão de imagens, é utilizada para eliminar a redundância espacial. A imagem é dividida por meio de filtros, em duas componentes: uma de baixas freqüências, contendo as principais informações sobre a imagem; e outra de altas freqüências, contendo as informações irrelevantes. A aplicação é feita por meio da convolução do sinal com as componentes de baixa e alta freqüência.

WURFL - Wireless Universal Resource File (Arquivo Universal de Recursos Sem Fio). É um arquivo de configuração central baseado em XML que descreve capacidades e funcionalidades de diversos tipos de dispositivos sem fio. 